From the preceding tables the following expressions were derived:

$$
\begin{aligned}
& \mathrm{s} \\
& \mathrm{W}_{10}-\mathrm{N}=-0.003 \sin \alpha+0.006 \cos \alpha+0.000 \sin 2 \alpha+0.007 \cos 2 \alpha \\
& \mathrm{W}_{10}-\mathrm{B}=-0.004 \sin \alpha+0.009 \cos \alpha+0.000 \sin 2 \alpha+0.005 \cos 2 \alpha \\
& \mathrm{W}_{10}-\mathrm{W}_{00}=-0.003 \sin \alpha+0.001 \cos \alpha+0.002 \sin 2 \alpha+0.003 \cos 2 \alpha \\
& \mathrm{W}_{10}-\mathrm{Gr}_{10}=+0.003 \sin \alpha+0.005 \cos \alpha+0.004 \sin 2 \alpha-0.001 \cos 2 \alpha \\
& \mathrm{W}_{10}-\mathrm{C}_{00}=+0.007 \sin \alpha-0.002 \cos \alpha+0.000 \sin 2 \alpha-0.002 \cos 2 \alpha
\end{aligned}
$$

\title{
DECLINATIONS
}

The value of one revolution of the zenith distance micrometer screw used in the reduction of all the observations in declination after 1911 was derived from measures over the nadir of the lengths of three $10^{\prime}$ arcs of Circle A. These arcs were from $38^{\circ} 50^{\prime}$ to $39^{\circ} 0^{\prime}, 38^{\circ} 48^{\prime}$ to $38^{\circ} 58^{\prime}$, and from $38^{\circ} 46^{\prime}$ to $38^{\circ} 56^{\prime}$, respectively. The adopted value is:

$$
1 \text { revolution }=28 " .500
$$

\begin{tabular}{|c|c|c|c|c|c|c|c|c|c|c|}
\hline Year Rev. & $40-41$ & $41-42$ & $42-43$ & $43-44$ & $44-45$ & $45-46$ & $46-47$ & $47-48$ & $48-49$ & $49-50$ \\
\hline $\begin{array}{l}1911 \\
1913 \\
1917\end{array}$ & $\begin{array}{r}c \\
-0.02 \\
0.00 \\
-\end{array}$ & $\begin{array}{r}\prime \prime \\
0.00 \\
-0.03 \\
-0.03\end{array}$ & $\begin{array}{r}0.00 \\
-0.01 \\
-0.04\end{array}$ & $\begin{array}{c} \\
\quad " \\
+0.01 \\
+0.01 \\
+0.02\end{array}$ & $\begin{array}{r} \\
0.00 \\
+0.02 \\
-0.06\end{array}$ & $\begin{array}{r}\text { ". } \\
0.00 \\
0.00 \\
-0.02\end{array}$ & $\begin{array}{c}\prime \prime \\
-0.01 \\
-0.02 \\
+0.04\end{array}$ & $\begin{array}{r}\prime \prime \\
0.00 \\
+0.02 \\
+0.04\end{array}$ & $\begin{array}{r} \\
0.00 \\
+0.02 \\
+0.02\end{array}$ & $\begin{array}{r}\prime \prime \\
0.00 \\
0.00 \\
+0.02\end{array}$ \\
\hline
\end{tabular}

The perıdic and progressive errors of this screw were measured with the Stackpole comparator in 1911, 1913, and 1917. The middle of the field is designated as 40 revolutions and all the observations were made between 40 and 50 revolutions.

Progressive Errors of the Zenith Distance Micrometer Screw

Periodic Errors of the Zenith Distance Micrometer Screw

$$
\begin{aligned}
\Delta & =-0.033 \cos u-0.010 \sin u+0.001 \cos 2 u+\dot{0} .000 \sin 2 u \\
& =-0.024 \cos u-0.014 \sin u+0.004 \cos 2 u+0.006 \sin 2 u \\
& =-0.004 \cos u-0.004 \sin u+0.006 \cos 2 u+0.004 \sin 2 u
\end{aligned}
$$

In the above expressions $u$ is the decimal of a revolution in angular measure.

Corrections have been applied for periodic errors but not for progressive errors. These corrections were computed from the expression,

$$
\Delta=-0.033 \cos u-0 " .010 \sin u
$$

which was derived in 1911. The measures made in 1917 tend to show that the continued use of the screw has decreased these periodic errors.

The errors of the screws of the eight microscopes were measured in a similar manner in 1909 and 1910. They were found to be inappreciable. The error of runs was determined frequently and the microscopes were adjusted when necessary so as to keep this error small. No corrections have been applied either for the error of runs or for the errors of the microscope screws.

Inclination of the zenith distance threads. - The inclination of the zenith distance threads was determined by observations of equatorial stars. Since the stellar 
focus varies with the temperature, it was found necessary to adjust the focus about four times each year. After each adjustment the inclination of the threads was redetermined.

Zenith point correction.- The values of the zenith point corrections were determined by observing the reflected images of the zenith distance threads over the mercury.

Refraction.-In 1909-1910, the preliminary corrections for refraction were computed by means of the refraction tables of Dr. L. DE BALL. In 1911-1918, the tables given in Appendix II, Volume IV, Publications of the United States Naval Observatory, Second Series, were used. The latter tables are based on the Pulkowa refraction tables.

Latitude.-In transforming observed zenith distances into declinations, a provisional value of the latitude of the instrument, $+38^{\circ} 55^{\prime} 14^{\prime \prime} .00$, was adopted.

REDUCTION TO MEAN PLACE

The apparent declinations were reduced to mean place for those stars not contained in the American Ephemeris by using the independent star numbers of that volume. The short-period terms were included and for stars north of $86^{\circ} .0$ declination the second order terms were added.

REDUCTION TO 1910.0

In reducing the positions of the stars not contained in the American Ephemeris from the mean equator and equinox of the beginning of the year of observation to 1910.0, the precessions and secular variations were computed by means of the Precession Tables Adapted to Newcomb's Value of the Precessional Constant and Reduced to the Epoch 1910.0 by A. M. W. Downing.

For the stars in the American Ephemeris, the mean correction to the ephemeris for each star was applied to Newcomb's position for 1910.0 which had first been reduced by the proper motion of that catalogue to the mean epoch of observation.

Each final position is therefore referred to the mean equator and equinox of 1910.0, but its epoch is the mean epoch of the observations.

CORRECTIONS FOR DIVISION ERRORS

The method employed in determining the division errors of the circles is the same as that adopted by the late Prof. Lewis Boss, director of the Dudley Observatory, in his determination of the graduation errors of the Olcott meridian circle at Albany. This method is fully described by him in the Astronomical Journal, Volume XVI, pp. 189-194; 197-201.

Briefly stated, it consists in directly comparing the two circles of an instrument by rotating one circle on the axis with respect to the other. For example, if it is desired to ascertain the errors of the $15^{\circ}$ arcs of Circle A, some particular $15^{\circ}$ arc of Circle $\mathrm{B}$ is chosen as a standard of comparison and all the $15^{\circ}$ arcs of Circle A are compared with this one $15^{\circ}$ standard arc of Circle B. In making this comparison, Circle B will have to be rotated on the axis six times, each time through an angle of $15^{\circ}$. The process may be repeated with other $15^{\circ}$ arcs of Circle B as standards of comparison until all have been used, in which case the errors of the $15^{\circ}$ arcs are determined for both circles. 
Two observers, one for each circle, as well as a recorder, are necessary and it is advisable to repeat the measures with the observers interchanged.

In what follows, the correction for division error is to be understood as a quantity to be applied to the mean of four microscopes, the lines of reference being the divisions $0^{\circ}, 90^{\circ}, 180^{\circ}$, and $270^{\circ}$. The division corrections for the lines which are multiples of $15^{\circ}$ were first determined for both circles with considerable accuracy, since they were used as a basis for the determination of the corrections for the other lines. The results are given in the following table:

Division Corrections for Lines which are Multiples of $15^{\circ}$

\begin{tabular}{|c|c|c|c|c|c|c|c|c|c|c|}
\hline \multirow[t]{2}{*}{$\cdot$} & \multicolumn{5}{|c|}{ Circle A } & \multicolumn{5}{|c|}{ Circle B } \\
\hline & $15^{\circ}$. & $30^{\circ}$ & $45^{\circ}$ & $60^{\circ}$ & $75^{\circ}$ & $15^{\circ}$ & $30^{\circ}$ & $45^{\circ}$ & $60^{\circ}$ & $75^{\circ}$ \\
\hline 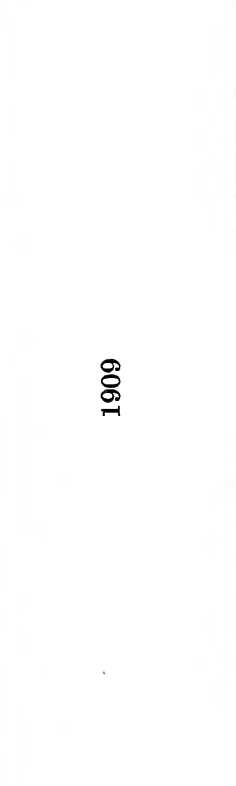 & 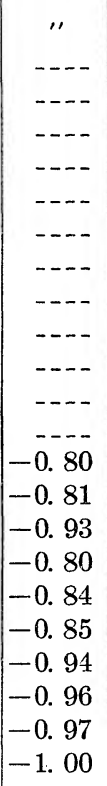 & $\begin{array}{r}. \\
-.- \\
-.- \\
-.- \\
--.- \\
+0.88 \\
+1.07 \\
+0.99 \\
+1.11 \\
+1.00 \\
+0.94 \\
+0.89 \\
+1.01 \\
+1.12 \\
+1.12 \\
+1.06 \\
+1.07 \\
+0.82 \\
+0.94 \\
+0.95 \\
+1.00 \\
-. .- \\
-. .-\end{array}$ & 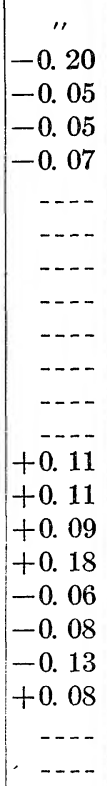 & $\begin{array}{c}. \\
-. .- \\
-. .- \\
-. .- \\
-0 .- \\
-0.32 \\
-0.15 \\
-0.31 \\
-0.11 \\
-0.27 \\
-0.33 \\
-0.32 \\
-0.22 \\
-0.05 \\
-0.14 \\
-0.12 \\
-0.08 \\
-0.37 \\
-0.29 \\
-0.44 \\
-0.27 \\
-. .- \\
-. .-\end{array}$ & 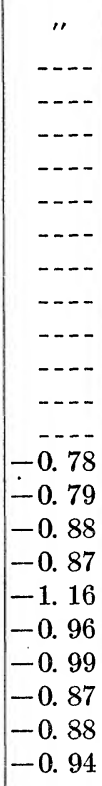 & 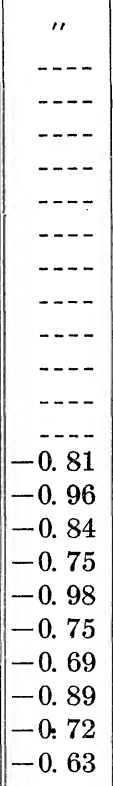 & 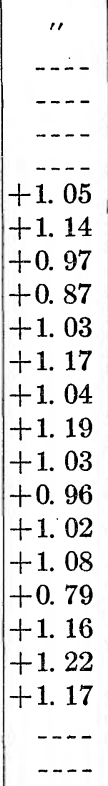 & 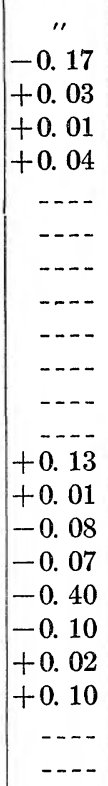 & $\begin{array}{r}\prime \prime \\
--.- \\
--.- \\
-. .- \\
--.- \\
-0.05 \\
+0.21 \\
-0.23 \\
0.00 \\
-0.06 \\
+0.08 \\
+0.03 \\
+0.05 \\
+0.06 \\
+0.24 \\
-0.04 \\
-0.12 \\
-0.17 \\
-0.12 \\
+0.11 \\
+0.24 \\
-.-- \\
-. .-\end{array}$ & 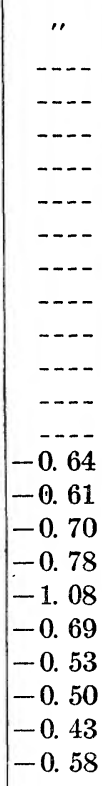 \\
\hline Means, 1909 & -0.89 & +1.00 & -0.01 & -0.24 & -0.91 & -0.80 & +1.06 & -0.04 & +0.01 & -0.65 \\
\hline $\begin{array}{c}\stackrel{0}{\sigma} \\
\stackrel{\sigma}{\sigma} \\
.\end{array}$ & $\begin{array}{l}-0.88 \\
-0.72 \\
-0.62 \\
-1.03 \\
-0.86 \\
-0.95\end{array}$ & $\begin{array}{l}+1.27 \\
+1.17 \\
+1.40 \\
+1.00 \\
+0.32 \\
+1.04\end{array}$ & $\begin{array}{r}-0.04 \\
0.00 \\
+0.17 \\
0.00 \\
-0.02 \\
-0.12\end{array}$ & $\begin{array}{l}+0.05 \\
-0.12 \\
+0.20 \\
-0.18 \\
-0.06 \\
-0.28\end{array}$ & $\begin{array}{l}-0.96 \\
-0.77 \\
-0.59 \\
-0.97 \\
-0.77 \\
-1.00\end{array}$ & $\begin{array}{l}-0.73 \\
-0.84 \\
-0.74 \\
-0.66 \\
-0.68 \\
-0.76\end{array}$ & $\begin{array}{l}+1.12 \\
+0.90 \\
+1.30 \\
+1.10 \\
+1.10 \\
+1.02\end{array}$ & $\begin{array}{r}+0.06 \\
-0.01 \\
+0.01 \\
0.00 \\
-0.05 \\
-0.12\end{array}$ & $\begin{array}{l}+0.07 \\
-0.01 \\
+0.11 \\
-0.03 \\
+0.11 \\
-0.23\end{array}$ & $\begin{array}{l}-0.67 \\
-0.59 \\
-0.55 \\
-0.61 \\
-0.62 \\
-0.74\end{array}$ \\
\hline Means, 1910 & -0.84 & +1.20 & 0.00 & -0.06 & -0.84 & -0.74 & +1.09 & -0.02 & 0. 00 & -0.63 \\
\hline
\end{tabular}

The marked similarity in the corrections for the two circles is noticeable. This is accounted for by the manner in which the circles were graduated. According to a letter from Warner and Swasey, the $0^{\circ}$ line of the dividing engine corresponded to the $0^{\circ}$ line of Circle A and to the $90^{\circ}$ line of Circle B. Since Circle B was not used regularly and since this circle was rotated on its axis after each night's work 
in order to eliminate as far as possible the effect of division error, it was considered sufficiently accurate to adopt the same division corrections for Circle B as for Circle A down to the $10^{\prime}$ divisions. The $2^{\prime}$ divisions are subject to a periodic error which is of the same amplitude but of different phase for the two circles.

The corrections to the other lines of Circle $\mathrm{A}$ which are multiples of $5^{\circ}$ were next determined, based upon the corrections to the $15^{\circ}$ lines.

Division Corrections for the Other Lines of Circle A which are Multiples of $5^{\circ}$

\begin{tabular}{|c|c|c|c|c|c|c|c|c|c|c|c|c|}
\hline & $5^{\circ}$ & $10^{\circ}$ & $20^{\circ}$ & $25^{\circ}$ & $35^{\circ}$ & $40^{\circ}$ & $50^{\circ}$ & $55^{\circ}$ & $65^{\circ}$ & $70^{\circ}$ & $80^{\circ}$ & $85^{\circ}$ \\
\hline 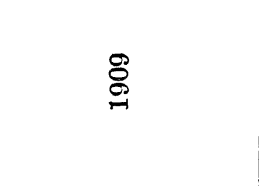 & $\mid \begin{array}{c}\prime \prime \\
-0.92 \\
-1.11 \\
-0.81 \\
-1.06\end{array}$ & $\begin{array}{c}\prime \prime \\
-0.38 \\
-0.64 \\
-0.42 \\
-0.40\end{array}$ & $\begin{array}{r}\prime \prime \\
+0.77 \\
+0.67 \\
+0.82 \\
+0.77\end{array}$ & $\begin{array}{c}\prime \prime \\
+0.10 \\
-0.02 \\
+0.27 \\
-0.07\end{array}$ & $\begin{array}{c}\prime \prime \\
+0.03 \\
+0.01 \\
+0.15 \\
+0.10\end{array}$ & $\begin{array}{r} \\
\prime \prime \\
+0.59 \\
+0.60 \\
+0.63 \\
+0.42\end{array}$ & $\begin{array}{r} \\
+0.08 \\
+0.10 \\
+0.17 \\
-0.15\end{array}$ & $\begin{array}{c}11 \\
-0.96 \\
-1.03 \\
-1.00 \\
-1.16\end{array}$ & $\begin{array}{c} \\
\prime \prime \\
+0.07 \\
+0.13 \\
+0.17 \\
+0.22\end{array}$ & $\begin{array}{c} \\
+0.23 \\
+0.25 \\
+0.29 \\
+0.27\end{array}$ & $\begin{array}{c}\prime \prime \\
-0.09 \\
-0.26 \\
+0.07 \\
-0.25\end{array}$ & $\begin{array}{c}\prime \prime \\
-0.34 \\
-0.25 \\
-0.06 \\
-0.62\end{array}$ \\
\hline Means, 1909_.. & -0.98 & -0.46 & +0.76 & +0.07 & +0.07 & +0.56 & +0.05 & -1.04 & +0.15 & +0.26 & -0.13 & -0.32 \\
\hline$\stackrel{\circ}{\stackrel{\circ}{\sigma}}$ & $\begin{array}{l}-0.92 \\
-0.77 \\
-0.85 \\
-0.80 \\
-0.89 \\
-1.05\end{array}$ & $\begin{array}{l}-0.43 \\
-0.35 \\
-0.41 \\
-0.35 \\
-0.70 \\
-0.47\end{array}$ & $\begin{array}{r}+0.79 \\
+1.00 \\
+1.00 \\
+1.30 \\
+1.14 \\
+1.31\end{array}$ & $\begin{array}{l}-0.25 \\
+0.08 \\
+0.23 \\
+0.18 \\
+0.12 \\
+0.30\end{array}$ & $\begin{array}{l}+0.20 \\
+0.50 \\
+0.29 \\
+0.09 \\
+0.06 \\
+0.02\end{array}$ & $\begin{array}{l}+0.39 \\
+0.71 \\
+0.44 \\
+0.71 \\
+0.66 \\
+0.43\end{array}$ & $\begin{array}{l}+0.30 \\
+0.05 \\
+0.14 \\
-0.06 \\
-0.29 \\
-0.08\end{array}$ & $\begin{array}{l}-0.78 \\
-0.87 \\
-0.96 \\
-0.87 \\
-1.12 \\
-0.84\end{array}$ & $\begin{array}{r}0.00 \\
0.00 \\
-0.06 \\
+0.12 \\
+0.01 \\
-0.01\end{array}$ & $\begin{array}{l}+0.01 \\
+0.37 \\
-0.09 \\
+0.33 \\
+0.29 \\
+0.33\end{array}$ & $\begin{array}{r}-0.06 \\
-0.12 \\
+0.04 \\
0.00 \\
+0.07 \\
+0.09\end{array}$ & $\begin{array}{l}-0.46 \\
-0.36 \\
-0.14 \\
-0.47 \\
-0.38 \\
-0.51\end{array}$ \\
\hline Yeans, 1910 & -0.88 & -0.45 & +1.09 & +0.11 & +0.19 & +0.56 & +0.01 & -0.91 & +0.01 & +0.21 & 0.00 & -0.39 \\
\hline
\end{tabular}

The corrections for the other degree lines were based on the corrections for the $5^{\circ}$ lines. The results follow: 
Division Corrections for the Other Degree Lines of Circle A

\begin{tabular}{|c|c|c|c|c|c|c|c|c|c|c|c|}
\hline Line & \multicolumn{2}{|c|}{1909} & \multicolumn{2}{|c|}{1910} & \multirow{2}{*}{$\frac{\text { Means }}{\prime \prime}$} & \multirow{2}{*}{$\frac{\text { Line }}{\circ}$} & \multicolumn{2}{|c|}{1909} & \multicolumn{2}{|c|}{1910} & \multirow{2}{*}{ Means } \\
\hline 。 & " & " & " & $" \prime$ & & & " & " & " & " & \\
\hline 1 & +0.03 & -0.13 & -0.43 & -0.18 & -0.18 & 46 & -0.21 & +0.08 & -0.13 & +0.03 & -0.06 \\
\hline 2 & -0.20 & -0.28 & -0.71 & -0.47 & -0.42 & 47 & +0.13 & +0.15 & +0.05 & +0.25 & +0.14 \\
\hline 3 & -0.58 & -0.86 & -1.04 & -0.69 & -0.79 & 48 & +0.11 & +0.07 & +0.27 & +0.03 & +0.12 \\
\hline 4 & -1.00 & -0.88 & -1.00 & -1.06 & -0.98 & 49 & +0.28 & -0.02 & +0.45 & +0.35 & +0.26 \\
\hline 6 & -0.69 & -0.68 & -0.61 & -0.76 & -0.68 & 51 & +0.18 & -0.16 & +0.02 & -0.06 & -0.01 \\
\hline 7 & -0.80 & -0.51 & -0.75 & -0.60 & -0.67 & 52 & +0.14 & -0.40 & +0.15 & +0.08 & -0.01 \\
\hline 8 & -0.62 & -0.07 & -0.33 & -0.19 & -0.30 & 53 & -0.43 & -0.92 & +0.01 & -0.23 & -0.39 \\
\hline 9 & -0.46 & -0.35 & -0.35 & -0.38 & -0.38 & 54 & -0.59 & -0.89 & -0.59 & -1.12 & -0.80 \\
\hline 11 & -0.24 & 0.00 & -0.09 & 0.00 & -0.08 & 56 & -0.85 & -1.05 & -1.20 & -0.91 & -1.00 \\
\hline 12 & -0.18 & +0.05 & -0.17 & +0.12 & -0.04 & 57 & -0.58 & -0.61 & -0.84 & -0.33 & -0.59 \\
\hline 13 & -0.64 & -0.57 & -0.61 & -0.69 & -0.63 & 58 & -0.11 & -0.07 & -0.22 & +0.10 & -0.08 \\
\hline 14 & -0.81 & -0.92 & -0.69 & -0.90 & -0.83 & 59 & -0.14 & -0.20 & -0.23 & +0.18 & -0.10 \\
\hline 16 & -0.44 & -0.78 & -0.28 & -0.55 & -0.51 & 61 & -0.28 & -0.17 & -0.09 & -0.13 & -0.17 \\
\hline 17 & +0.14 & -0.40 & +0.30 & -0.21 & -0.04 & 62 & -0.21 & -0.36 & -0.03 & -0.25 & -0.21 \\
\hline 18 & +0.18 & +0.09 & +0.82 & +0.23 & +0.33 & 63 & -0.38 & -0.26 & -0.29 & -0.42 & -0.34 \\
\hline 19 & +0.39 & +0.35 & +0.82 & +0.45 & +0.50 & 64 & -0.15 & -0.02 & -0.09 & +0.12 & -0.03 \\
\hline 21 & +0.66 & +0.42 & +1.10 & +0.86 & +0.76 & 66 & +0.10 & -0.17 & +0.34 & +0.08 & +0.09 \\
\hline 22 & +0.92 & +0.60 & +0.98 & +1.00 & +0.87 & 67 & +0.23 & +0.23 & +0.48 & +0.17 & +0.28 \\
\hline 23 & +0.53 & +0.38 & +0.71 & +1.02 & +0.66 & 68 & +0.19 & +0.59 & +0.90 & +0.55 & +0.56 \\
\hline 24 & +0.41 & +0.46 & +0.75 & +0.52 & +0.54 & 69 & +0.52 & +0.69 & +0.66 & +0.73 & +0.65 \\
\hline 26 & +0.33 & +0.10 & +0.32 & +0.17 & +0.23 & 71 & +0.28 & +0.18 & +0.74 & +0.71 & +0.48 \\
\hline 27 & +0.05 & +0.21 & +0.41 & +0.17 & +0.21 & 72 & -0.27 . & -0.30 & +0.04 & -0.17 & -0.18 \\
\hline 28 & +0.28 & +0.33 & +0.49 & +0.49 & +0.40 & 73 & -0.58 & -0.59 & -0.21 & -0.54 & -0.48 \\
\hline 29 & +0.62 & +0.76 & +0.72 & +0.59 & +0.67 & 74 & -0.82 & -0.55 & -0.43 & -0.68 & -0.62 \\
\hline 31 & +1.09 & +1.21 & +1.47 & +1.42 & +1.30 & 76 & -0.55 & -0.64 & -0.55 & -0.58 & -0.58 \\
\hline 32 & +0.71 & +0.90 & +1.17 & +1.04 & +0.95 & 77 & -0.44 & -0.71 & -0.24 & -0.18 & -0.39 \\
\hline 33 & +0.34 & +0.29 & +0.74 & +0.71 & +0.52 & 78 & -0.63 & -0.76 & -0.34 & -0.14 & -0.47 \\
\hline 34 & +0.39 & +0.12 & +0.36 & +0.47 & +0.34 & 79 & -0.52 & -0.41 & -0.49 & -0.42 & -0.46 \\
\hline 36 & +0.27 & +0.05 & +0.26 & +0.37 & +0.24 & 81 & +0.03 & -0.03 & -0.04 & +0.06 & 0.00 \\
\hline 37 & +0.20 & +0.36 & +0.33 & +0.56 & +0.36 & 82 & -0.06 & -0.04 & 0.00 & -0.02 & -0.03 \\
\hline 38 & +0.63 & +0.82 & +0.60 & +1.30 & +0.84 & 83 & +0.15 & +0.26 & +0.19 & +0.13 & +0.18 \\
\hline 39 & +0.61 & +0.82 & +0.55 & +0.75 & +0.68 & 84 & -0.13 & -0.17 & -0.28 & -0.11 & -0.17 \\
\hline 41 & +0.59 & +0.63 & +0.70 & +0.71 & +0.66 & 86 & -0.05 & -0.14 & -0.18 & +0.21 & -0.04 \\
\hline 42 & +0.50 & +0.45 & +0.45 & +0.59 & +0.50 & 87 & -0.14 & +0.15 & -0.20 & +0.33 & +0.03 \\
\hline 43 & +0.31 & +0.16 & +0.17 & +0.26 & +0.23 & 88 & +0.17 & +0.32 & +0.32 & +0.82 & +0.41 \\
\hline 44 & +0.04 & 0.00 & +0.19 & +0.09 & +0.08 & 89 & -0.03 & +0.02 & -0.05 & +0.24 & +0.05 \\
\hline
\end{tabular}

Additional Determinations for the Degree Lines Between $50^{\circ}$ and $55^{\circ}$ and Between $70^{\circ}$ and $75^{\circ}$

\begin{tabular}{|c|c|c||c|c|c|}
\hline Lines & \multicolumn{2}{|c|}{ Corrections } & Lines & \multicolumn{2}{|c|}{ Corrections } \\
\hline 0 & $\prime \prime$ & $\prime \prime$ & $\circ$ & $\prime \prime$ & $\prime \prime$ \\
51 & -0.02 & -0.05 & 71 & +0.39 & +0.50 \\
52 & -0.18 & -0.31 & 72 & -0.24 & -0.38 \\
53 & -0.31 & -0.44 & 73 & -0.46 & -0.47 \\
54 & -0.66 & -0.75 & 74 & -0.72 & -0.66 \\
\hline
\end{tabular}

The probable errors of the final mean corrections in the preceding tables derived from the agreement of the individual measures are:

\footnotetext{
For the $15^{\circ}$ lines, $\quad r= \pm 0.022$ For 16 determinations

For the other $5^{\circ}$ lines, $= \pm 0.036$ For 10 determinations

For the other $1^{\circ}$ lines, $= \pm 0.067$ For 4 determinations
} 
In computing the probable errors for the $5^{\circ}$ lines and the $1^{\circ}$ lines the errors in the base divisions were included.

Before attempting to determine the corrections to all the $10^{\prime}$ lines an investigation was made of the errors of these lines between two consecutive degree lines in various parts of the circle. It was found that the corrections for the $10^{\prime}$ lines could be interpolated from the corrections for the degree lines without serious error.

A similar investigation was made of the errors of the $2^{\prime}$ lines in various parts of both circles. It was found that a very regular periodic error with a period of $10^{\prime}$ existed and that the amplitude was the same for both circles, the phase only being different. The following periodic corrections were derived for the $2^{\prime}$ lines:

\begin{tabular}{|c|c|c|c|c|}
\hline & $2^{\prime}$ & $4^{\prime}$ & $6^{\prime}$ & $8^{\prime}$ \\
\hline $\begin{array}{l}\text { Circle A } \\
\text { Circle B }\end{array}$ & $\begin{array}{l}\text { " } \\
+0.58 \\
+0.13\end{array}$ & $\begin{array}{c}\prime \prime \\
-0.34 \\
+0.58\end{array}$ & $\begin{array}{c}\prime \prime \\
-0.58 \\
+1.16\end{array}$ & $\begin{array}{c}\prime \prime \\
-0.45 \\
+0.24\end{array}$ \\
\hline
\end{tabular}

The work was begun in June, 1909, and completed in August, 1910.

The adopted corrections for division error are given in Table VII. The corrections for the $10^{\prime}$ lines have been interpolated between consecutive degree lines; the corrections for the $2^{\prime}$ lines have been obtained by adding the periodic corrections to the corrections for the $10^{\prime}$ lines.

\section{VARIATION OF LATITUDE}

The corrections for variation of latitude for the period 1909 to 1918.0 were derived from the results of the International Geodetic Association as published in various numbers of the Astronomische Nachrichten. From 1918.0 to the end of the work the corrections were based on the results obtained with the photographic zenith tube at the United States Naval Observatory, the results of the Association not being available in time for use.

During the period 1909 to 1914 , inclusive, there were six stations; in 1915, four stations; and in 1916 and 1917, three stations, engaged in the work of the Association. For the years 1915 to 1917, inclusive, corrections were applied to reduce the results to the system of the six stations of the preceding years. These corrections, given in Astronomische Nachrichten No. 4908, are:

$$
\begin{gathered}
\prime \prime \\
\Delta x=+0.02 \\
\Delta y=-0.06 \\
\Delta z=+0.03
\end{gathered}
$$

A correction, $+0^{\prime \prime} .14$, was applied to the results of the photographic zenith tube to reduce them to the same system. This correction was obtained by comparing the results of the zenith tube with those of the Association for the years 1916 and 1917. The mean value of the variation $\left(\varphi-\varphi_{0}\right)$ for the period 1911 to 1918 was subtracted from the individual results to refer them to the mean pole for the period covered by the major part of the observations. 
The values of $\Delta \delta$ which have been applied to the observed declinations for the effect of variation of latitude are given in Table VIII.

\section{PERSONAL EQUATION IN DECLINATION}

After applying corrections for variation of latitude, the observed declinations of the various stars for each clamp were grouped by observers. Differences were then formed for each pair of observers, and these differences arranged in order of declination, separate means being determined for stars south and north of the zenith. The results for Circle A are as follows:

$1909-1910$

\begin{tabular}{|c|c|c|c|c|c|c|}
\hline \multirow[b]{2}{*}{$\cdot$} & \multicolumn{2}{|c|}{$\delta_{\mathrm{U}}-\delta_{\mathbf{H d}}$} & \multicolumn{2}{|c|}{$\delta_{\mathrm{U}}-\delta_{\mathrm{T}}$} & \multicolumn{2}{|c|}{$\delta_{\mathrm{Bd}}-\delta_{\mathrm{T}}$} \\
\hline & East & West & East & West & East & West \\
\hline $\begin{array}{l}\text { South of Zenith } \\
\text { North of Zenith }\end{array}$ & 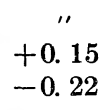 & $\begin{array}{c}\text { " } \\
-0.06 \\
-0.19\end{array}$ & $\begin{array}{c}\prime \prime \\
+0.05 \\
+0.26\end{array}$ & $\begin{array}{c}\prime \prime \\
-0.58 \\
-0.20\end{array}$ & $\begin{array}{c}\prime \prime \\
-0.12 \\
+0.02\end{array}$ & $\begin{array}{c}\prime \prime \\
-0.38 \\
-0.01\end{array}$ \\
\hline
\end{tabular}

$1911-1918$

\begin{tabular}{|c|c|c|c|c|c|c|c|c|c|c|}
\hline & \multicolumn{2}{|c|}{$\delta_{\mathrm{Hd}}-\delta_{\mathrm{Fn}}$} & \multicolumn{2}{|c|}{$\delta_{\mathrm{Hd}}-\delta_{\mathrm{T}}$} & \multicolumn{2}{|c|}{$\delta_{\mathrm{Fn}}-\delta_{\mathrm{T}}$} & \multicolumn{2}{|c|}{$\delta_{\mathrm{Hd}}-\delta_{\mathrm{R}}$} & \multicolumn{2}{|c|}{$\delta_{\mathrm{Hd}}-\delta_{\mathrm{Wy}}$} \\
\hline & East & West & East & West & East & West & East & West & East & West \\
\hline \multirow[t]{3}{*}{$\begin{array}{l}\text { South of Zenith } \\
\text { North of Zenith }\end{array}$} & $\begin{array}{c}\prime \prime \\
+0.16 \\
+0.08\end{array}$ & $\begin{array}{r}\prime \prime \\
+0.08 \\
+0.02\end{array}$ & $\begin{array}{c}\prime \prime \\
+0.23 \\
-0.03\end{array}$ & $\begin{array}{c}\prime \prime \\
+0.26 \\
-0.35\end{array}$ & $\begin{array}{c}\cdot 1 " \\
+0.03 \\
-0.19\end{array}$ & $\begin{array}{r}\prime \prime \\
0.00 \\
+0.59\end{array}$ & $\begin{array}{c}\prime \prime \\
+0.01 \\
-0.13\end{array}$ & $\begin{array}{c}\prime \prime \\
+0.24 \\
-0.02\end{array}$ & $\begin{array}{c}\prime \prime \\
+0.31 \\
+0.03\end{array}$ & $\begin{array}{c}\prime \prime \\
-0.06 \\
-0.25\end{array}$ \\
\hline & \multicolumn{2}{|c|}{$\delta_{\mathrm{Hd}}-\delta_{\mathrm{An}}$} & \multicolumn{2}{|c|}{$\delta_{F_{n}}-\delta_{R}$} & \multicolumn{2}{|c|}{$\delta_{\mathrm{Fn}}-\delta_{\mathrm{Wy}}$} & \multicolumn{2}{|c|}{$\delta_{\mathrm{Fn}}-\delta_{\mathrm{An}}$} & \multicolumn{2}{|c|}{$\delta_{\mathrm{W} y}-\delta_{\mathrm{An}}$} \\
\hline & East & West & East & West & East & West & East & West & East & West \\
\hline $\begin{array}{l}\text { South of Zenith.- } \\
\text { North of Zenith. }\end{array}$ & $\begin{array}{r}\prime \prime \\
+0.46 \\
0.00\end{array}$ & $\begin{array}{c}\prime \prime \\
+0.28 \\
-0.19\end{array}$ & $\begin{array}{c}\prime \prime \\
-0.10 \\
-0.11\end{array}$ & $\begin{array}{c}\prime \prime \\
+0.13 \\
+0.03\end{array}$ & $\begin{array}{c}\prime \prime \\
+0.05 \\
-0.13\end{array}$ & $\begin{array}{c}\prime \prime \\
-0.11 \\
-0.31\end{array}$ & $\begin{array}{c}\prime \prime \\
+0.28 \\
-0.20\end{array}$ & $\begin{array}{c}\prime \prime \\
-0.05 \\
-0.20\end{array}$ & $\begin{array}{r} \\
+0.23 \\
+0.16\end{array}$ & $\begin{array}{c}\prime \prime \\
+0.22 \\
+0.01\end{array}$ \\
\hline
\end{tabular}

Period 1909-1910.-Most of the observations in this period were made by UPDEGRAFF and HAMMOND, and the difference in personal equation for these observers is small. The results for TILLYER are based on but few observations and are consequently uncertain. No corrections for personal equation have been applied.

Period 1911-1918.-The differences for this period indicate a break at the zenith for all observers except Hammond and Frederickson. The apparent small break for these two disappeared in another discussion, in which the azimuth stars were omitted. From the results in the preceding table, corrections were derived to reduce each observer to the system Hammond. In so doing, small adjustments were made so that the breaks at the zenith for Tillyer,. Rines, WrLIE, and Aston are the same for both clamps. 
Preliminary Corrections to Reduce to System Hammond

\begin{tabular}{|c|c|c|c|c|c|c|c|c|c|c|}
\hline & \multicolumn{2}{|c|}{ Fn. } & \multicolumn{2}{|c|}{$\mathrm{T}$. } & \multicolumn{2}{|c|}{ R. } & \multicolumn{2}{|c|}{ Wy. } & \multicolumn{2}{|c|}{ An. } \\
\hline & East & West & East & West & East & West & East & West & East & West \\
\hline & " & " & $"$ & 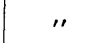 & " & " & $"$ & " & $"$ & " \\
\hline South of Zenith & +0.12 & +0.05 & +0.13 & +0.22 & +0.05 & +0.18 & +0.23 & -0.05 & +0.42 & +0.17 \\
\hline North of Zenith & +0.12 & +0.05 & 0.00 & +0.09 & -0.08 & +0.05 & +0.02 & -0.26 & +0.04 & -0.21 \\
\hline
\end{tabular}

These corrections were modified somewhat by a discussion of the differences, Clamp East minus Clamp West. These differences were formed for each observer and the results compared, as in the following table:

\begin{tabular}{|c|c|c|c|c|c|}
\hline & $\begin{array}{l}(\mathrm{E}-\mathrm{W})_{\mathrm{Hd}} \\
\text { minus } \\
(\mathrm{E}-\mathrm{W})_{\mathrm{Fn}}\end{array}$ & $\begin{array}{c}(\mathrm{E}-\mathrm{W})_{\mathrm{Hd}} \\
\text { minus } \\
(\mathrm{E}-\mathrm{W})_{\mathrm{T}}\end{array}$ & $\begin{array}{c}(E-W)_{\mathbf{H} d} \\
\operatorname{minus}_{(\mathrm{E}-\mathrm{W})_{\mathbf{R}}}\end{array}$ & $\begin{array}{c}(\mathrm{E}-\mathrm{W})_{\mathrm{Hd}} \\
\text { minus } \\
(\mathrm{E}-\mathrm{W})_{\mathrm{Wy}}\end{array}$ & $\begin{array}{c}(\mathrm{E}-\mathrm{W})_{\mathrm{Hd}} \\
\text { minus } \\
(\mathrm{E}-\mathrm{W})_{\mathbf{A n}}\end{array}$ \\
\hline $\begin{array}{l}\text { South of Zenith-. } \\
\text { North of Zenith }\end{array}$ & $\begin{array}{c}\prime \prime \\
+0.08 \\
+0.07\end{array}$ & $\begin{array}{c}\prime \prime \\
+0.15 \\
+0.10\end{array}$ & $\begin{array}{c}\prime \prime \\
-0.29 \\
-0.23\end{array}$ & $\begin{array}{c}\prime \prime \\
+0.21 \\
+0.28\end{array}$ & $\begin{array}{c}\prime \prime \prime \\
+0.35 \\
+0.30\end{array}$ \\
\hline & & +0.10 & -0.23 & +0.28 & +0.30 \\
\hline
\end{tabular}

The final corrections for relative personal equation to reduce to the system Hammond; which are given in Table IX, were determined by adjusting the preliminary corrections so that the differences $(\mathrm{E}-\mathrm{W})$ should be the mean of those derived from the preliminary personal equation corrections and those in the above table.

\section{FLEXURE}

The correction to the circle reading for flexure for any star was assumed to be of the form

$$
e_{1} \sin z+e_{2} \cos z
$$

where $z$ is the zenith distance of the star reckoned as positive in the direction in which the circle readings increase. The circle readings increase toward the south when the instrument is Clamp East.

Horizontal collimators. - The horizontal flexure, $e_{1}$, was determined with the horizontal collimators, by setting one collimator on the other and determining the zenith distances of the two collimators with the transit circle. If $\mathrm{N}$ and $\mathrm{S}$ are the circle readings on the north and south collimators, respectively, we have from the above expression

$$
\begin{aligned}
& e_{1}=1 / 2(\mathrm{~N}-\mathrm{S})-90^{\circ} \quad \text { For Clamp East } \\
& =1 / 2(\mathrm{~S}-\mathrm{N})-90^{\circ} \text { For Clamp West }
\end{aligned}
$$

The following table contains the determination of $e_{1}$ made with the horizontal collimators. All of the determinations, except two made in 1909, were made with a reversing prism on the transit circle and one on the north collimator. Screens were added to the instrument in December, 1910. 
Determinations of the Horizontal Flexure with the Horizontal Collimators

POSITION I

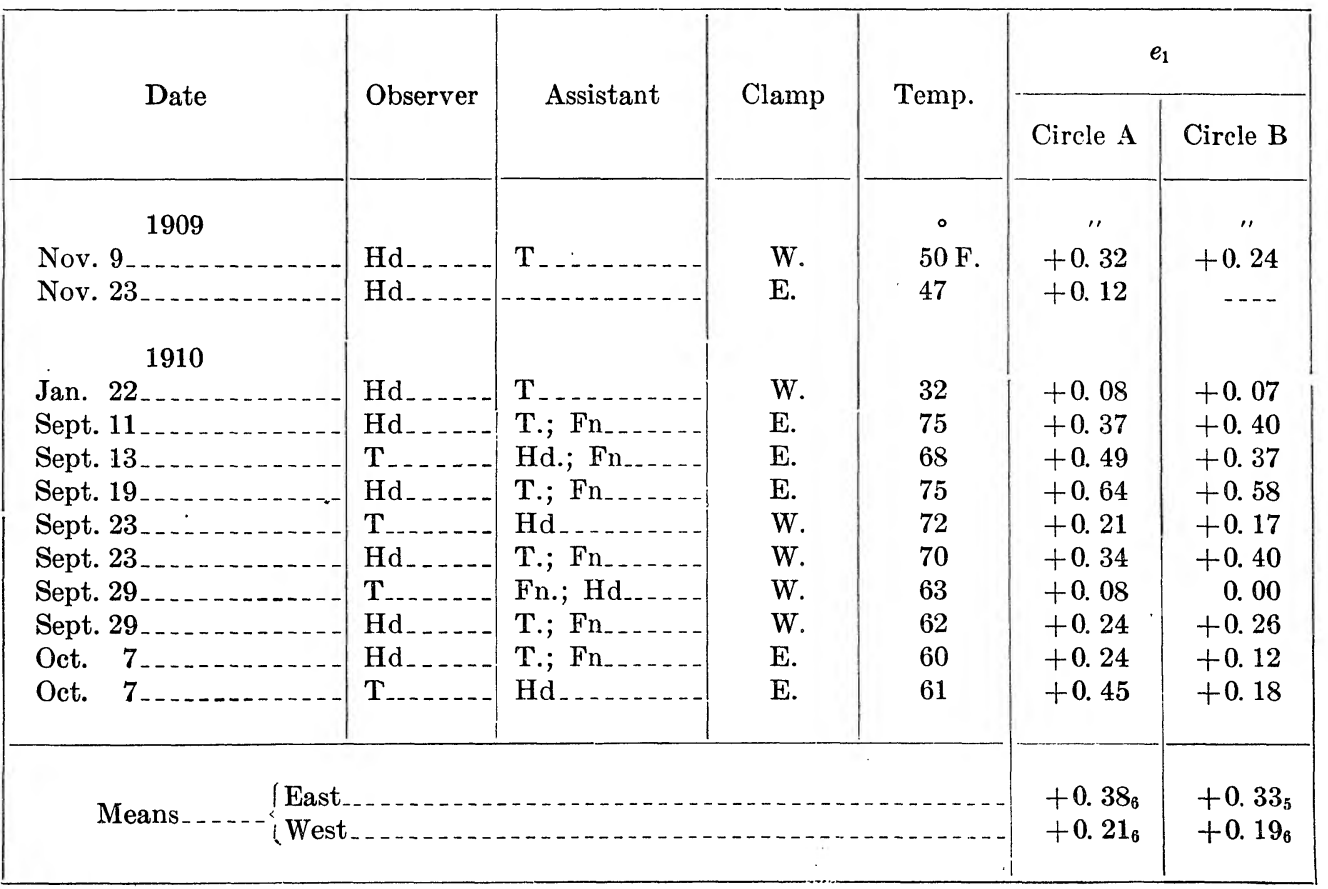

POSITION II

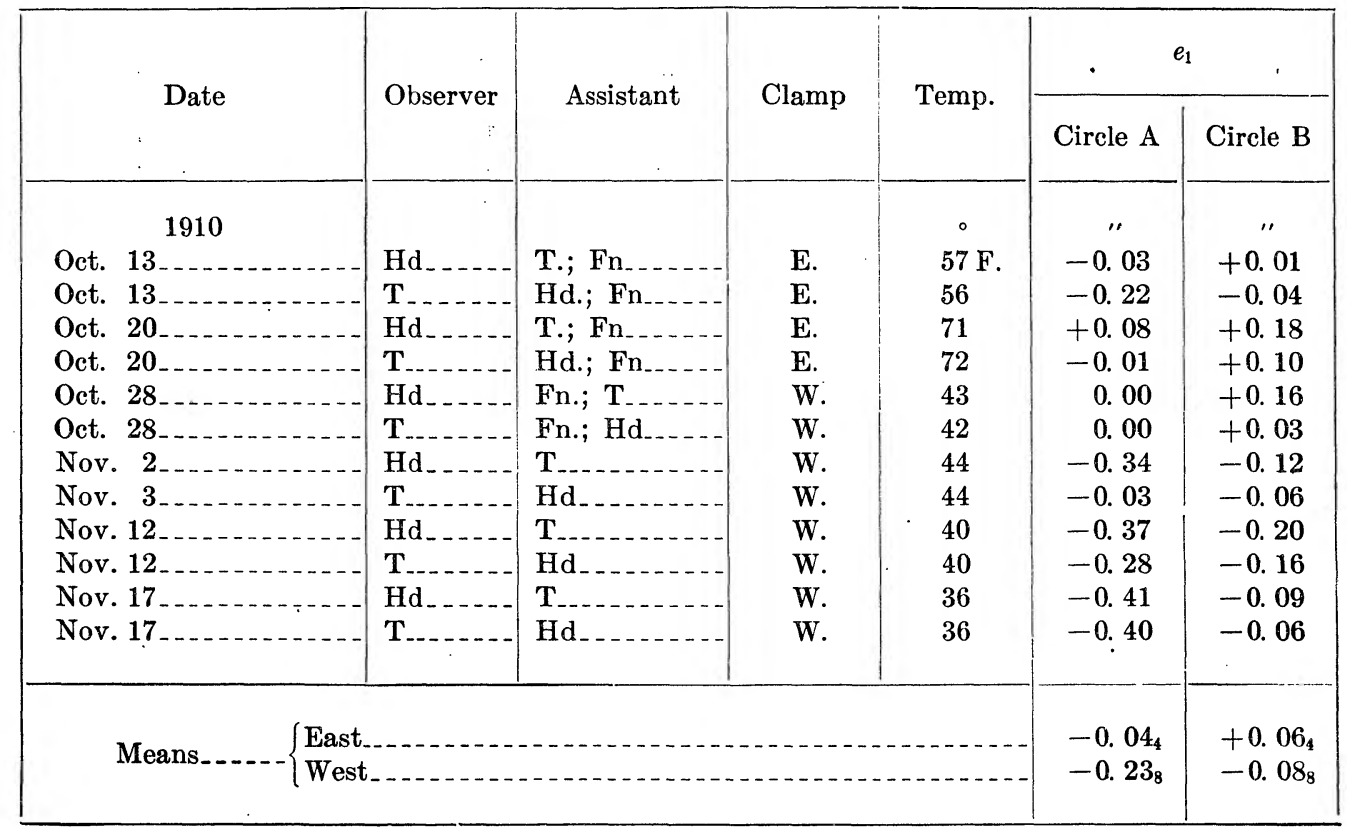

$93432^{\circ}-27-5$ 
Determinations of the Horizontal Flexure with the Horizontal Collimators-Continued POSITION II. CIRCLE A ONLY

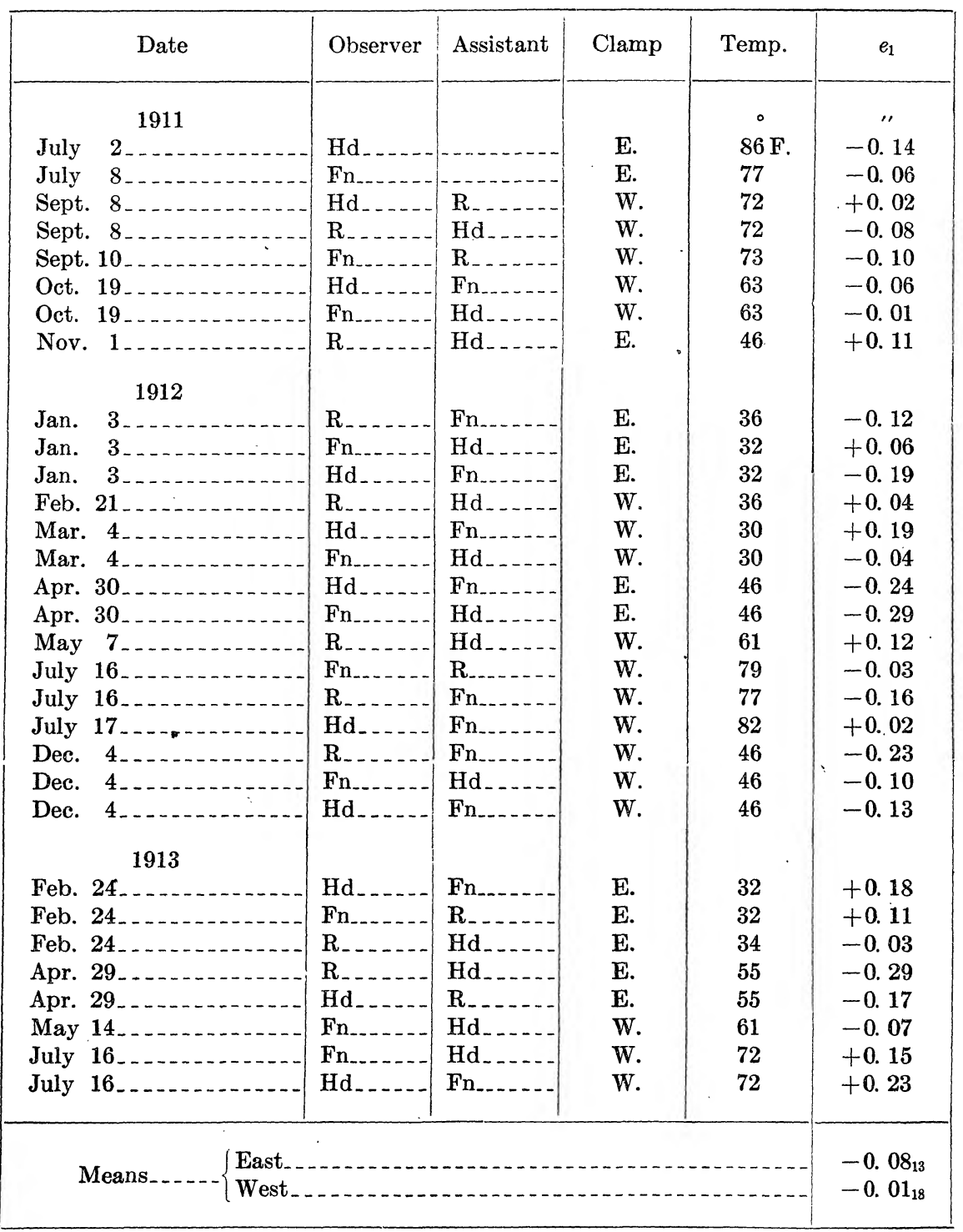

POSITION I. CIRCLE A ONLY

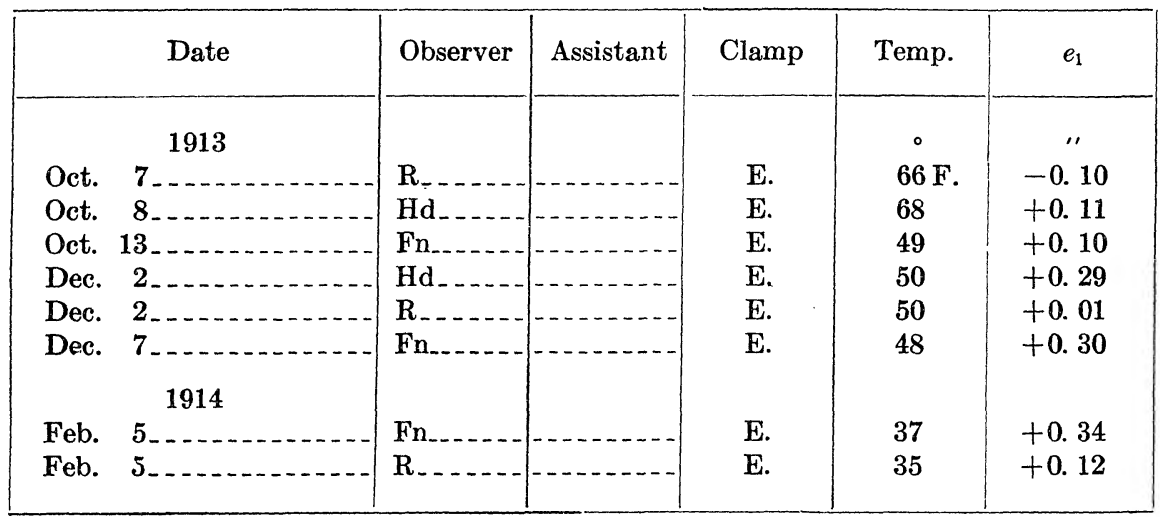


Determinations of the Horizontal Flexure with the Horizontal Collimators-Continued POSITION I. CIRCLE A ONLY

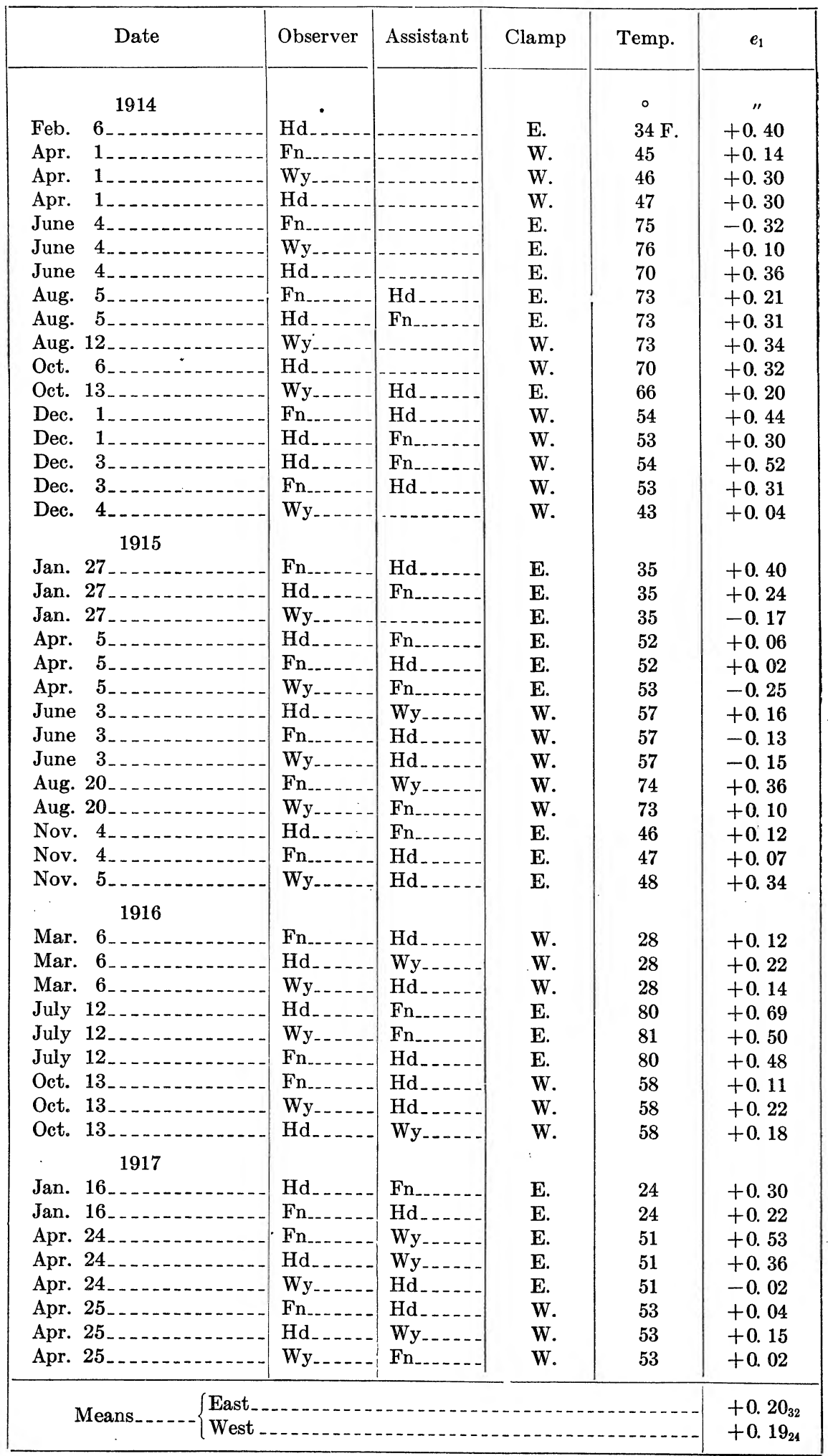


Determinations of the Horizontal Flexure uith the Horizontal Collimators-Continued POSITION II. CIRCLE A ONLY

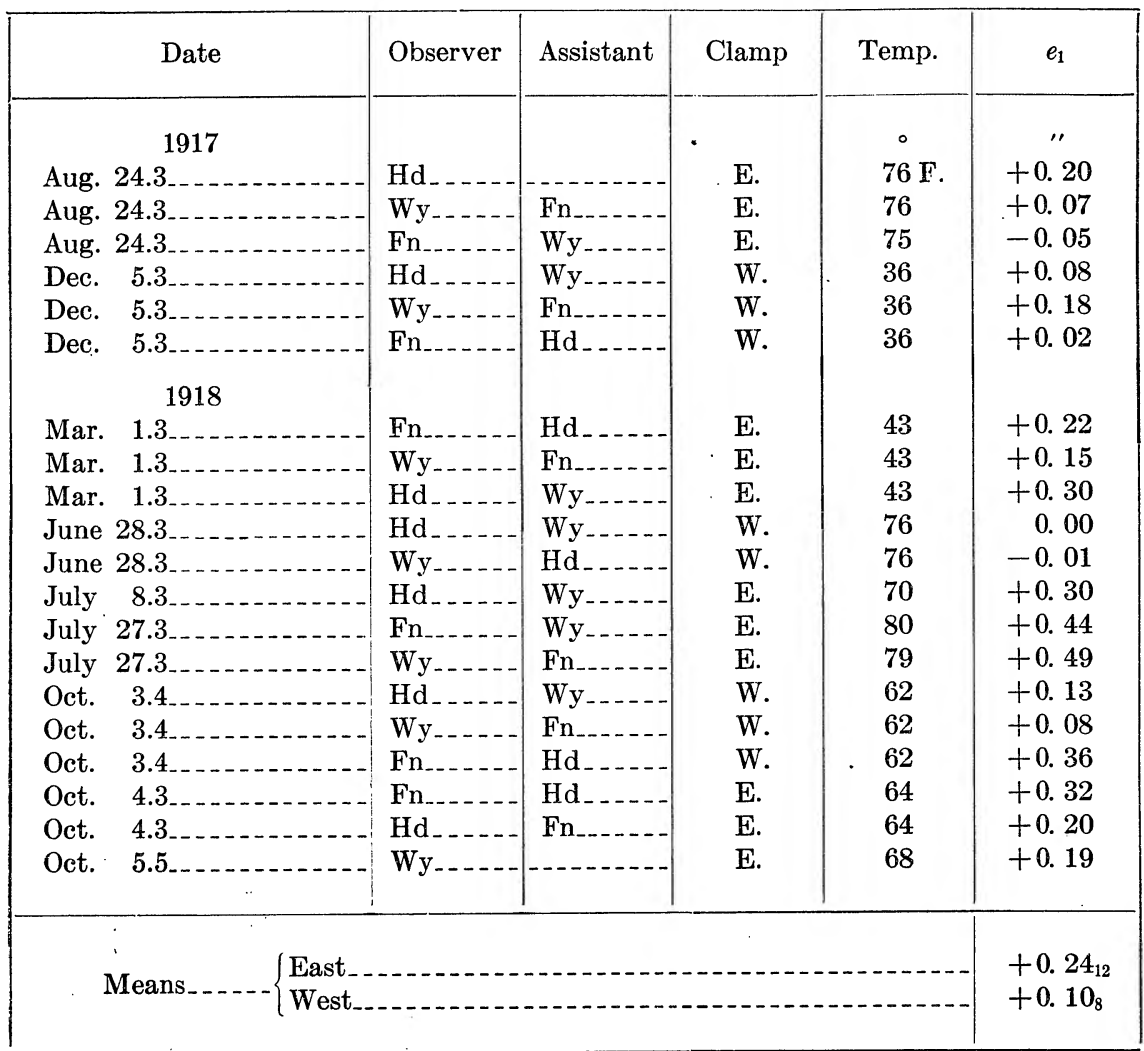

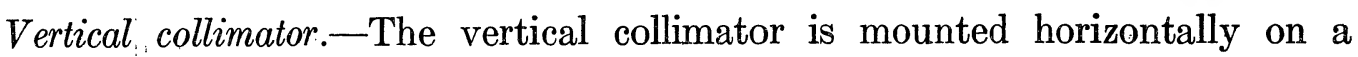
pillar on the east pier and is provided with a mirror in front of the objective inclined at an angle of $45^{\circ}$ with the horizontal, so that the movable wires of the collimator can be made to coincide with their reflected images from the nadir basin. If $B$ 
and $\mathrm{C}$ are the circle readings of the instrument on the nadir and on the collimator wires respectively, we have

$$
e_{2}=1 / 2(\mathrm{~B}-\mathrm{C}) \pm 90^{\circ} \quad \text { For either clamp }
$$

No determinations with the vertical collimator were made in 1909-1910. The following table gives the results for the 1911-1918 work:

Determinations of the Vertical Flexure with the Vertical Collimator

POSITION II. CIRCLE A ONLY

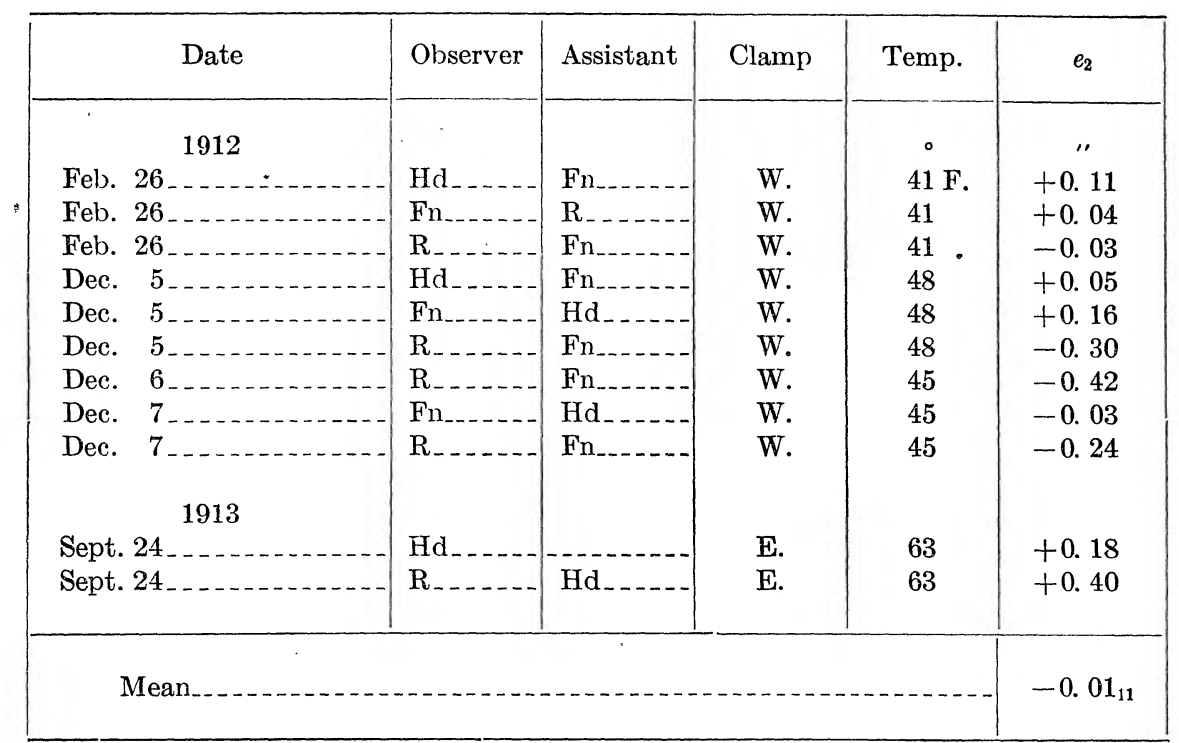


Determinations of the Vertical Flexure with the Vertical Collimator-Continued POSITION I. CIRCLE A ONLY

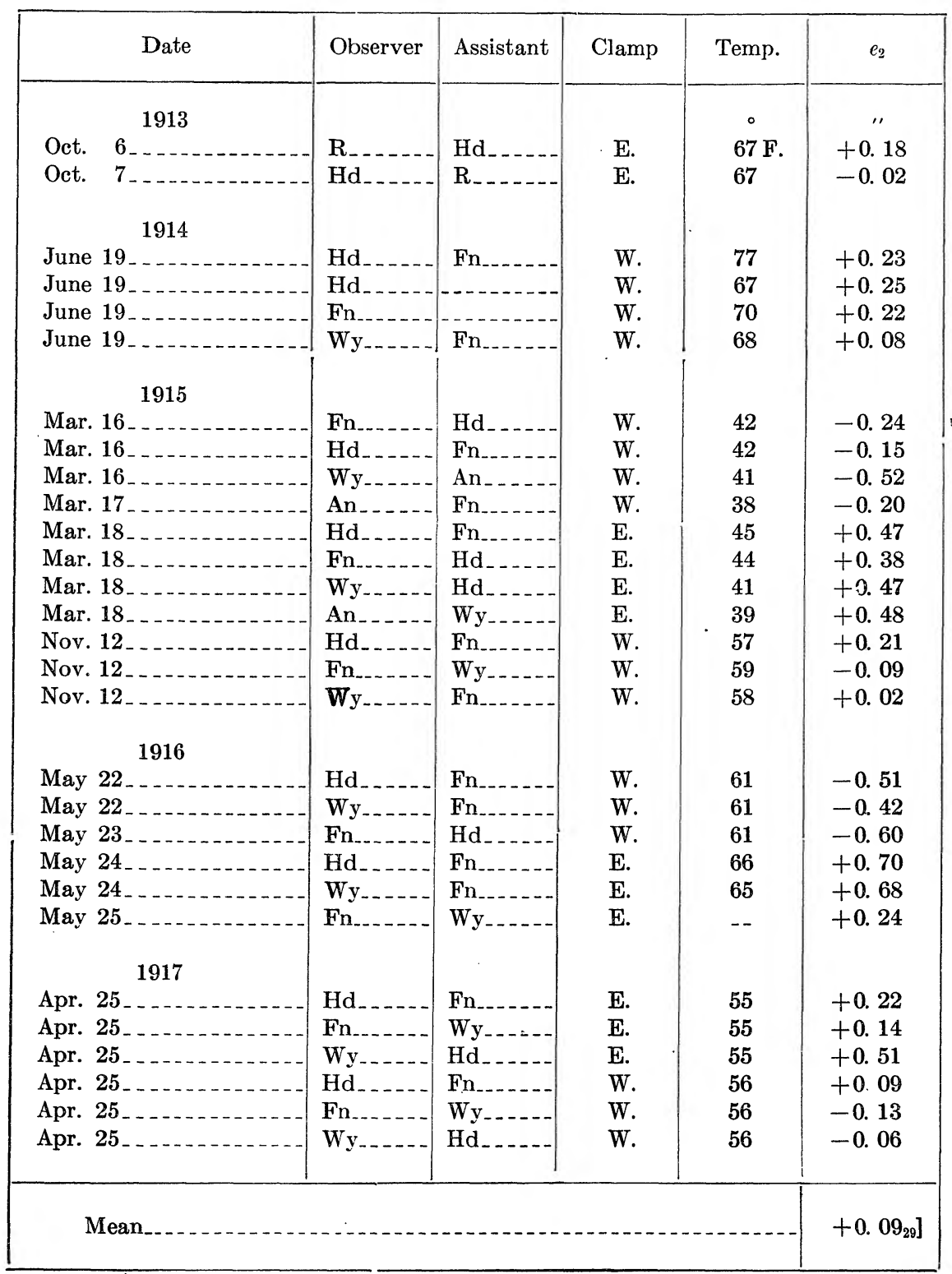


Determinations of the Vertical Flexure with the Vertical Collimator-Continued

POSITION II. CIRCLE A ONLY

\begin{tabular}{|c|c|c|c|c|c|c|}
\hline & Date & Observer & Assistant & Clamp & Temp. & $e_{2}$ \\
\hline & 1917 & & & & ${ }^{\circ}$ & "I \\
\hline Nov. & $8 \ldots \ldots$ & $\mathrm{Hd}_{-}$ & $\mathrm{Wy}_{\ldots} \ldots$ & E. & $49 \mathrm{~F}$. & -0.05 \\
\hline Nov. & $8 \ldots \ldots$ & $\mathrm{Fn}_{-}$ & $\mathrm{Hd} \ldots \ldots$ & E. & 52 & -0.29 \\
\hline Nov. & $8 \ldots \ldots \ldots$ & $W_{y_{-}}$ & $\mathrm{Fn} \ldots \ldots$ & E. & 54 & -0.15 \\
\hline Nov. & $9_{\ldots} \ldots$ & $\mathrm{Hd}$ & $\mathrm{Wy}$ & W. & 59 & -0.21 \\
\hline Nov. & $9 \ldots$ & $F_{n}$ & $\mathrm{Hd} \ldots \ldots$ & W. & 54 & +0.22 \\
\hline Nov. & $9 \ldots$ & $\mathrm{Wy}_{--}$ & $F_{n} \ldots \ldots$ & W. & 54 & +0.10 \\
\hline & 1918 & & & & & \\
\hline Oct. & $3 \ldots$ & $\mathrm{Fn}_{\ldots}$ & $\mathrm{Hd}_{-}$ & W. & 66 & -0.15 \\
\hline Oct. & 3. & $\mathrm{Wy}_{-}$ & $\mathrm{Hd}$ & W. & 66 & -0.45 \\
\hline Oct. & $3 \ldots$ & Hd.. & $W_{y} \ldots \ldots$ & W. & 66 & -0.22 \\
\hline Oct. & $4 \ldots$ & $\mathrm{Wy}_{-.}$ & Fn ........ & E. & 64 & +0.25 \\
\hline Oct. & $4 \ldots$ & $\mathrm{Hd} \ldots \ldots$ & $\mathrm{Fn} \ldots \ldots$ & E. & 64 & +0.21 \\
\hline Oct. & $4 \ldots \ldots$ & Fn $\ldots \ldots$ & $\mathrm{Hd} \ldots \ldots$ & E. & 64 & +0.15 \\
\hline
\end{tabular}

The following mean values of $e_{1}$ and $e_{2}$ were derived from the preceding determinations with the collimators. The probable errors are those resulting from the agreement between the individual measures.

\begin{tabular}{|c|c|c|c|}
\hline Period & Position & $e_{1}$ & $e_{2}$ \\
\hline & & " & " \\
\hline $1909-1910$ & I & $+0.28 \pm 0.081$ & $\ldots \ldots$ \\
\hline 1910 & II & $-0.10 \pm 0.075$ & $\ldots$ \\
\hline $1911-1913$ & II & $-0.04 \pm 0.017$ & $-0.01 \pm 0.048$ \\
\hline $1913-1917$ & I & $+0.20 \pm 0.018$ & $+0.09 \pm 0.043$ \\
\hline $1917-1918$ & II & $+0.18 \pm 0.022$ & $-0.05 \pm 0.045$ \\
\hline
\end{tabular}

Direct and reflected observations. - If the zenith distance of a star, $z$, is taken as positive toward the north and negative toward the south, for both clamps, the correction to an observed declination above the pole for flexure is

$$
\left.\begin{array}{rll}
\Delta \delta & =-e_{2}+\Delta N+e_{1} \sin z-e_{2} \cos z & \text { Clamp East, Direct } \\
& =+e_{2}-\Delta N-e_{1} \sin z-e_{2} \cos z & \text { Clamp East, Reflected } \\
& =+e_{2}-\Delta N+e_{1} \sin z+e_{2} \cos z & \text { Clamp West, Direct } \\
& =-e_{2}+\Delta N-e_{1} \sin z+e_{2} \cos z & \text { Clamp West, Reflected }
\end{array}\right\}
$$

The quantity $\Delta N$ has been introduced to take account of any error in the adopted corrections for division error of the nadir divisions.

If $(\mathrm{R}-\mathrm{D})$ is the difference between reflected and direct observed declinations, then we have for stars above the pole

$$
\begin{aligned}
& 1 / 2(\mathrm{R}-\mathrm{D})=-e_{2}+\Delta N+e_{1} \sin z \quad \text { Clamp East } \\
& =+e_{2}-\Delta N+e_{1} \sin z \quad \text { Clamp West }
\end{aligned}
$$


If $z_{1}$ and $z_{2}$ are the values of $z$ for two different stars or groups of stars and if $(\mathrm{R}-\mathrm{D})_{1}$ and $(\mathrm{R}-\mathrm{D})_{2}$ are the corresponding values of $(\mathrm{R}-\mathrm{D})$, we have for either clamp,

$$
\left(\sin z_{1}-\sin z_{2}\right) e_{1}=1 / 2(\mathrm{R}-\mathrm{D})_{1}-1 / 2(\mathrm{R}-\mathrm{D})_{2}
$$

This equation will yield the strongest values of $e_{1}$ when stars on opposite sides of the zenith are used.

If $(\mathrm{E}-\mathrm{W})$ is the difference between observed declinations in the two clamps, we have for stars above the pole

and therefore

$$
\begin{aligned}
1 / 2(\mathrm{E}-\mathrm{W}) & =e_{2}(\cos z+1)-\Delta N & & \text { Direct observations } \\
& =e_{2}(\cos z-1)+\Delta N & & \text { Reflected observations }
\end{aligned}
$$

$$
e_{2} \cos z=1 / 4(\mathrm{E}-\mathrm{W})_{\mathrm{D}}+1 / 4(\mathrm{E}-\mathrm{W})_{\mathrm{R}}
$$

Period 1909-1910.-The following table shows the results of direct and reflected observations made by HAmmond from October 30 to November 27, 1909. The stars were observed both direct and reflected on the same night.

\begin{tabular}{|c|c|c|c|c|c|c|}
\hline \multirow{2}{*}{ Star } & \multirow{2}{*}{$\alpha$} & \multirow{2}{*}{$z$} & \multicolumn{2}{|c|}{$1 / 2(\mathrm{R}-\mathrm{D})$} & \multicolumn{2}{|c|}{$1 / 2(E-W)$} \\
\hline & & & East & West & Direct & Reflected \\
\hline & $\mathrm{h} \quad \mathrm{m}$ & $\circ$ & " & $\prime \prime$ & $"$ & $"$ \\
\hline$i^{1}$ Aquarii $\ldots$ & 2339 & -57.7 & $-0.55_{5}$ & $-0.30_{5}$ & $+0.13_{5}$ & $-0.12_{5}$ \\
\hline$\iota$ Ceti $\ldots$ & 014 & -48.2 & $-0.05_{3}$ & $-0.04_{4}$ & $+0.35_{3}$ & $+0.33_{3}$ \\
\hline 12 Ceti $_{\ldots} \ldots$ & 025 & -43.4 & $-0.44_{5}$ & $-0.22_{4}$ & $+0.07_{4}$ & $-0.04_{4}$ \\
\hline$\epsilon$ Piscium & 058 & -31.5 & $-0.35_{3}$ & 0. $00_{4}$ & $+0.14_{3}$ & $-0.21_{3}$ \\
\hline$\beta$ Arietis $\ldots$ & 149 & -18.5 & $-0.20_{4}$ & $-0.65_{1}$ & $-0.40_{2}$ & $+0.04_{2}$ \\
\hline$v$ Piscium & 114 & -12.1 & $+0.32_{4}$ & $+0.17_{3}$ & $-0.08_{4}$ & $+0.07_{4}$ \\
\hline$\epsilon$ Andromedx.- & 034 & -10.1 & -0.025 & $-0.32_{4}$ & $-0.20_{4}$ & $+0.11_{4}$ \\
\hline$\varphi$ Persei $\ldots \ldots$ & 138 & +11.3 & 0. $00_{4}$ & $-0.48_{2}$ & $-0.02_{3}$ & $+0.47_{3}$ \\
\hline$\beta$ Cassiopeix... & $0 \quad 4$ & +19.8 & $-0.13_{5}$ & $-0.30_{4}$ & $-0.30_{4}$ & $-0.14_{5}$ \\
\hline Gr. $4163 \ldots$ & 2350 & +35.0 & $-0.26_{6}$ & $-0.06_{4}$ & $-0.10_{4}$ & $-0.31_{4}$ \\
\hline 44 H. Cephei $\ldots$ & 14 & +40.3 & $-0.24_{5}$ & $+0.08_{4}$ & $-0.05_{4}$ & $-0.36_{4}$ \\
\hline$\alpha$ Ursæ Minoris & 126 & +49.9 & $-0.45_{4}$ & $-0.05_{4}$ & $+0.20_{4}$ & $-0.19_{4}$ \\
\hline $32^{2}$ H. Camelop. s. P. & 1248 & +57.2 & $-0.34_{5}$ & $-0.16_{4}$ & $+0.06_{4}$ & $-0.11_{4}$ \\
\hline
\end{tabular}

Direct and Reflected Observations-Series 1

POSITION I. CIRCLE A ONLY. NO REVERSING PRISM

The following tables show the results of direct and reflected observations made from September to November, 1910. Two observers, Hammond and Tillyer, took part in the observations, the stars being observed direct on one night and reflected on another. A reversing prism was used which was kept in one position throughout a night and the micrometer and objective were interchanged after the series was half completed. Both circles were read on the same bisection of a star. 


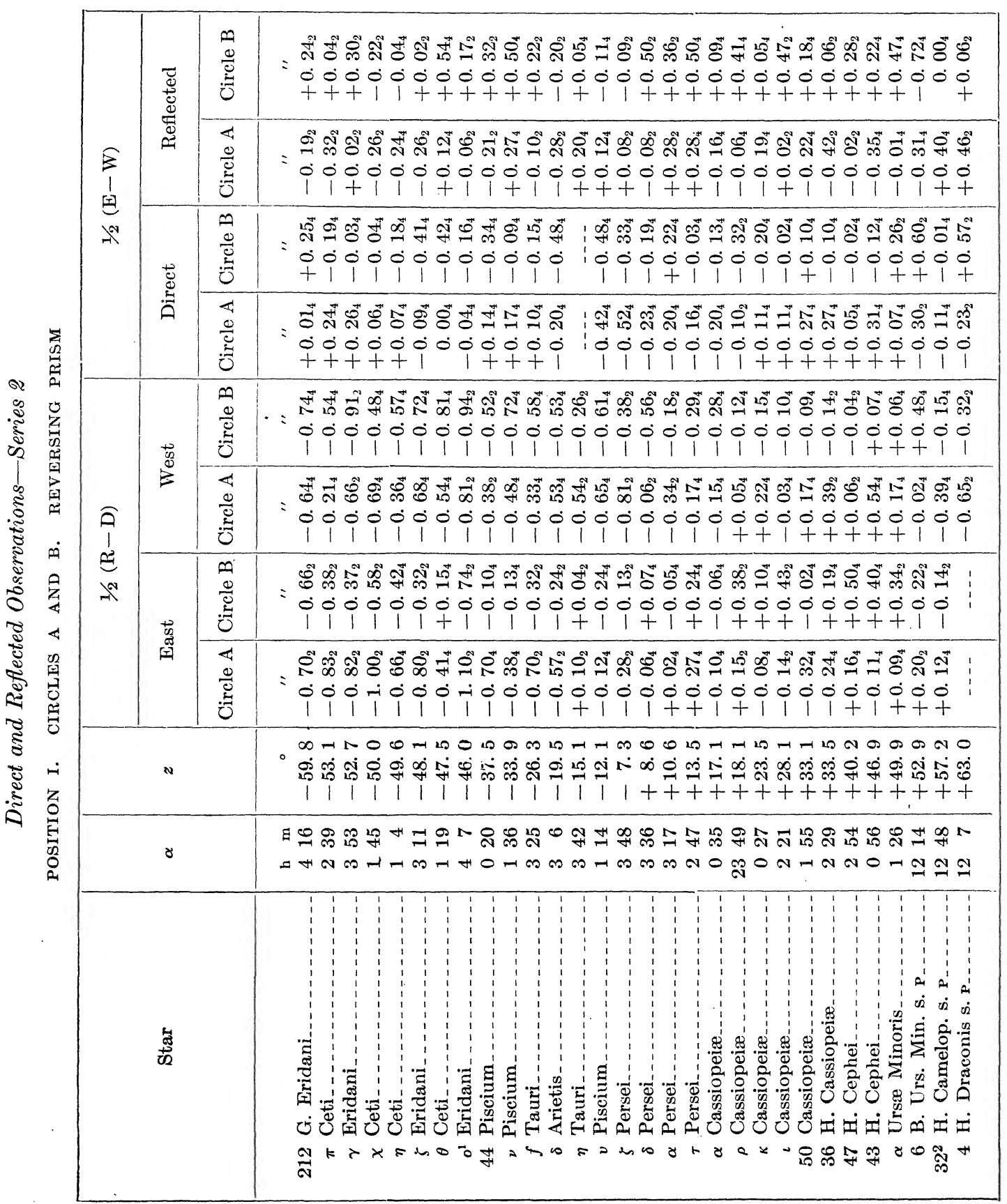




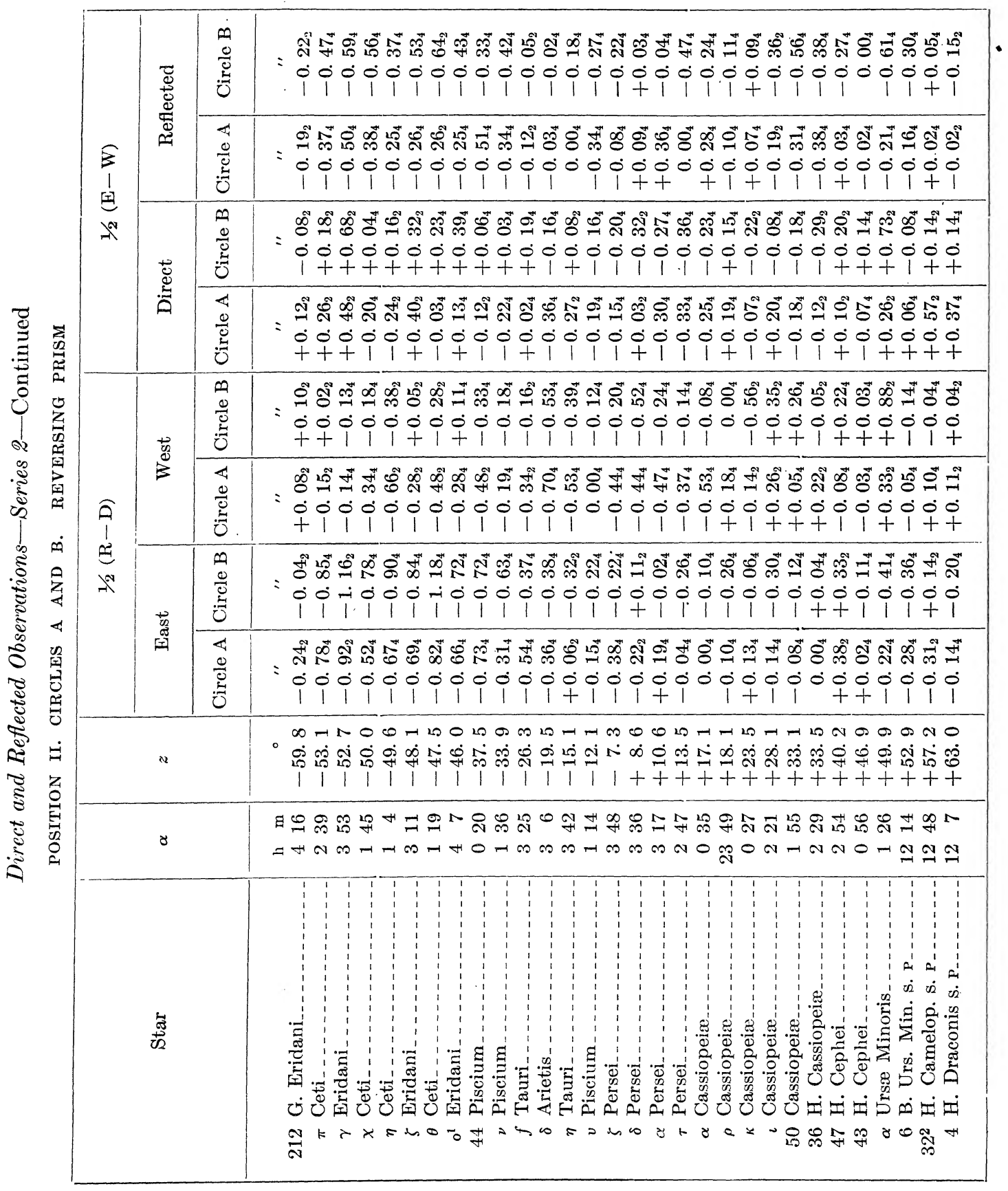


The following table contains a summary of the results for Series 2 , each quantity tabulated being the mean for three stars.

Summary of the Results for Series 2

\begin{tabular}{|c|c|c|c|c|c|c|c|c|c|}
\hline & \multirow{3}{*}{$z$} & \multicolumn{4}{|c|}{$1 / 2(R-D)$} & \multicolumn{4}{|c|}{$1 / 2(E-W)$} \\
\hline & & \multicolumn{2}{|c|}{ East } & \multicolumn{2}{|c|}{ West } & \multicolumn{2}{|c|}{ Direct } & \multicolumn{2}{|c|}{ Reflected } \\
\hline & & Circle A & Circle B & Circle A & Circle B & Circle A & Circle B & Circle A & Circle B \\
\hline 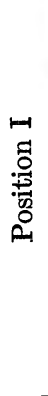 & $\begin{array}{c}\circ \\
-55 \\
-49 \\
-44 \\
-27 \\
-12 \\
+11 \\
+19 \\
+31 \\
+46 \\
+58\end{array}$ & $\begin{array}{c}\prime \prime \\
-0.78 \\
-0.78 \\
-0.66 \\
-0.51 \\
-0.10 \\
+0.08 \\
-0.04 \\
-0.25 \\
+0.05 \\
+0.14\end{array}$ & $\begin{array}{c}\prime \prime \\
-0.47 \\
-0.44 \\
-0.13 \\
-0.20 \\
-0.14 \\
+0.08 \\
+0.09 \\
+0.15 \\
+0.43 \\
-0.17\end{array}$ & $\begin{array}{c}\prime \prime \\
-0.47 \\
-0.58 \\
-0.57 \\
-0.45 \\
-0.66 \\
-0.18 \\
+0.04 \\
+0.13 \\
+0.30 \\
-0.29\end{array}$ & $\begin{array}{c}\prime \prime \\
-0.70 \\
-0.59 \\
-0.77 \\
-0.61 \\
-0.46 \\
-0.33 \\
-0.19 \\
-0.10 \\
+0.04 \\
+0.07\end{array}$ & $\begin{array}{c}\prime \prime \\
+0.17 \\
+0.01 \\
+0.03 \\
+0.02 \\
-0.46 \\
-0.20 \\
-0.06 \\
+0.22 \\
+0.14 \\
-0.19\end{array}$ & 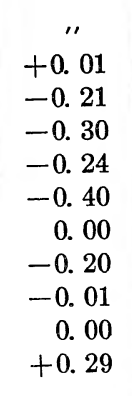 & $\begin{array}{r}\prime \prime \\
-0.16 \\
-0.25 \\
0.00 \\
+0.04 \\
+0.14 \\
+0.19 \\
-0.14 \\
-0.21 \\
-0.15 \\
+0.13\end{array}$ & $\begin{array}{c}\prime \prime \\
+0.19 \\
-0.07 \\
+0.40 \\
+0.25 \\
-0.04 \\
+0.46 \\
+0.18 \\
+0.22 \\
+0.33 \\
-0.27\end{array}$ \\
\hline 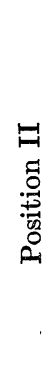 & $\begin{array}{l}-55 \\
-49 \\
-44 \\
-27 \\
-12 \\
+11 \\
+19 \\
+31 \\
+46 \\
+58\end{array}$ & $\begin{array}{l}-0.68 \\
-0.63 \\
-0.74 \\
-0.40 \\
-0.20 \\
+0.02 \\
+0.01 \\
-0.08 \\
-0.01 \\
-0.23\end{array}$ & $\begin{array}{l}-0.72 \\
-0.84 \\
-0.87 \\
-0.46 \\
-0.24 \\
-0.09 \\
-0.14 \\
-0.13 \\
-0.14 \\
-0.19\end{array}$ & $\begin{array}{l}-0.09 \\
-0.40 \\
-0.38 \\
-0.42 \\
-0.32 \\
-0.43 \\
-0.17 \\
+0.14 \\
+0.02 \\
+0.04 \\
.\end{array}$ & $\begin{array}{l}-0.04 \\
-0.17 \\
-0.14 \\
-0.31 \\
-0.24 \\
-0.30 \\
-0.14 \\
+0.20 \\
+0.28 \\
-0.06\end{array}$ & $\begin{array}{l}+0.29 \\
-0.06 \\
+0.02 \\
-0.19 \\
-0.19 \\
-0.24 \\
-0.04 \\
-0.02 \\
+0.06 \\
+0.29\end{array}$ & $\begin{array}{l}+0.26 \\
+0.14 \\
+0.23 \\
+0.02 \\
-0.13 \\
-0.32 \\
-0.08 \\
-0.16 \\
+0.30 \\
+0.05\end{array}$ & $\begin{array}{l}-0.39 \\
-0.30 \\
-0.35 \\
-0.18 \\
-0.14 \\
+0.15 \\
+0.08 \\
-0.31 \\
-0.07 \\
-0.06\end{array}$ & $\begin{array}{l}-0.47 \\
-0.49 \\
-0.43 \\
-0.19 \\
-0.22 \\
-0.16 \\
-0.09 \\
-0.45 \\
-0.29 \\
-0.13\end{array}$ \\
\hline
\end{tabular}

For discussing the flexure during the period 1909-1910, there were also available the differences in declination, Clamp East minus Clamp West, based on the other observations made in this period. The means of these differences arranged in zones of approximately equal weight are given in the following table:

Summary of Differences $1 / 2(E-W)$ for Direct Observations, 1909-1910

POSITION I. CIRCLES A AND B. NO PRISM

\begin{tabular}{|c|c|c|c|c|c|c|c|c|}
\hline \multirow{2}{*}{$z$} & \multicolumn{2}{|c|}{$1 / 2(E-W)$} & \multirow{2}{*}{$z$} & \multicolumn{2}{|c|}{$1 / 2(E-W)$} & \multirow{2}{*}{$z$} & \multicolumn{2}{|c|}{$1 / 2(E-W)$} \\
\hline & Circle A & Circle B & & Circle A & Circle B & & Circle A & Circle B \\
\hline $\begin{array}{r}\circ \\
-67 \\
-60 \\
-55 \\
-51 \\
-44 \\
-39 \\
-36 \\
-33\end{array}$ & $\begin{array}{c}\prime \prime \\
+0.10 \\
+0.24 \\
+0.17 \\
+0.09 \\
+0.05 \\
+0.04 \\
+0.09 \\
+0.04\end{array}$ & $\begin{array}{c}\prime \prime \\
-0.10 \\
-0.11 \\
-0.24 \\
-0.01 \\
-0.31 \\
-0.01 \\
-0.21 \\
-0.18\end{array}$ & $\begin{array}{r}\circ \\
-30 \\
-28 \\
-24 \\
-19 \\
-15 \\
-12 \\
-9 \\
-5\end{array}$ & $\begin{array}{c}\prime \prime \\
-0.01 \\
+0.17 \\
-0.14 \\
-0.02 \\
+0.07 \\
-0.17 \\
-0.02 \\
-0.10\end{array}$ & $\begin{array}{c}\prime \prime \\
-0.15 \\
-0.05 \\
-0.15 \\
-0.13 \\
-0.05 \\
+0.02 \\
-0.14 \\
-0.08\end{array}$ & $\begin{array}{r}\circ \\
+5 \\
+13 \\
+21 \\
+28 \\
+35 \\
+45 \\
+56 \\
+68\end{array}$ & $\begin{array}{c}\prime \prime \\
-0.14 \\
-0.17 \\
-0.23 \\
-0.12 \\
+0.06 \\
-0.02 \\
-0.16 \\
+0.02\end{array}$ & $\begin{array}{c}\prime \prime \\
-0.22 \\
-0.07 \\
+0.03 \\
-0.08 \\
+0.04 \\
0.00 \\
-0.08 \\
-0.06\end{array}$ \\
\hline
\end{tabular}


In forming the differences in the preceding tables, the only corrections applied to the observed declinations were those for variation of latitude, and it should be noted that the signs of the differences for observations made below the pole must be changed to make them comparable with the differences above the pole.

The vertical flexure $e_{2}$ and the correction $\Delta N$, defined above, might be determined from the differences, Clamp East minus Clamp West, resulting from the direct observations, by the equation

$$
1 / 2(\mathbf{E}-\mathrm{W})=e_{2}(\cos z+1)-\Delta N
$$

However, the coefficient of $e_{2}$ in this equation changes so slowly with the zenith distance that this is not practicable. Solutions for $e_{2}$ were therefore made using equation (5),

$$
e_{2} \cos z=1 / 4(\mathrm{E}-\mathrm{W})_{\mathrm{D}}+1 / 4(\mathrm{E}-\mathrm{W})_{\mathrm{B}}
$$

The resulting values of $e_{2}$ are

Vertical Flexure, $e_{2}$, from Observations of Stars

\begin{tabular}{|c|c|c|c|c|}
\hline & \multicolumn{2}{|c|}{ Position I } & \multicolumn{2}{c|}{ Position II } \\
\cline { 2 - 4 } & Circle A & Circle B & Circle A & Circle B \\
\hline & $\ldots$ & $\prime \prime$ & $\prime \prime$ & $\ldots$ \\
Series 1.... & -0.04 & -0.05 & -0.13 & -0.16 \\
\hline
\end{tabular}

These values of $e_{2}$ were substituted in equations (4) to obtain $\Delta N$, with the following results:

\begin{tabular}{|c|c|c|c|c|c|c|c|c|}
\hline \multirow{3}{*}{. } & \multicolumn{4}{|c|}{ Direct } & \multicolumn{4}{|c|}{ Reflected } \\
\hline & \multicolumn{2}{|c|}{ Position I } & \multicolumn{2}{|c|}{ Position II } & \multicolumn{2}{|c|}{ Position I } & \multicolumn{2}{|c|}{ Position II } \\
\hline & Circle A & Circle B & Circle A & Circle B & Circle A & Circle B & Circle A & Circle B \\
\hline Series 1 & $\begin{array}{c}\prime \prime \\
-0.05\end{array}$ & $"$ & $"$ & " & $\begin{array}{c}\prime \prime \\
-0.03\end{array}$ & " & " & $"$ \\
\hline Series 2 & -0.08 & +0.25 & -0.17 & -0.31 & -0.07 & +0.26 & -0.17 & -0.30 \\
\hline Other direct observations & -0.07 & +0.17 & $\ldots$ & $-\ldots$ & $\ldots$ & $\ldots$ & $-\ldots$ & $\ldots$ \\
\hline
\end{tabular}

Values of $\Delta N$ from Observations of Stars

The horizontal flexure, $e_{1}$, was derived from the direct and reflected observations by the use of equation (3)

$$
\left(\sin z_{1}-\sin z_{2}\right) e_{1}=1 / 2(\mathrm{R}-\mathrm{D})_{1}-1 / 2(\mathrm{R}-\mathrm{D})_{2}
$$

Observations of stars or groups of stars on opposite sides of the zenith and at about the same zenith distance were combined to form an equation of condition. The solution of the equations of condition gave the following results: 
Horizontal Flexure, $e_{1}$, from Observations of Stars

\begin{tabular}{|c|c|c|c|c|c|c|c|c|}
\hline \multirow[b]{3}{*}{. } & \multicolumn{4}{|c|}{ Position I } & \multicolumn{4}{|c|}{ Position II } \\
\hline & \multicolumn{2}{|c|}{ Clamp East } & \multicolumn{2}{|c|}{ Clamp West } & \multicolumn{2}{|c|}{ Clamp East } & \multicolumn{2}{|c|}{ Clamp West } \\
\hline & Circle A & Circle B & Circle A & Circle B & Circle A & Circle B & Circle A & Circle B \\
\hline $\begin{array}{l}\text { Series } 1 \\
\text { Series } 2\end{array}$ & $\begin{array}{r}\prime \prime \\
+0.15 \\
+0.44\end{array}$ & $\begin{array}{c}\prime \prime \\
+0.42\end{array}$ & $\begin{array}{r}\prime \prime \\
+0.14 \\
+0.55\end{array}$ & $\begin{array}{c}\prime \prime \\
+0.45\end{array}$ & $\begin{array}{c}\prime \prime \\
+\overline{0.51}\end{array}$ & $\begin{array}{c}\prime \prime \\
+0.52\end{array}$ & $\begin{array}{c}\prime \prime \\
+-\overline{0.22}\end{array}$ & $\begin{array}{c}\prime \prime \\
+0 . \overline{17}\end{array}$ \\
\hline
\end{tabular}

The values of the horizontal flexure derived from the collimators are in fairly good agreement with those derived from the stars, for Position I but not for Position II. After careful consideration it was decided to adopt the values of $e_{1}$ determined from the collimators and to use the same values for both circles. Since all the observations in 1909-1910 were made in Position I, with the exception of a part of the direct and reflected observations in Series 2, the final declinations will not be affected materially by this choice.

Since no determinations of the vertical flexure were made with the vertical collimator, the adopted values of $e_{2}$ and $\Delta N$ are those resulting from observations of stars.

Adopted Values of $e_{1}, e_{2}$, and $\Delta N$

[1909-1910]

\begin{tabular}{|c|c|c|c|c|}
\hline & \multicolumn{2}{|c|}{ Position I } & \multicolumn{2}{c|}{ Position II } \\
\cline { 2 - 4 } & Circle A & Circle B & Circle A & Circle B \\
\cline { 2 - 4 } & $\prime \prime$ & $\prime \prime$ & $\prime \prime$ & $\prime \prime$ \\
\hline$e_{1}$ & +0.28 & +0.28 & -0.10 & -0.10 \\
$\Delta N \ldots .04$ & +0.05 & -0.13 & -0.16 \\
& -0.06 & +0.23 & -0.17 & -0.30 \\
\hline
\end{tabular}

From these adopted values, the corrections to the observed declinations for flexure which are given in Table $\mathrm{X}$ were computed.

Period 1911-1918.-The flexures for the period 1911-1918 were first discussed in the same manner as those for 1909-1910, but certain small anomalies arising, it was decided to investigate a possible circle flexure. This circle flexure was assumed to be equivalent to a slight rotation of the circle on its axis such as would be produced if a weight were added to the circle at some point $A$.

Let

$$
\begin{aligned}
& o=\text { the circle reading of the objective. } \\
& k=\text { the circle reading of the point } A . \\
& \theta=o-k=\text { the angle between the point } A \text { and the objective. }
\end{aligned}
$$

Then the correction to a circle reading for flexure at any zenith distance, $z$, is

$$
e_{1} \sin z+e_{2} \cos z+f \sin (z+\theta)
$$


The first two terms represent the tube flexure and the last term the circle flexure. The zenith distance is reckoned from $0^{\circ}$ to $360^{\circ}$ in the direction in which the circle readings increase.

If $H$ and $V$ are the measured horizontal and vertical flexures as determined with the collimators, we have for either clamp,

$$
\begin{aligned}
& H=e_{1}+f \cos \theta=e_{1}+f \cos k \cos o+f \sin k \sin o \\
& V=e_{2}+f \sin \theta=e_{2}+f \cos k \sin o-f \sin k \cos o
\end{aligned}
$$

The following are the values of $o, H$, and $V$ for the three periods in which the

\begin{tabular}{|c|c|c|c|c|}
\hline Period & Position & $o$ & $H$ & $V$ \\
\hline & & 。 & " & 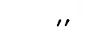 \\
\hline $1911-1913$ & $\mathrm{II}_{\mathrm{i}}$ & $179 \quad 56$ & -0.04 & -0.01 \\
\hline $1913-1917$ & I & 45 & +0.20 & +0.09 \\
\hline $1917-1918$ & $\mathrm{II}_{2}$ & $330 \quad 54$ & +0.18 & -0.05 \\
\hline
\end{tabular}
work was divided:

It became apparent from a preliminary discussion that the horizontal tube flexure, $e_{1}$, had different values in the two positions of the instrument, instead of simply having different signs; also that the vertical tube flexure, $e_{2}$, was practically zero at all times. Accordingly, a different horizontal tube flexure, $d_{1}$, was assumed for Position I and the terms containing $e_{2}$ were omitted. There resulted the following six equations of condition, containing four unknowns:

$$
\begin{aligned}
& d_{1} \quad e_{1} \quad f \cos k f \sin k \quad n_{\text {obs. }} n_{\text {" comp. }} \\
& 0.00+1.00-1.00 \quad 0.00=-0.04 \quad-0.04 \\
& 1.000 .00+0.71+0.71=+0.20+0.20 \\
& 0.00+1.00+0.87-0.49=+0.18+0.18 \\
& \begin{array}{lll}
0.00 & 0.00 & 0.00+1.00=-0.01-0.01
\end{array} \\
& 0.00 \quad 0.00+0.71-0.71=+0.09+0.09 \\
& 0.00 \quad 0.00-0.49-0.87=-0.05-0.05
\end{aligned}
$$

The solution of these equations gives

Whence

$$
\begin{array}{cc}
e_{1}=+0.074 & f \cos k=+0.116 \\
d_{1}=+0.127 & f \sin k=-0.012
\end{array}
$$

$$
f=+0.117 \text { and } k=-5 \text { i } 54
$$

It happened that the equations of condition were satisfied exactly. Since it was found to be impossible to satisfy the differences $(\mathrm{E}-\mathrm{W}),(\mathrm{R}-\mathrm{D})$, and $(\mathrm{II}-\mathrm{I})$, and the determinations made with the collimators, with a single set of values of the flexure, it was decided to use the values given above and to derive empirical terms to reduce the observations made in the various positions to a common basis, this common basis to be the mean of all positions for direct observations only.

If $z$ is reckoned as positive toward the north, the correction to an observed declination for flexure and nadir division error is

$$
\begin{aligned}
\Delta \delta & =-e_{2}+\Delta N+e_{1} \sin z-e_{2} \cos z-f \sin \theta-f \sin (\theta-z) & & \text { Clamp East, Direct } \\
& =+e_{2}-\Delta N-e_{1} \sin z-e_{2} \cos z+f \sin \theta-f \sin (\theta+z) & & \text { Clamp East, Reflected } \\
& =+e_{2}-\Delta N+e_{1} \sin z+e_{2} \cos z+f \sin \theta+f \sin (\theta+z) & & \text { Clamp West, Direct } \\
& =-e_{2}+\Delta N-e_{1} \sin z+e_{2} \cos z-f \sin \theta+f \sin (\theta-z) & & \text { Clamp West, Reflected }
\end{aligned}
$$


It should be understood that $d_{1}$ must be substituted for $e_{1}$ in Position I.

If $(\mathrm{E}-\mathrm{W})$ is the difference between observed declinations in the two clamps, we have, since $e_{2}$ is assumed to be zero,

$$
\begin{array}{lll}
1 / 2(\mathrm{E}-\mathrm{W})_{1}=-\Delta N_{1}+f(1+\cos z) \sin \left(o_{1}-k\right)+X_{1} & \text { Position } \mathrm{II}_{1} \\
1 / 2(\mathrm{E}-\mathrm{W})_{2}=-\Delta N_{2}+f(1+\cos z) \sin \left(o_{2}-k\right)+X_{2} & \text { Position I } \\
1 / 2(\mathrm{E}-\mathrm{W})_{3}=-\Delta N_{3}+f(1+\cos z) \sin \left(o_{3}-k\right)+X_{3} & \text { Position } \mathrm{II}_{2}
\end{array}
$$

where $X_{1}, X_{2}$, and $X_{3}$ are empirical terms necessary to reduce each clamp to the mean of both.

If $\left(\mathrm{II}_{1}-\mathrm{I}\right)$ and $\left(\mathrm{II}_{2}-\mathrm{I}\right)$ are differences between the observed declinations of a star (mean of both clamps) in the three positions of the instrument, we have

$$
\begin{aligned}
& \left(\mathrm{II}_{1}-\mathrm{I}\right)=\left\{d_{1}-e_{1}+f\left[\cos \left(o_{2}-k\right)-\cos \left(o_{1}-k\right)\right]\right\} \sin z+Y_{1} \\
& \left(\mathrm{II}_{2}-\mathrm{I}\right)=\left\{d_{1}-e_{1}+f\left[\cos \left(o_{2}-k\right)-\cos \left(o_{3}-k\right)\right]\right\} \sin z+Y_{2}
\end{aligned}
$$

where $Y_{1}$ and $Y_{2}$ are empirical terms.

If $(\mathrm{R}-\mathrm{D})$ is the-difference between declinations observed reflected and direct, we have

$$
\begin{array}{rlrl}
1 / 2(\mathrm{R}-\mathrm{D}) & =+\Delta N_{1}-f \sin \left(o_{1}-k\right)+\left[e_{1}+f \cos \left(o_{1}-k\right)\right] \sin z+Z_{1} & & \text { Clamp East, Position } \mathrm{II}_{1} \\
& =-\Delta N_{1}+f \sin \left(o_{1}-k\right)+\left[e_{1}+f \cos \left(o_{1}-k\right)\right] \sin z+Z_{2} & \text { Clamp West, Position } \mathrm{II}_{1} \\
& =+\Delta N_{2}-f \sin \left(o_{2}-k\right)+\left[d_{1}+f \cos \left(o_{2}-k\right)\right] \sin z+Z_{3} & & \text { Clamp East, Position I } \\
& =-\Delta N_{2}+f \sin \left(o_{2}-k\right)+\left[d_{1}+f \cos \left(o_{2}-k\right)\right] \sin z+Z_{4} & & \text { Clamp West, Position I }
\end{array}
$$

where $Z_{1}, Z_{2}, Z_{3}$, and $Z_{4}$ are other empirical terms. No reflected observations were made in Position $\mathrm{II}_{2}$.

The differences, $(\mathrm{E}-\mathrm{W})$, were formed from the observed declinations of all the standard stars, except that the clock stars were omitted in the period 1911 to 1916, since there was sufficient material available without using them. The differences were always made between observations by the same observer and were afterwards combined in zones of declination. The results are given in the following table:

Differences $1 / 2(E-W)$ in Declination

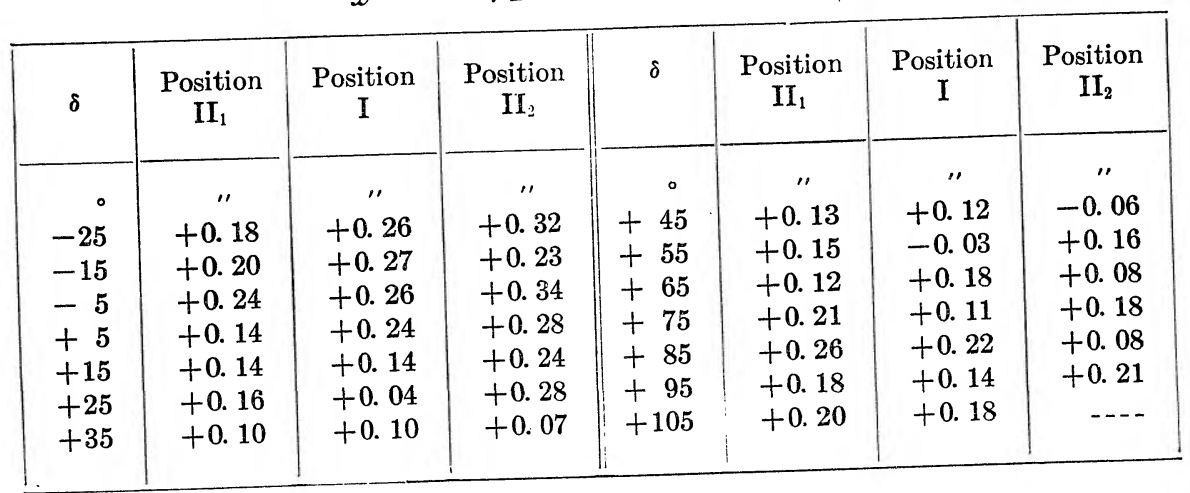

If we compute the values of $f(1+\cos z) \sin (o-k)$. for the various values of $z$ in each position and subtract them from the corresponding values of $1 / 2(E-W)$, we obtain the following values of $(-\Delta N+X)$. 
SIX-INCH TRANSIT CIRCLE

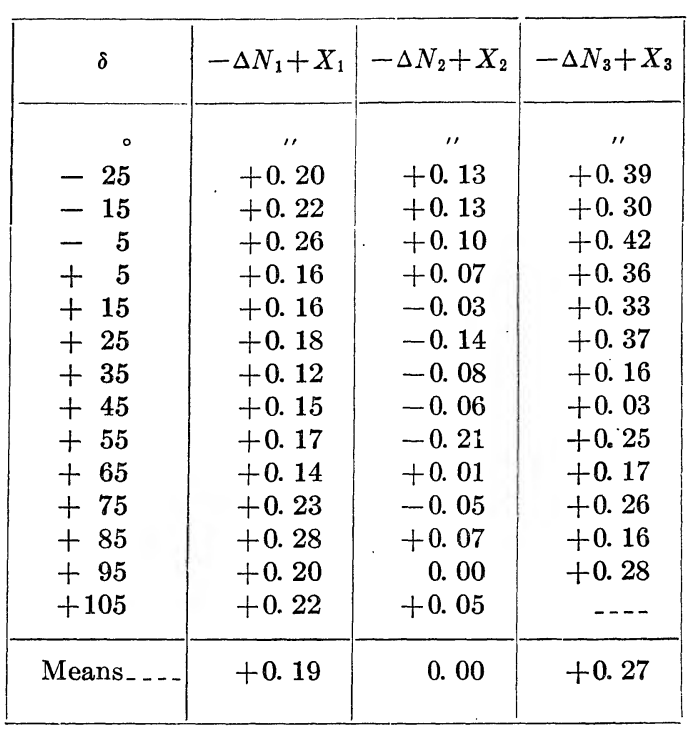

It was decided not to include the arbitrary term $X$ in the expression for $1 / 2(\mathrm{E}-\mathrm{W})$, since the quantities in the preceding table, with the possible exception of those pertaining to Position I, do not show any variation that can not be ascribed to accidental errors. The mean values for each position; with the signs changed, were adopted as the values of $\Delta N$, the additional correction for error in the division correction for the nadir:

$$
\begin{array}{lr}
\Delta N_{1}=-0.19 \\
\Delta N_{2}=0.00 \\
\Delta N_{3}=-0.27
\end{array}
$$

After applying corrections for variation of latitude and for relative personal equation, preliminary means were taken of the observed declinations in each of the three positions, giving equal weight to Clamp East and Clamp West. The clock and azimuth stars were excluded in the period 1911-1916. The differences $\left(\mathrm{II}_{1}-\mathrm{I}\right)$ and $\left(\mathrm{II}_{2}-\mathrm{I}\right)$ were formed for each star, applying corrections for proper motion whenever necessary and obtainable. The differences were then combined in zones of declination and the results, using only those stars for which allowance has been made for proper motion, are given in the following table:

Differences $\left(I I_{1}-I\right)$ and $\left(I I_{2}-I\right)$ in Declination

\begin{tabular}{|c|c|c||c|c|c|}
\hline$\delta$ & $\mathrm{II}_{1}-\mathrm{I}$ & $\mathrm{II}_{2}-\mathrm{I}$ & $\delta$ & $\mathrm{II}_{1}-\mathrm{I}$ & $\mathrm{II}_{2}-\mathrm{I}$ \\
\hline$\circ$ & $\prime \prime$ & $\prime \prime$ &. & $\prime \prime$ & $\prime \prime$ \\
-25 & -0.13 & -0.34 & +45 & -0.12 & +0.14 \\
-15 & -0.08 & -0.35 & +55 & -0.07 & +0.02 \\
-5 & -0.03 & -0.26 & +65 & -0.05 & +0.12 \\
+5 & +0.03 & -0.26 & +75 & -0.18 & +0.04 \\
+15 & -0.01 & -0.22 & +85 & -0.01 & +0.22 \\
+25 & -0.04 & -0.21 & +95 & -0.04 & +0.59 \\
+35 & -0.15 & -0.14 & +105 & -0.07 &..- \\
\hline
\end{tabular}


If we compute values of $\left\{d_{1}-e_{1}+f\left[\cos \left(o_{2}-k\right)-\cos \left(o_{1}-k\right)\right]\right\}$ sin $z$ and $\left\{d_{1}-e_{1}+f\left[\cos \left(o_{2}-k\right)-\cos \left(o_{3}-k\right)\right]\right\}$ sin $z$ and subtract them from the corresponding values of $\left(\mathrm{II}_{1}-\mathrm{I}\right)$ and $\left(\mathrm{II}_{2}-\mathrm{I}\right)$, respectively, we obtain the values of $Y_{1}$ and $Y_{2}$ given under the heading Observed in the following table.

\begin{tabular}{|c|c|c|c|c|c|c|}
\hline \multirow{2}{*}{$\delta$} & \multicolumn{3}{|c|}{$Y_{1}$} & \multicolumn{3}{|c|}{$Y_{2}$} \\
\hline & Observed & Computed & $\mathrm{O}-\mathrm{C}$ & Observed & Computed & $\mathrm{O}-\mathrm{C}$ \\
\hline & " & " & " & " & " & " \\
\hline-25 & +0.09 & +0.09 & 0.00 & -0.32 & -0.27 & -0.05 \\
\hline-15 & +0.12 & +0.12 & 0.00 & -0.33 & -0.32 & -0.01 \\
\hline-5 & +0.14 & +0.13 & +0.01 & -0.25 & -0.33 & +0.08 \\
\hline+5 & +0.17 & +0.12 & +0.05 & -0.25 & -0.31 & +0.06 \\
\hline+15 & +0.09 & +0.08 & +0.01 & -0.21 & -0.26 & +0.05 \\
\hline+25 & +0.02 & +0.03 & -0.01 & -0.21 & -0.18 & -0.03 \\
\hline+35 & -0.13 & -0.03 & -0.10 & -0.14 & -0.08 & -0.06 \\
\hline+45 & -0.14 & -0.10 & -0.04 & +0.14 & +0.02 & +0.12 \\
\hline+55 & -0.14 & -0.16 & +0.02 & +0.01 & +0.11 & -0.10 \\
\hline+65 & -0.16 & -0.21 & +0.05 & +0.11 & +0.19 & -0.08 \\
\hline+75 & -0.32 & -0.24 & -0.08 & +0.03 & +0.24 & -0.21 \\
\hline+85 & -0.18 & -0.25 & +0.07 & +0.21 & +0.25 & -0.04 \\
\hline+95 & -0.24 & -0.24 & 0.00 & +0.57 & +0.23 & +0.34 \\
\hline+105 & -0.29 & -0.21 & -0.08 & $\ldots$ & $-\cdots$ & $\ldots$ \\
\hline
\end{tabular}

If we put

$$
\begin{aligned}
& Y_{1}=c_{1}+y_{1} \sin 2 z \\
& Y_{2}=c_{2}+y_{2} \sin 2 z
\end{aligned}
$$

and solve by least squares, we obtain the following results:

$$
\begin{array}{ll}
c_{1}=-0.062 & y_{1}=-0.193 \\
c_{2}=-0.035 & y_{2}=+0.292
\end{array}
$$

The computed values of $Y_{1}$ and $Y_{2}$ and the residuals are given in the preceding table. It will be noted that the values of $Y_{2}$ are quite different from those of $Y_{1}$ although Position $\mathrm{II}_{2}$ is the same as Position $\mathrm{II}_{1}$.

Reflected observations of selected lists of stars were made during the following periods:

1912, June 10 to July 8; Instrument in Position $\mathrm{II}_{1}$, 1913, August 7 to September 4; Instrument in Position $\mathrm{II}_{1}$, 1915, February 10 to March 9; Instrument in Position I, 1916, March 23 to April 20; Instrument in Position I.

In addition to the above lists, about one hundred reflected observations of circumpolar stars were made each year from 1911 to 1916, inclusive.

The following tables contain the differences $1 / 2(R-D)$ for the stars included in the four selected lists of stars arranged in order of zenith distance. The signs of the differences have been changed for stars observed at lower culmination. The subscripts indicate the number of reflected observations.

$93432^{\circ}-27-6$ 


\begin{tabular}{|c|c|c|c|c|c|c|}
\hline \multirow[b]{2}{*}{ Star } & \multirow[b]{2}{*}{ Year } & \multirow[b]{2}{*}{$\alpha$} & \multirow[b]{2}{*}{$z$} & \multicolumn{2}{|c|}{$1 / 2(\mathrm{R}-\mathrm{D})$} & \multirow{2}{*}{ Zone } \\
\hline & & & & $\begin{array}{c}\text { Clamp } \\
\text { East }\end{array}$ & $\begin{array}{c}\text { Clamp } \\
\text { West }\end{array}$ & \\
\hline 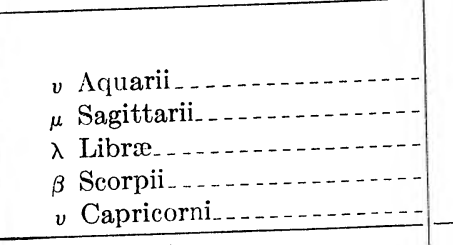 & $\begin{array}{l}1913 \\
1912 \\
1912 \\
1912 \\
1913 \\
\end{array}$ & $\begin{array}{cr}\mathrm{h} & \mathrm{m} \\
22 & 30 \\
18 & 8 \\
15 & 48 \\
16 & 0 \\
20 & 35 \\
\end{array}$ & $\begin{array}{r}\circ \\
-60.1 \\
60.0 \\
58.8 \\
58.5 \\
57.4 \\
\end{array}$ & $\begin{array}{l}\text {-0. } 59_{4} \\
-0.01_{4} \\
-0.58_{2} \\
-0.66_{5} \\
-0.62_{6} \\
\end{array}$ & $\begin{array}{l}\text {-0. } 01_{4} \\
-0.07_{4} \\
-0.26_{4} \\
+0.19_{4} \\
-0.24_{4} \\
\end{array}$ & (1) \\
\hline 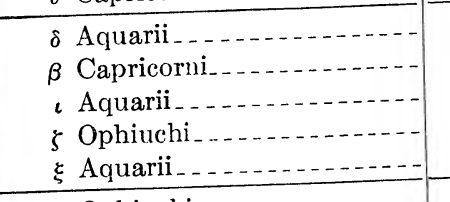 & $\begin{array}{l}1913 \\
1913 \\
1913 \\
1912 \\
1913 \\
\end{array}$ & $\begin{array}{rr}22 & 50 \\
20 & 16 \\
22 & 2 \\
16 & 32 \\
21 & 33 \\
\end{array}$ & $\begin{array}{r}-55.2 \\
54.0 \\
53.2 \\
49.3 \\
47.2 \\
\end{array}$ & $\begin{array}{l}-0.84_{4} \\
-0.26_{5} \\
-0.64_{4} \\
-0.45_{4} \\
-0.43_{3} \\
\end{array}$ & $\begin{array}{r}-0.17_{4} \\
-0.27_{5} \\
+0.08_{4} \\
-0.08_{4} \\
+0.19_{5} \\
\end{array}$ & $(2)$ \\
\hline $\begin{aligned} \delta & \text { Ophiuchi } \\
\theta & \text { Aquilæ. } \\
\alpha & \text { Serpentis } \\
\alpha & \text { Aquilæ. }\end{aligned}$ & $\begin{array}{l}1912 \\
1913 \\
1912 \\
1913 \\
\end{array}$ & $\begin{array}{rr}16 & 10 \\
20 & 7 \\
15 & 40 \\
19 & 46 \\
\end{array}$ & $\begin{array}{r}-42.4 \\
40.0 \\
32.2 \\
30.3 \\
\end{array}$ & $\begin{array}{l}-0.64_{5} \\
-0.44_{5} \\
-0.65_{5} \\
-0.48_{7} \\
\end{array}$ & $\begin{array}{r}-0.04_{4} \\
-0.23_{5} \\
+0.02_{4} \\
-0.08_{4} \\
\end{array}$ & (3) \\
\hline $\begin{array}{r}\beta \text { Sagittæ } \ldots \text { Sagittæ } \ldots \\
\gamma \text { Sagittæ } \\
110 \text { Herculis } \\
110 \text { Herculis } \\
\lambda \text { Pegasi }\end{array}$ & $\begin{array}{l}1912 \\
1913 \\
1913 \\
1912 \\
1913 \\
1913 \\
\end{array}$ & $\begin{array}{ll}19 & 37 \\
19 & 37 \\
19 & 55 \\
18 & 42 \\
18 & 42 \\
22 & 42 \\
\end{array}$ & $\begin{array}{r}-21.6 \\
21.6 \\
19.7 \\
18.5 \\
18.5 \\
15.8 \\
\end{array}$ & $\begin{array}{r}-0.40_{4} \\
-0.56_{5} \\
-0.26_{5} \\
-0.65_{4} \\
-0.27_{5} \\
-0.44_{4} \\
\end{array}$ & $\begin{array}{c}+0.01_{3} \\
+0.16_{4} \\
-0.32_{5} \\
+0.08_{4} \\
-0.20_{3} \\
\end{array}$ & $(4)$ \\
\hline 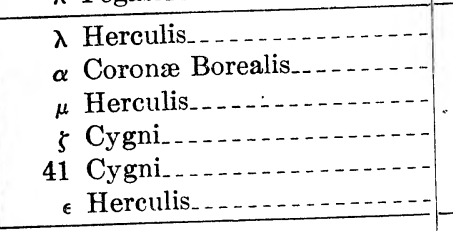 & \begin{tabular}{|l|}
1912 \\
1912 \\
1912 \\
1913 \\
1913 \\
1912 \\
\end{tabular} & $\begin{array}{rr}17 & 27 \\
15 & 31 \\
17 & 43 \\
21 & 9 \\
20 & 26 \\
16 & 57 \\
\end{array}$ & $\begin{array}{r}-12.7 \\
11.9 \\
11.1 \\
9.0 \\
8.8 \\
-7.9 \\
\end{array}$ & $\begin{array}{l}-0.34_{4} \\
-0.40_{4} \\
-0.28_{4} \\
+0.02_{4} \\
-0.23_{8} \\
-0.34_{5} \\
\end{array}$ & $\begin{array}{l}+0.33_{4} \\
+0.11_{3} \\
+0.27_{4} \\
+0.04_{5} \\
-0.34_{4} \\
-0.04_{4} \\
\end{array}$ & (5) \\
\hline $\begin{array}{r}\pi^{2} \text { Cygni } \\
\gamma \text { Draconis } \\
\text { ¿ Cygni }\end{array}$ & $\begin{array}{l}1913 \\
1912 \\
1912 \\
1913 \\
\end{array}$ & $\begin{array}{ll}21 & 44 \\
17 & 55 \\
19 & 28 \\
19 & 28 \\
\end{array}$ & $\begin{array}{r}+10.0 \\
12.6 \\
12.6 \\
12.6 \\
\end{array}$ & $\begin{array}{l}+0.10_{4} \\
-0.41_{4} \\
-0.45_{4} \\
-0.08_{6} \\
\end{array}$ & $\begin{array}{r}-0.21_{5} \\
+0.01_{4} \\
-0.02_{4} \\
+0.55_{5} \\
\end{array}$ & $(6)$ \\
\hline $\begin{array}{l}\text { Gr. 2377 } \\
\eta_{0} \text { Draconis } \\
\alpha \text { Cephei }\end{array}$ & $\begin{array}{l}1912 \\
1912 \\
1913 \\
1913 \\
1913 \\
\end{array}$ & $\begin{array}{ll}16 & 44 \\
18 & 50 \\
18 & 50 \\
20 & 44 \\
21 & 16 \\
\end{array}$ & $\begin{array}{r}+18.0 \\
20.4 \\
20.4 \\
22.6 \\
23.3 \\
\end{array}$ & $\begin{array}{l}-0.41_{5} \\
-0.42_{4} \\
-0.14_{5} \\
-0.24_{6} \\
-0.19_{3} \\
\end{array}$ & $\begin{array}{l}+0.08_{4} \\
-0.16_{4} \\
+0.14_{4} \\
+0.08_{5} \\
-0.08_{5} \\
\end{array}$ & (7) \\
\hline $\begin{aligned} & \text { Cephei } \\
\chi & \text { Draconis } \\
\tau & \text { Draconis } \\
\tau & \text { Draconis } \\
79 & \text { Draconis } \\
\eta & \text { Ursæ Minoris }\end{aligned}$ & $\begin{array}{l}1913 \\
1912 \\
1912 \\
1913 \\
1913 \\
1912 \\
\end{array}$ & $\begin{array}{rr}22 & 8 \\
18 & 23 \\
19 & 17 \\
19 & 17 \\
21 & 52 \\
16 & 20 \\
\end{array}$ & $\begin{array}{r}+33.0 \\
33.8 \\
34.3 \\
34.3 \\
34.4 \\
37.0 \\
\end{array}$ & $\begin{array}{l}+0.01_{3} \\
-0.43_{4} \\
-0.64_{4} \\
-0.41_{4} \\
-0.28_{3} \\
-0.35_{5} \\
\end{array}$ & $\begin{array}{r}+0.14_{4} \\
+0.01_{4} \\
-0.03_{4} \\
+0.45_{5} \\
+0.21_{3} \\
+0.14_{4} \\
\end{array}$ & (8) \\
\hline 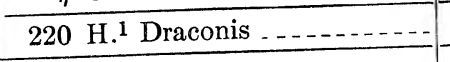 & 1913 & 2052 & +41.3 & $-0.05_{5}$ & $+0.14_{5}$ & $(9)$ \\
\hline $\begin{array}{l}\lambda \text { Ursæ Minoris } \ldots \ldots \\
\lambda \text { Ursæ Minoris } \ldots \ldots\end{array}$ & $\begin{array}{l}1912 \\
1913 \\
\end{array}$ & $\begin{array}{ll}19 & 9 \\
19 & 9 \\
\end{array}$ & $\begin{array}{r}+50.1 \\
50.1 \\
\end{array}$ & $\begin{array}{l}-0.44_{4} \\
-0.26_{6} \\
\end{array}$ & $\begin{array}{r}+0.11_{4} \\
+0.44_{5} \\
\end{array}$ & (11) \\
\hline $\begin{array}{l}51 \text { H. Cephei s. } P \\
51 \text { H. Cephei s. } P_{\ldots}\end{array}$ & $\begin{array}{l}1912 \\
1913 \\
\end{array}$ & $\begin{array}{ll}7 & 0 \\
7 & 0 \\
\end{array}$ & $\begin{array}{r}+53.9 \\
53.9 \\
\end{array}$ & $\begin{array}{l}-0.44_{4} \\
-0.01_{8} \\
\end{array}$ & $\begin{array}{r}-0.14_{4} \\
+0.18_{5} \\
\end{array}$ & (12) \\
\hline Gr. 944 s. P. & 1912 & $\begin{array}{ll}5 & 34 \\
\end{array}$ & +55.9 & $-0.40_{4}$ & $+0.37_{4}$ & (13) \\
\hline $\begin{aligned} 30 & \text { H. Camelopardalis s. P. } \\
1 & \text { H. Draconis s. P. } \\
23 & \text { H. Camelopardalis s. P. } \\
19 & \text { H. Camelopardalis s. P. }\end{aligned}$ & $\begin{array}{l}1913 \\
1913 \\
1912 \\
1912\end{array}$ & $\begin{array}{rr}10 & 21 \\
9 & 25 \\
6 & 31 \\
5 & 8\end{array}$ & $\begin{array}{r}+58.1 \\
59.4 \\
61.4 \\
+62.0\end{array}$ & $\begin{array}{l}-0.14_{2} \\
+0.04_{3} \\
-0.38_{4} \\
+0.02_{4}\end{array}$ & $\begin{array}{l}-0.17_{3} \\
+0.14_{4} \\
+0.10_{3} \\
-0.04_{4}\end{array}$ & (14) \\
\hline
\end{tabular}


Differences $1 / 2(R-D)$ for Position I

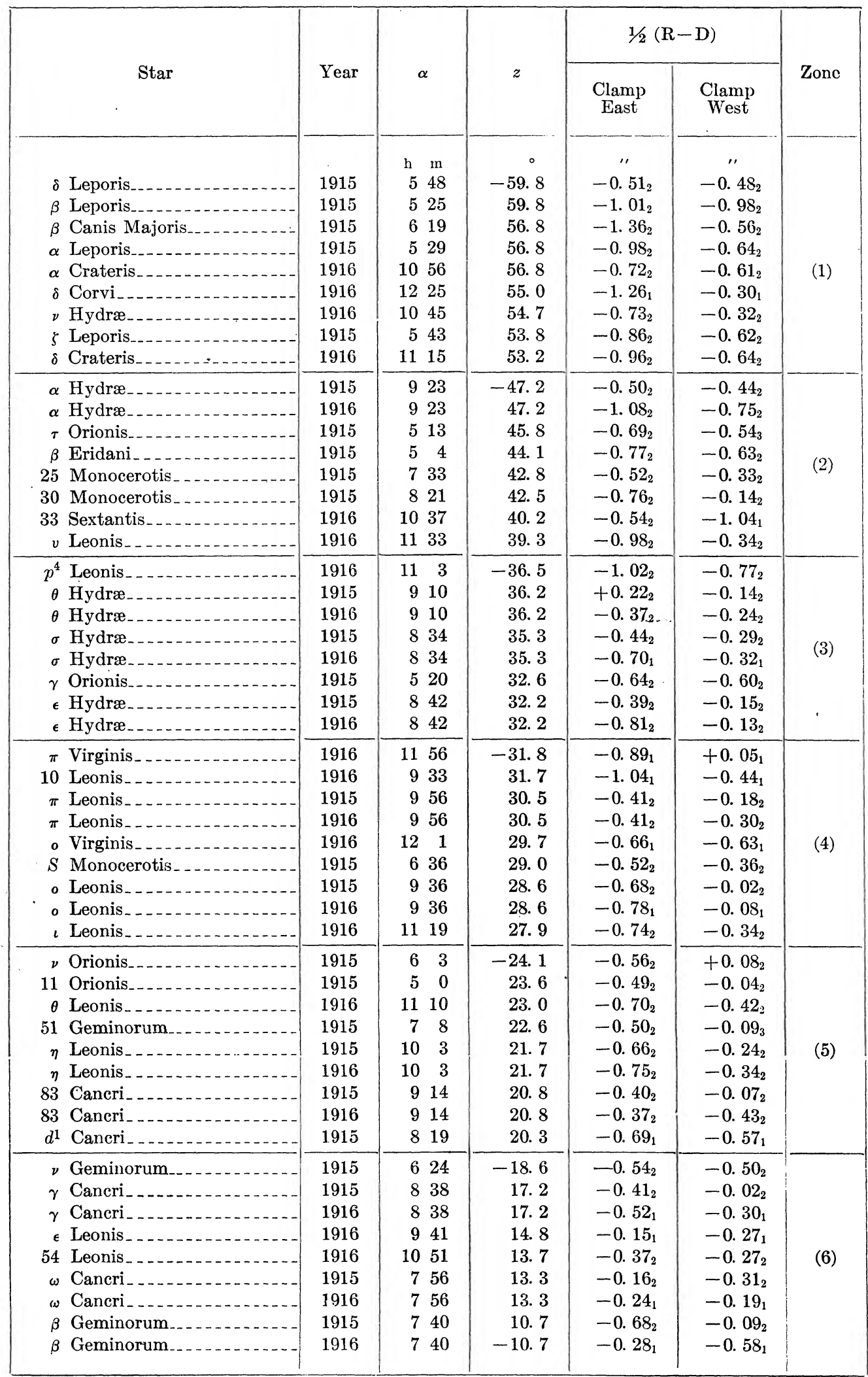


Differences $1 / 2(R-D)$ for Position I

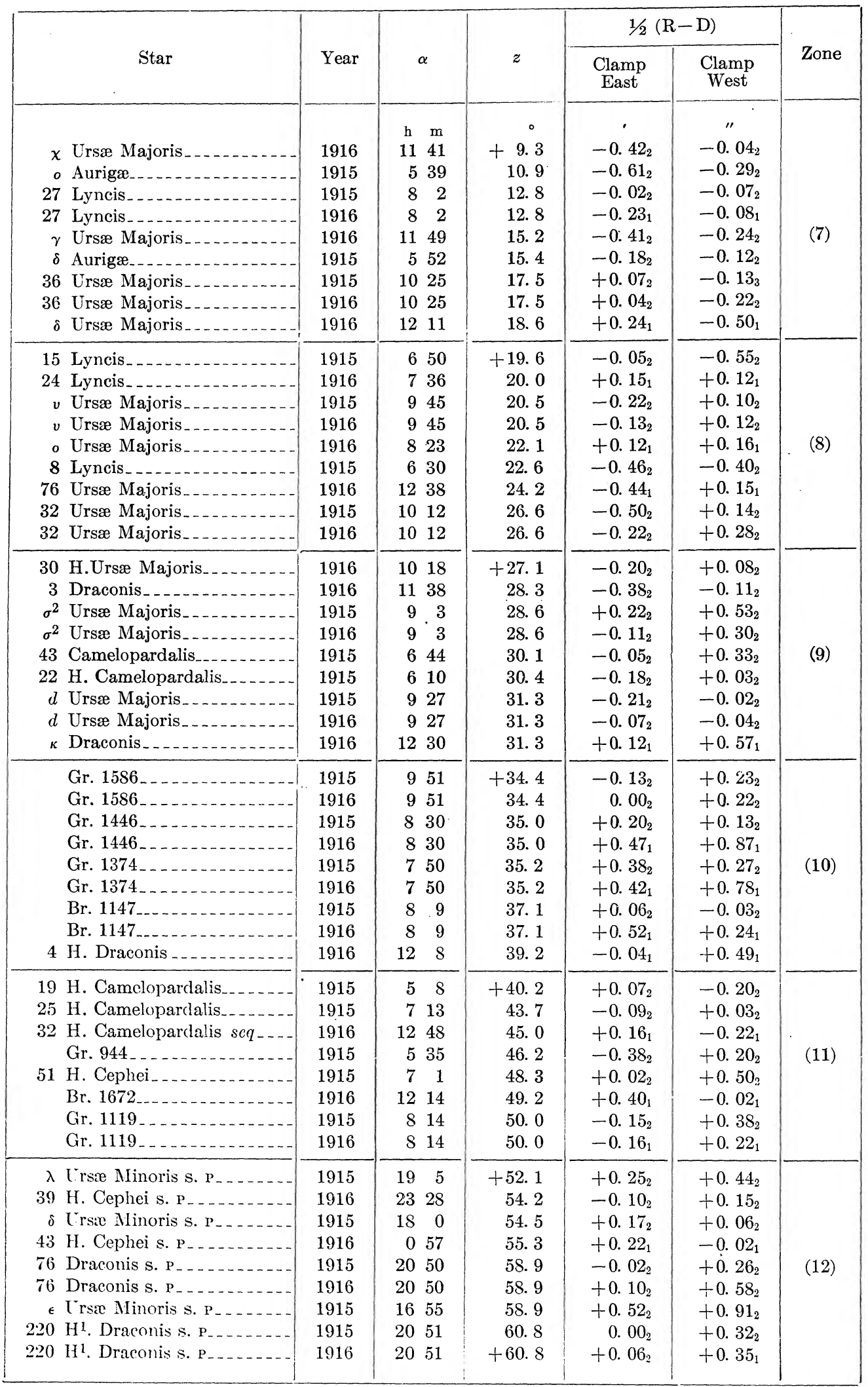


The following table contains the differences $1 / 2(R-D)$ for the circumpolar stars observed during the period 1911-1916 but not included in the selected lists. The zones are numbered to correspond with those in the preceding tables, with which they have been combined to form final means.

Differences 1/2 $(R-D)$ for Circumpolar Stars not Included in the Preceding Lists

\begin{tabular}{|c|c|c|c|c|c|c|c|c|}
\hline \multirow{3}{*}{ Star } & \multirow{3}{*}{$\alpha$} & \multirow{3}{*}{$z$} & \multicolumn{6}{|c|}{$1 / 2(R-D)$} \\
\hline & & & \multicolumn{3}{|c|}{ Position $\mathrm{Il}_{1}$} & \multicolumn{3}{|c|}{ Position I } \\
\hline & & & Clamp & $\begin{array}{l}\text { Clamp } \\
\text { West }\end{array}$ & Zone & $\underset{\text { East }}{\text { Clamp }}$ & $\underset{\text { West }}{\text { Clamp }}$ & Zone \\
\hline . & $\mathrm{h} \mathrm{m}$ & $\circ$ & " & " & & " & " & \\
\hline $1 \mathrm{H}$. Draconis & 924 & +42.8 & $-0.51_{6}$ & $+0.20_{7}$ & & $-0.04_{10}$ & $+0.34_{13}$ & \\
\hline$\epsilon$ Ursæ Minoris & 1655 & 43.3 & $-0.51_{2}$ & $+0.78_{4}$ & & $\ldots$ & - - - & \\
\hline 76 Draconis. & 2049 & 43. 3 & $-0.40_{9}$ & $+0.80_{2}$ & (9) & $0.00_{7}$ & $+0.28_{9}$ & \\
\hline $30 \mathrm{H}$. Camelopardalis.... & 1020 & 44. 1 . & $-0.52_{8}$ & $+0.40_{3}$ & & $+0.02_{8}$ & $+0.42_{11}$ & \\
\hline Gr. 944 & 533 & 46. 2 & $-0.80_{3}$ & $+0.04_{2}$ & & $-\cdots$ & $+0.44_{2}$ & \\
\hline Gr. 750 & 48 & 46. 4 & $-0.22_{4}$ & $+0.20_{7}$ & & $-\cdots$ & - - - & \\
\hline 43 H. Cephei & 056 & 46. 9 & $-0.28_{3}$ & $+0.70_{5}$ & (10) & $+0.15_{8}$ & $+0.36_{4}$ & \\
\hline$\delta$ Ursæ Minoris & 180 & 47. 7 & $-0.48_{6}$ & $+0.15_{4}$ & (10) & $-0.23_{3}$ & $+0.52_{5}$ & $(11)$ \\
\hline 39 H. Cephei & 2328 & 47.9 & $-0.04_{5}$ & $-0.04_{3}$ & & $-0.07_{6}$ & $+0.54_{9}$ & \\
\hline 51 H. Cephei. & 659 & 48. 3 & $-0.19_{5}$ & $+0.07_{7}$ & & $-0.01_{2}$ & $+0.61_{2}$ & \\
\hline Gr. 2283. & 155 & 48. 6 & $-0.28_{3}$ & $+0.16_{3}$ & & $\ldots$ & $\ldots$ & \\
\hline Br. 1672 $\ldots$ & 1214 & 49. 3 & $-0.15_{7}$ & $+0.34_{4}$ & & $-0.17_{6}$ & $+0.23_{5}$ & \\
\hline$\alpha$ Ursæ Minoris $\ldots . . .$. & 127 & 49. 9 & $-0.37_{5}$ & $+0.19_{16}$ & (11) & $-0.08_{11}$ & $+0.17_{5}$ & \\
\hline Gr. 1119 & 810 & 50.0 & $-0.23_{6}$ & $+0.51_{3}$ & & $-0.30_{2}$ & $+0.26_{3}$ & \\
\hline$\lambda$ Ursæ Minoris $\ldots . . . .$. & 198 & 50.1 & $-0.15_{3}$ & $+0.17_{5}$ & & $-\cdots$ & $+0.66_{5}$ & \\
\hline$\lambda$ Ursæ Minoris s. P & 198 & 52.1 & $-0.21_{5}$ & $0.00_{7}$ & & $\ldots$ & $+0.75_{4}$ & \\
\hline Gr. 1119 s. P. & 810 & 52.2 & $-0.06_{6}$ & $+0.86_{3}$ & & $+0.42_{3}$ & $+0.13_{4}$ & \\
\hline$\alpha$ Ursæ Minoris s. P... & 127 & 52.3 & $-0.44_{10}$ & $+0.02_{13}$ & (12) & $+0.16_{5}$ & $+0.44_{11}$ & \\
\hline Br. 1672 s. $P_{\ldots}$ & 1214 & 52.9 & $-0.22_{3}$ & $+0.58_{3}$ & (12) & $+0.34_{4}$ & $+0.30_{5}$ & \\
\hline Gr. 2283 s. P & 155 & 53.5 & $-0.06_{4}$ & $+0.32_{5}$ & & $+0.65_{2}$ & --- & \\
\hline 51 H. Cephei s. P............... & 659 & 53.9 & $-0.18_{5}$ & $+0.39_{7}$ & & $+0.23_{4}$ & $+0.46_{5}$ & \\
\hline 39 H. Cephei s. P...... & 2328 & 54.3 & -0.189 & $+0.38_{3}$ & & $+0.10_{6}$ & $+0.35_{11}$ & \\
\hline$\delta$ Ursæ Minoris s. P & 180 & 54.5 & $-0.26_{7}$ & $+0.06_{4}$ & (13) & $-0.27_{4}$ & $+0.38_{5}$ & $(12)$ \\
\hline 43 H. Cephei s. P....... & 056 & 55.3 & $-0.18_{6}$ & $+0.09_{6}$ & (10) & $-0.09_{5}$ & $+0.33_{5}$ & \\
\hline Gr. 750 s. P. & 48 & 55.8 & $-1.12_{3}$ & $+030_{4}$ & & $\ldots$ & $-\cdots$ & \\
\hline Gr. 944 s. P. & 533 & 55.9 & $-0.74_{3}$ & $\cdots$ & & --- & $\cdots$ & \\
\hline 30 H. Camelopardalis s. $P_{-}$ & 1020 & 58.1 & $-0.02_{5}$ & $+0.13_{6}$ & & $+0.08_{10}$ & $+0.68_{8}$ & \\
\hline 76 Draconis s. P & 2049 & 58.9 & $-0.27_{5}$ & $+0.52_{3}$ & (14) & $-0.08_{7}$ & $+0.35_{6}$ & \\
\hline$\epsilon$ Ursæ Minoris S. P & 1655 & 58.9 & $-0.23_{5}$ & $+0.43_{2}$ & (14) & --- & --- & \\
\hline $1 \mathrm{H}$. Draconis s. P. & 924 & +59.4 & $-0.15_{8}$ & $+0.26_{2}$ & & $+0.22_{16}$ & $+0.36_{11}$ & \\
\hline
\end{tabular}


The weighted means of the differences $1 / 2(\mathrm{R}-\mathrm{D})$ given in the preceding tables were taken in zones. The results are given in the following table:

Summary of Differences $1 / 2(R-D)$

\begin{tabular}{|c|c|c|c|c|c|c|c|}
\hline \multicolumn{4}{|c|}{ Position $\mathrm{II}_{1}$} & \multicolumn{4}{|c|}{ Position I } \\
\hline \multirow[b]{2}{*}{ Zone } & \multirow[b]{2}{*}{$z$} & \multicolumn{2}{|c|}{$1 / 2(R-D)$} & \multirow[b]{2}{*}{ Zone } & \multirow[b]{2}{*}{$z$} & \multicolumn{2}{|c|}{$1 / 2(R-D)$} \\
\hline & & $\begin{array}{c}\text { Clamp } \\
\text { East }\end{array}$ & $\underset{\text { West }}{\text { Clamp }}$ & & & $\begin{array}{l}\text { Clamp } \\
\text { East }\end{array}$ & $\begin{array}{c}\text { Clamp } \\
\text { West }\end{array}$ \\
\hline & 。 & " & $"$ & & 。 & " & " \\
\hline 1 & -59.0 & -0.49 & -0.08 & 1 & -56.3 & -0.91 & -0.59 \\
\hline 2 & 51. 8 & -0.52 & -0.05 & 2 & 43. 6 & -0.73 & -0.50 \\
\hline 3 & 36.2 & -0.55 & -0.08 & 3 & 34.6 & -0.52 & -0.33 \\
\hline 4 & 19. 3 & -0.43 & -0.05 & 4 & 29. 8 & -0.63 & -0.25 \\
\hline 5 & -10.2 & -0.26 & +0.06 & 5 & 22.1 & -0.56 & -0.21 \\
\hline 6 & +12.0 & -0.21 & +0.08 & 6 & -14.4 & -0.39 & -0.27 \\
\hline 7 & 20.9 & -0.28 & +0.01 & 7 & +14.4 & -0.19 & -0.17 \\
\hline 8 & 34.5 & -0.35 & +0.15 & 8 & 22.5 & -0.22 & -0.01 \\
\hline 9 & 43. 0 & -0.39 & +0.38 & 9 & 29. 7 & -0.11 & +0.16 \\
\hline 10 & 47. 2 & -0.31 & +0.21 & 10 & 35.8 & +0.17 & +0.29 \\
\hline 11 & 49. 7 & -0.27 & +0.23 & 11 & 46. 4 & -0.04 & +0.35 \\
\hline 12 & 53.1 & -0.23 & +0.19 & 12 & 56. 0 & +0.13 & +0.40 \\
\hline 13 & 55.3 & -0.37 & +0.23 & & & & \\
\hline 14 & +59.5 & -0.14 & +0.14 & & & & \\
\hline
\end{tabular}

If we compute values of $\Delta N_{1}-f \sin \left(o_{1}-k\right)+\left[e_{1}+f \cos \left(o_{1}-k\right)\right] \sin z$, etc., assuming $\Delta N_{1}=-0^{\prime \prime} .19$ and $\Delta N_{2}=0^{\prime \prime} .00$, which are the values derived from the discussion of the differences $1 / 2(\mathrm{E}-\mathrm{W})$, and subtract them from the corresponding values of $1 / 2(\mathrm{R}-\mathrm{D})$, we obtain the values of $Z_{1}, Z_{2}, Z_{3}$, and $Z_{4}$ given under the heading Observed in the following table:

\begin{tabular}{|c|c|c|c|c|c|c|c|c|c|}
\hline \multicolumn{5}{|c|}{ Position $\mathrm{II}_{1}$} & \multicolumn{5}{|c|}{ Position I } \\
\hline \multirow{2}{*}{$z$} & \multicolumn{2}{|c|}{$Z_{1}$} & \multicolumn{2}{|c|}{$Z_{2}$} & \multirow{2}{*}{$z$} & \multicolumn{2}{|c|}{$Z_{3}$} & \multicolumn{2}{|c|}{$Z_{4}$} \\
\hline & $\begin{array}{c}\text { Ob- } \\
\text { served }\end{array}$ & $\begin{array}{l}\text { Com- } \\
\text { puted }\end{array}$ & $\begin{array}{c}\text { Ob- } \\
\text { served }\end{array}$ & $\begin{array}{l}\text { Com- } \\
\text { puted }\end{array}$ & & $\begin{array}{l}\text { Ob- } \\
\text { served }\end{array}$ & $\begin{array}{l}\text { Com- } \\
\text { puted }\end{array}$ & $\begin{array}{c}\text { Ob- } \\
\text { served }\end{array}$ & $\begin{array}{l}\text { Com- } \\
\text { puted }\end{array}$ \\
\hline$\circ$ & " & " & ", & $"$ & $\circ$ & " & " & " & " \\
\hline-59.0 & -0.35 & -0.35 & -0.30 & -0.32 & -56.3 & -0.65 & -0.54 & -0.51 & -0.46 \\
\hline 51.8 & -0.37 & -0.34 & -0.26 & -0.30 & 43.6 & -0.50 & -0.49 & -0.45 & -0.41 \\
\hline 36.2 & -0.39 & -0.30 & -0.28 & -0.25 & 34.6 & -0.32 & -0.44 & -0.31 & -0.37 \\
\hline 19. 3 & -0.26 & -0.25 & -0.24 & -0.20 & 29. 8 & -0.44 & -0.42 & -0.24 & -0.35 \\
\hline-10.2 & -0.09 & -0.22 & -0.13 & -0.16 & 22.1 & -0.39 & -0.38 & -0.22 & -0.31 \\
\hline+12.0 & -0.02 & -0.16 & -0.09 & -0.07 & -14.4 & -0.25 & -0.33 & -0.31 & -0.27 \\
\hline 20. 9 & -0.08 & -0.13 & -0.15 & -0.04 & +14.4 & -0.15 & -0.16 & -0.31 & -0.11 \\
\hline 34.5 & -0.15 & -0.09 & -0.01 & +0.01 & 22.5 & -0.21 & -0.12 & -0.18 & -0.06 \\
\hline 43.0 & -0.18 & -0.07 & +0.23 & +0.04 & 29.7 & -0.12 & -0.07 & -0.03 & -0.03 \\
\hline 47. 2 & -0.10 & -0.06 & +0.06 & +0.05 & 35.8 & +0.14 & -0.04 & +0.08 & 0.00 \\
\hline 49.7 & -0.06 & -0.06 & +0.08 & +0.06 & 46. 4 & -0.10 & +0.01 & +0.11 & +0.05 \\
\hline 53.1 & -0.02 & -0.05 & +0.04 & +0.06 & +56.0 & +0.05 & +0.04 & +0.14 & +0.08 \\
\hline 55.3 & -0.16 & -0.04 & +0.08 & +0.07 & & & & & \\
\hline+59.5 & +0.08 & -0.04 & 0.00 & +0.08 & & & & & \\
\hline
\end{tabular}


If we put $Z=m+n \sin z$ and solve by least squares, we obtain as values of $m$ and $n$,

\begin{tabular}{|c|c|c|c|c|}
\hline \multirow{2}{*}{} & \multicolumn{2}{|c|}{ Position $\mathrm{II}_{1}$} & \multicolumn{2}{c|}{ Position I } \\
\cline { 2 - 5 } & $\begin{array}{c}\text { Clamp } \\
\text { East }\end{array}$ & $\begin{array}{c}\text { Clamp } \\
\text { West }\end{array}$ & $\begin{array}{c}\text { Clamp } \\
\text { East }\end{array}$ & $\begin{array}{c}\text { Clamp } \\
\text { West }\end{array}$ \\
\hline$m$ & $\begin{array}{c}\prime \prime \\
-0.19 \\
+0.18\end{array}$ & $\begin{array}{c}-0.12 \\
+0.23\end{array}$ & $\begin{array}{c}\text {-0.25 } \\
+0.35\end{array}$ & $\begin{array}{c}\text {-0.19 } \\
+0.32\end{array}$ \\
\hline
\end{tabular}

The quantities $Z$ are fairly well represented by the expression $m+n \sin z$, as shown by the computed values. The quantity $m$ represents a constant difference between direct and reflected observations, while $n$ represents an excess of horizontal flexure over that determined with the collimators. The adopted values of the horizontal flexure were $+0^{\prime \prime} .074$ for Position $\mathrm{II}_{1}$ and $+0^{\prime \prime} .127$ for Position $\mathrm{I}$. The reflected observations indicate that these values should be increased by about $+0^{\prime \prime} .2$ and $+0^{\prime \prime} .3$, respectively.

As the result of the preceding discussion, the following corrections have been applied to the observed declinations, both direct and reflected:

(1) Corrections for horizontal and circle flexure.

(2) Corrections to reduce to the mean of the two clamps.

(3) Additional empirical corrections to reduce the declinations observed direct in any position of the instrument to the mean of the three positions. If $\Delta \mathrm{II}_{1}, \Delta \mathrm{I}$, and $\Delta \mathrm{II}_{2}$ are the corrections necessary to accomplish this after the corrections in (1) and (2) have been applied,

we have

and also

where

and

It follows that

$$
\begin{gathered}
\mathrm{II}_{1}+\Delta \mathrm{II}_{1}=\mathrm{I}+\mathrm{I} \mathrm{I}=\mathrm{II}_{2}+\Delta \mathrm{II}_{2}, \\
\Delta \mathrm{II}_{1}+\Delta \mathrm{I}+\Delta \mathrm{II}_{2}=0 \\
\mathrm{II}_{1}-\mathrm{I}=Y_{1} \\
\mathrm{II}_{2}-\mathrm{I}=Y_{2} \\
\Delta \mathrm{II}_{1}=\frac{Y_{2}-2 Y_{1}}{3} \\
\Delta \mathrm{I}=\frac{Y_{1}+Y_{2}}{3} \\
\Delta \mathrm{II}_{2}=\frac{Y_{1}-2 Y_{2}}{3} .
\end{gathered}
$$

The adopted values of $e, f, \theta, \Delta N, \Delta \mathrm{II}_{1}, \Delta \mathrm{I}$, and $\Delta \mathrm{II}_{2}$ used in computing these corrections are given in the following table:

$$
\text { Adopted Values of e, } f, \theta, \Delta N, \Delta I I_{1}, \Delta I \text {, and } \Delta I I_{2}
$$

[1911-1918]

\begin{tabular}{|c|c|c|c|c|c|}
\hline Position & $e$ & $f$ & 0 & $\Delta N$ & $\Delta \mathrm{II}_{1}, \Delta \mathrm{I}$, and $\Delta \mathrm{II}_{2}$ \\
\hline & $\prime \prime$ & $\prime \prime$ & $\circ$, & $\prime \prime$ & $\prime \prime$ \\
$\mathrm{II}_{1}$ & +0.074 & +0.117 & 18550 & -0.19 & $+0.030+0.226 \sin 2 z$ \\
$\mathrm{I}$ & +0.127 & +0.117 & 5056 & 0.00 & $-0.032+0.033 \sin 2 z$ \\
$\mathrm{II}_{2}$ & +0.074 & +0.117 & 33648 & -0.27 & $+0.003-0.259 \sin 2 z$ \\
\hline
\end{tabular}

Table $\mathrm{X}$ gives the values of these corrections for the various positions of the instrument. 
CORRECTIONS TO THE ASSUMED LATITUDE AND REFRACTION

The following table gives the results of direct observations of circumpolar stars made at night only:

Data from Circumpolar Observations

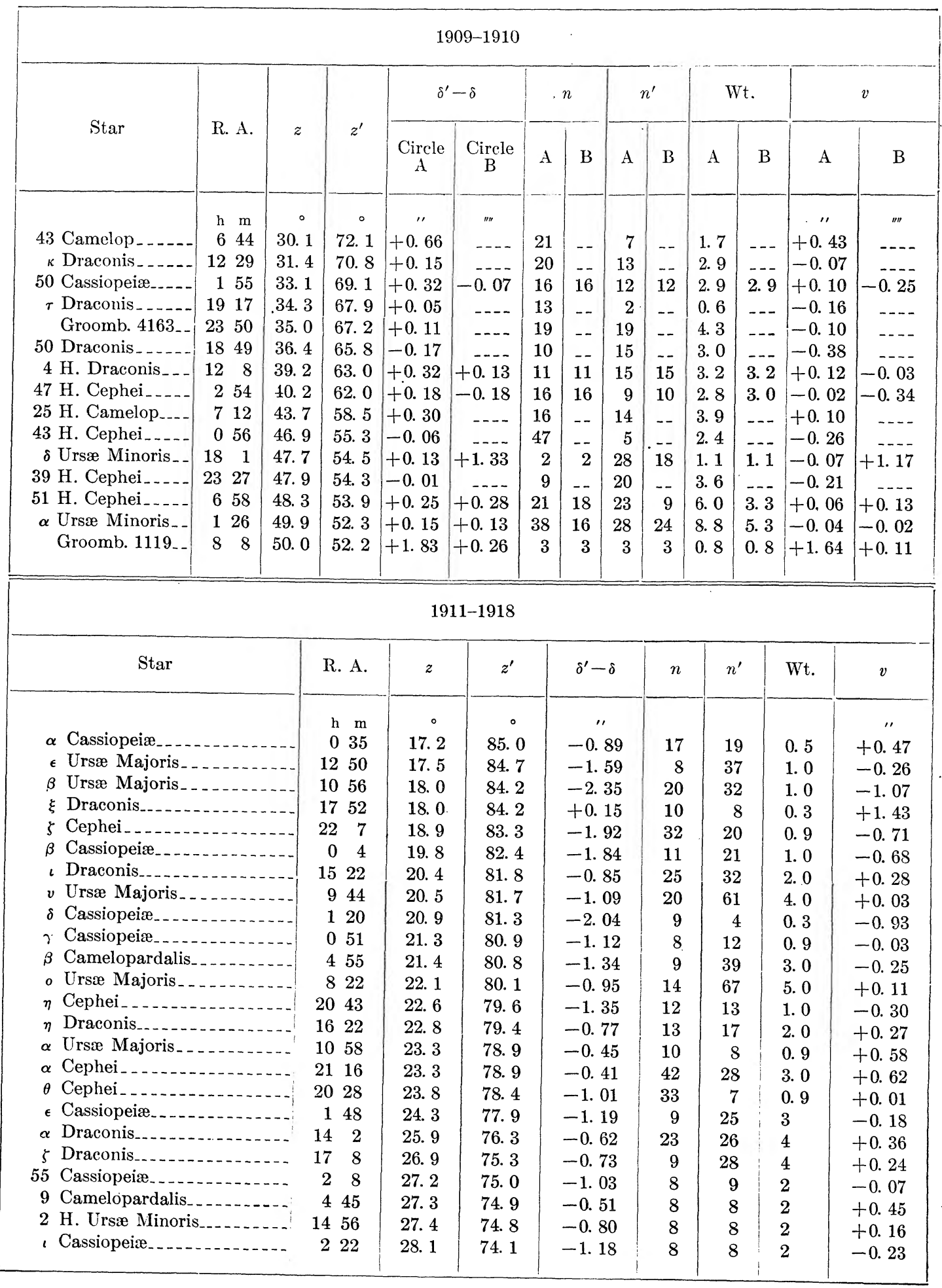


Data from Circumpolar Observations-Continued

\begin{tabular}{|c|c|c|c|c|c|c|c|c|c|}
\hline \multicolumn{10}{|c|}{$1911-1918$} \\
\hline & Star & R. A. & $z$ & $z^{\prime}$ & $\delta^{\prime}-\delta$ & $n$ & $n^{\prime}$ & Wt. & $v$ \\
\hline & & $\mathrm{h} \quad \mathrm{m}$ & $\circ$ & ${ }^{\circ}$ & " & & & & $"$ \\
\hline 3 & Draconis_-. & 1138 & 28.3 & 73.9 & -0.55 & 8 & $\mathbf{9}$ & 2 & +0.40 \\
\hline 41 & H. Cephei $\ldots$ & 2344 & 28. 4 & 73. 8 & -0.37 & 8 & 8 & 2 & +0.58 \\
\hline$\sigma^{2}$ & Ursæ Majoris_. & 92 & 28. 6 & 73.6 & -1.26 & 8 & 7 & 2 & -0.31 \\
\hline$\delta$ & Draconis & 1912 & 28.6 & 73.6 & -0.54 & 25 & 15 & 3 & +0.41 \\
\hline & Cassiopeiæ. & 135 & 28. 7 & 73.5 & -0.52 & 9 & 7 & 2 & +0.43 \\
\hline o & Cephei & 2315 & 28.7 & 73.5 & -1.13 & 9 & 8 & 2 & -0.18 \\
\hline$\psi$ & Cassiopeiæ. & 119 & 28.8 & 73.4 & -1.07 & 8 & 8 & 2 & -0.13 \\
\hline$\rho$ & Ursæ Majoris & 854 & 29. 1 & 73.1 & -1.13 & 8 & 8 & 2 & -0.19 \\
\hline & Groombridge 2320 & 166 & 29.1 & 73.1 & -0.95 & 8 & 8 & 2 & -0.01 \\
\hline & Draconis & 1732 & 29.3 & 72.9 & -1.27 & 8 & 9 & 2 & -0.33 \\
\hline & Groombridge 1308 & 722 & 29.7 & 72.5 & -0.85 & 8 & 8 & 2 & +0.09 \\
\hline & H. Ursæ Majoris_... & 84 & 29.8 & 72.4 & -0.99 & 8 & 11 & 2 & -0.05 \\
\hline & Draconis_....... & 1737 & 29.9 & 72.3 & -0.77 & 8 & 8 & 2 & +0.16 \\
\hline & Camelopardalis... & 644 & 30.1 & 72.1 & -0.84 & 8 & 9 & 2 & +0.09 \\
\hline & Draconis_..... & 1628 & 30.1 & 72.1 & -0.54 & 8 & 9 & 2 & +0.39 \\
\hline 22 & H. Camelopardalis_. & 69 & 30.5 & 71.7 & -0.62 & 8 & 11 & 3 & +0.31 \\
\hline 38 & Cassiopeiæ_._- & 124 & 30.9 & 71.3 & -0.71 & 8 & 9 & 2 & +0.22 \\
\hline$\lambda$ & Draconis...... & 1126 & 30.9 & 71.3 & -1.09 & 19 & 15 & 4 & -0.16 \\
\hline $\boldsymbol{\epsilon}$ & Draconis_....... & 1949 & 31.1 & 71.1 & -1.22 & 8 & 8 & 2 & -0.30 \\
\hline$d$ & Ursæ Majoris_. & 927 & 31.3 & 70.9 & -0.91 & 8 & 9 & 2 & +0.01 \\
\hline$\beta$ & Cephei_......... & 2128 & 31.3 & 70.9 & -0.80 & 8 & 8 & 2 & +0.12 \\
\hline$\kappa$ & Draconis_........ & 1230 & 31.4 & 70.8 & -0.78 & 8 & 8 & 2 & +0.14 \\
\hline 11 & Cephei $\ldots$ & 2140 & 32.0 & 70.2 & -0.77 & 8 & 8 & 2 & +0.15 \\
\hline 5 & H. Camelopardalis_. & 341 & 32.2 & 70.0 & -0.46 & 8 & 8 & 2 & +0.46 \\
\hline$v$ & Draconis_. & 1855 & 32.3 & 69.9 & -1.21 & 8 & 8 & 2 & -0.29 \\
\hline & Draconis_. & 1822 & 32.4 & 69. 8 & -0.95 & 8 & 8 & 2 & -0.03 \\
\hline & Fedorenko $1653 p r_{-}$ & 1011 & 32.6 & 69.6 & -0.82 & 8 & 9 & 3 & +0.09 \\
\hline & Groombridge $2437 \ldots$ & 1718 & 33.0 & 69.2 & -0.51 & 8 & 9 & 3 & +0.40 \\
\hline 24 & Cephei & 228 & 33.0 & 69.2 & -1.19 & 9 & 8 & 2 & -0.28 \\
\hline 50 & Cassiopeiæ. & 156 & 33. 1 & 69.1 & -0.78 & 8 & 8 & 2 & +0.13 \\
\hline & Groombridge $1262 \ldots$ & 7. 4 & 33.1 & 69.1 & -0.45 & 9 & 8 & 3 & +0.46 \\
\hline & B. D. $+72^{\circ} 664$ & 150 & 33.2 & 69.0 & -0.71 & 10 & 10 & 3 & +0.20 \\
\hline$\gamma$ & Ursæ Minoris_. & 1520 & 33.2 & 69.0 & -1.21 & 8 & 9 & 3 & -0.30 \\
\hline$\psi$ & Draconis & 1743 & 33.3 & 68.9 & -0.61 & 8 & 8 & 2 & +0.30 \\
\hline & Groombridge 3241 & 2030 & 33.3 & 68.9 & -0.60 & 8 & 8 & 2 & +0.31 \\
\hline & Groombridge 569 & 250 & 33.4 & 68.8 & -0.81 & 8 & 10 & 3 & +0.10 \\
\hline 36 & H. Cassiopeiæ_..... & 230 & 33.5 & 68.7 & -0.96 & 9 & 8 & 2 & -0.05 \\
\hline & B. D. $+72^{\circ} 515$ & 112 & 33.5 & 68.7 & -0.91 & 7 & 10 & 3 & 0.00 \\
\hline 40 & Cassiopeiæ. & 131 & 33.7 & 68.5 & -0.83 & 8 & 8 & 3 & +0.08 \\
\hline & Bradley 1160 & 811 & 33.8 & 68.4 & -0.68 & 8 & 8 & 3 & +0.23 \\
\hline$x$ & Draconis & 1822 & 33.8 & 68.4 & -1.40 & 8 & 8 & 3 & -0.49 \\
\hline & Groombridge $2001 \ldots$ & 1324 & 33.9 & 68.3 & -0.94 & 8 & 8 & 3 & -0.03 \\
\hline & Groombridge $1865 \ldots$ & 1212 & 34.2 & 68.0 & -1.12 & 8 & 8 & 3 & -0.22 \\
\hline$\tau$ & Draconis & 1917 & 34.3 & 67.9 & -0.69 & 8 & 8 & 3 & +0.21 \\
\hline 31 & Cephei & 2234 & 34.3 & 67.9 & -0.87 & 9 & 8 & 3 & +0.03 \\
\hline & Groombridge $1586 \ldots$ & 951 & 34.4 & 67.8 & -0.90 & 8 & 9 & 3 & 0.00 \\
\hline & Groombridge $1974 \ldots$ & 1311 & 34.4 & 67.8 & -0.46 & 8 & 8 & 3 & +0.44 \\
\hline 79 & Draconis & 2152 & 34.4 & 67.8 & -0.18 & 8 & 8 & 3 & +0.72 \\
\hline & Groombridge $4120 \ldots$ & 2336 & 34.6 & 67.6 & -1.32 & 9 & 8 & 3 & -0.42 \\
\hline & Schwerd 215 & 357 & 34.9 & 67.3 & -0.64 & 8 & 8 & 3 & +0.26 \\
\hline & Groombridge $911 \ldots \ldots$ & $5 \quad 1$ & 34.9 & 67.3 & -0.73 & 8 & 8 & 3 & +0.17 \\
\hline & Groombridge $1446 \ldots$ & 830 & 35.0 & 67.2 & -1.29 & 8 & 8 & 3 & -0.39 \\
\hline & Groombridge $4163 \ldots$ & 2351 & 35.0 & 67.2 & -0.92 & 9 & 9 & 3 & -0.02 \\
\hline & Groombridge $1374 \ldots$ & 750 & 35.2 & 67.0 & -0.26 & 8 & 8 & 3 & +0.64 \\
\hline & Groombridge $1522 \ldots$ & 911 & 35.5 & 66.7 & -0.90 & 8 & 8 & 3 & 0.00 \\
\hline
\end{tabular}


Data from Circumpolar Observations-Continued

\begin{tabular}{|c|c|c|c|c|c|c|c|c|c|}
\hline \multicolumn{10}{|c|}{$1911-1918$} \\
\hline & Star & R. A. & $z$ & $z^{\prime}$ & $\delta^{\prime}-\delta$ & $n$ & $n^{\prime}$ & Wt. & $v$ \\
\hline 21 & Cassiopeiæ & $\begin{array}{cc}\mathrm{h} & \mathrm{m} \\
0 & 40\end{array}$ & $\begin{array}{c}\circ \\
35.6\end{array}$ & 66. 6 & ${ }^{\prime \prime}=.27$ & 9 & 8 & 3 & $\begin{array}{c}\prime \prime \\
+0.63\end{array}$ \\
\hline$\beta$ & Ursæ Minoris & 1450 & 35.6 & 66.6 & -0.75 & 27 & 22 & 8 & +0.15 \\
\hline 73 & Draconis........ & 2033 & 35.7 & 66.5 & -0.43 & 8 & 10 & 3 & +0.47 . \\
\hline \multirow[t]{3}{*}{$\pi$} & Cephei....... & 235 & 36.0 & 66.2 & -0.93 & 8 & 8 & 3 & -0.03 \\
\hline & Groombridge 966 & 528 & 36.1 & 66.1 & -1.49 & 8 & 8 & 3 & -0.59 \\
\hline & Groombridge 379 & 144 & 36.2 & 66.0 & -1.15 & 8 & 9 & 3 & -0.25 \\
\hline \multirow[t]{5}{*}{50} & Draconis... & 1849 & 36.4 & 65.8 & -0.51 & 9 & 9 & 3 & +0.39 \\
\hline & Bradley 2099 & 1615 & 36.5 & 65.7 & -0.69 & 8 & 9 & 3 & +0.20 \\
\hline & Groombridge $2406 \ldots$ & 1656 & 36.6 & 65.6 & -0.47 & 8 & 10 & 4 & +0.42 \\
\hline & Groombridge 1030 & 553 & 36.7 & 65.5 & -1.21 & 9 & 8 & 3 & -0.32 \\
\hline & Groombridge 848 & 437 & 36.9 & 65.3 & -0.56 & 8 & 8 & 3 & +0.33 \\
\hline \multirow{3}{*}{226} & B. Cephei. & 2231 & 36.9 & 65.3 & -1.33 & 9 & 8 & 4 & -0.44 \\
\hline & Bradley 1147 & 89 & 37.1 & 65.1 & -0.84 & 8 & 8 & 3 & +0.05 \\
\hline & Radcliffe $1845,2950 \ldots$ & 1256 & 37.1 & 65.1 & -0.31 & 7 & 9 & 3 & +0.58 \\
\hline$\eta$ & Ursæ Minoris & 1620 & 37.1 & 65.1 & -0.98 & 8 & 8 & 3 & -0.09 \\
\hline 5 & Ursæ Minoris_. . . . . . . & 1428 & 37.2 & 65.0 & -0.89 & 8 & 8 & 3 & 0.00 \\
\hline 19 & Ursæ Minoris_. & 1613 & 37.2 & 65.0 & -0.94 & 8 & 10 & 4 & -0.05 \\
\hline \multirow[t]{3}{*}{9} & H. Draconis......... & 1028 & 37.3 & 64.9 & -0.65 & 8 & 10 & 4 & +0.24 \\
\hline & Radcliffe 1845,1260 & 434 & 37.5 & 64. 7 & -0.93 & 16 & 9 & 4 & -0.04 \\
\hline & Radcliffe $1845,4348 \ldots$ & 1924 & 37.5 & 64.7 & -0.69 & 8 & 8 & 3 & +0.20 \\
\hline 318 & B. Cephei mean & 011 & 37.6 & 64.6 & -0.76 & 8 & 8 & 3 & +0.13 \\
\hline 35 & Draconis.......... & 1753 & 38.1 & 64.1 & -0.53 & 8 & 8 & 3 & +0.36 \\
\hline 24 & H. Camelopardalis $\ldots \ldots$ & 647 & 38.2 & 64.0 & -0.64 & 9 & 8 & 3 & +0.25 \\
\hline \multirow[t]{2}{*}{$\gamma$} & Cephei & 2335 & 38.3 & 63.9 & -1.15 & 20 & 18 & 8 & -0.26 \\
\hline & Groombridge 4089 & 2328 & 38.4 & 63.8 & -0.94 & 9 & 10 & 4 & -0.05 \\
\hline 48 & H. Cephei & $\begin{array}{ll}3 & 9\end{array}$ & 38.5 & 63.7 & -0.68 & 8 & 8 & 3 & +0.21 \\
\hline \multirow[t]{2}{*}{$\kappa$} & Cephei & 2012 & 38.5 & 63.7 & -0.80 & 8 & 8 & 3 & +0.09 \\
\hline & Bradley 205 & 132 & 38.6 & 63.6 & -1.09 & 8 & 8 & 3 & -0.20 \\
\hline \multirow[t]{2}{*}{$\theta$} & Ursæ Minoris & 1534 & 38.7 & 63.5 & -0.74 & 8 & 8 & 3 & +0.15 \\
\hline & Bradley 2777 & 217 & 38.9 & 63.3 & -0.50 & 9 & 9 & 4 & +0.39 \\
\hline \multirow[t]{2}{*}{4} & Ursæ Minoris ... & 149 & 39.1 & 63.1 & -1.13 & 8 & 8 & 3 & -0.25 \\
\hline & Groombridge $1803 \ldots$ & 1132 & 39. 2 & 63.0 & -1.60 & 9 & 8 & 4 & -0.72 \\
\hline 4 & H. Draconis & $12 \cdot 8$ & 39.2 & 63.0 & -0.93 & 10 & 10 & 4 & -0.05 \\
\hline \multirow[t]{4}{*}{$\zeta$} & Ursæ Minoris . . . . . . & 1547 & 39. 2 & 63.0 & -1.15 & 7 & 9 & 3 & -0.27 \\
\hline & Groombridge $1706 \ldots$ & 1053 & 39.3 & 62.9 & -0.79 & 7 & 8 & 3 & +0.09 \\
\hline & Fedorenko 1373 $\ldots \ldots$ & 847 & 39.6 & 62.6 & -1.09 & 9 & 8 & 4 & -0.21 \\
\hline & Radcliffe $1845,1928 \ldots$ & 719 & 40.0 & 62.2 & -0.75 & 8 & 8 & 4 & +0.13 \\
\hline 47 & H. Cephei & 254 & 40.2 & 62.0 & -1.32 & 8 & 9 & 4 & -0.44 \\
\hline \multirow[t]{3}{*}{19} & H. Camelopardalis $\ldots$ & $5 \cdot 8$ & 40. 2 & 62.0 & -1.05 & 8 & 8 & 4 & -0.17 \\
\hline & Radcliffe 1845,4956 & 2040 & 40.2 & 62.0 & -0.81 & 8 & 8 & 4 & +0.07 \\
\hline & Bradley 2894 & 2153 & 40.2 & 62.0 & -0.83 & 9 & 8 & 4 & +0.05 \\
\hline \multirow[t]{2}{*}{44} & H. Cephei & 14 & 40. 3 & 61.9 & -0.30 & 8 & 8 & 4 & +0.58 \\
\hline & Fedorenko 1629 & 107 & 40.5 & 61.7 & -0.62 & 8 & 9 & 4 & +0.26 \\
\hline \multirow[t]{4}{*}{23} & H. Camelopardalis . . . . & 631 & 40.8 & 61.4 & -0.90 & 8 & 8 & 4 & -0.02 \\
\hline & Schwerd 986 & 1637 . & 41.1 & 61.1 & -1.04 & 8 & 9 & 4 & -0.16 \\
\hline & Bradley 2321 $\ldots$ & 187 & 41.1 & 61.1 & -1.45 & 8 & 8 & 4 & -0.57 \\
\hline & Groombridge 2456 & 1726 & 41.3 & 60.9 & -0.69 & 7 & 9 & 4 & +0.19 \\
\hline \multirow[t]{5}{*}{220} & $\mathrm{H}^{1}$. Draconis ................ & 2052 & 41.3 & 60.9 & -0.84 & 8 & 8 & 4 & +0.04 \\
\hline & Schwerd $1059 \ldots$ & 1749 & 41.4 & 60.8 & -1.18 & 10 & 8 & 4 & -0.30 \\
\hline & Radcliffe 1845,526 & 145 & 41.6 & 60. 6 & -1.28 & 8 & 9 & 4 & -0.40 \\
\hline & Bradley 1458 & 1035 & 42.0 & 60.2 & -1.04 & 8 & 8 & 4 & -0.16 \\
\hline & Groombridge $1977 \ldots$ & 1312 & 42.0 & 60.2 & -0.60 & 7 & 8 & 4 & +0.28 . \\
\hline \multirow[t]{2}{*}{142} & $\mathrm{H}^{1}$. Cephei. & 235 & 42.2 & 60.0 & -1.11 & 8 & 8 & 4 & -0.23 \\
\hline & Groombridge $1927 \ldots$ & 1242 & 42.2 & 60.0 & -1.01 & 8 & 8 & 4 & -0.13 \\
\hline
\end{tabular}


Data from Circumpolar Observations-Continued

\begin{tabular}{|c|c|c|c|c|c|c|c|c|c|}
\hline \multicolumn{10}{|c|}{$1911-1918$} \\
\hline & Star & R. A. & $z$ & $z^{\prime}$ & $\delta^{\circ}-\delta$ & $n$ & $n^{\prime}$ & Wt. & $v$ \\
\hline & & $\mathrm{h} \quad \mathrm{m}$ & $\circ$ & $\circ$ & " & & & & " \\
\hline & Carrington 2352 & 1535 & 42. 2 & 60.0 & -0.86 & 8 & 8 & 4 & +0.02 \\
\hline & Bradley 2704_. & 2034 & 42. 2 & 60.0 & -0.66 & 8 & 9 & 4 & +0.22 \\
\hline & Carrington 2188 & 1433 & 42.3 & 59. 9 & -0.98 & 9 & 8 & 4 & -0.10 \\
\hline & Groombridge 856 & 443 & 42.4 & 59. 8 & -1.42 & 8 & 8 & 4 & -0.54 \\
\hline & Groombridge 1782 & 1126 & 42.7 & 59.5 & -0.92 & 8 & 8 & 4 & -0.04 \\
\hline 1 & H. Draconis & 924 & 42. 8 & 59. 4 & -0.98 & 44 & 66 & 26 & -0.10 \\
\hline 319 & B. Cephei & 032 & 43. 1 & 59. 1 & -1.21 & 8 & 8 & 4 & -0.33 \\
\hline & Carrington 910 & 626 & 43. 3 & 58. 9 & -0.77 & 8 & 8 & 4 & +0.11 \\
\hline & Carrington 1651 & 113 & 43. 3 & 58. 9 & -1.09 & 9 & 8 & 4 & -0.21 \\
\hline & Ursæ Minoris & 1654 & 43. 3 & 58. 9 & -0.82 & 26 & 32 & 14 & +0.06 \\
\hline & Schwerd 1139_ & 194 & 43. 3 & 58. 9 & -0.76 & 8 & 8 & 4 & +0.12 \\
\hline 76 & Draconis & 2049 & 43. 3 & 58. 9 & -1.00 & 49 & 35 & 19 & -0.12 \\
\hline 25 & H. Camelopardalis & 713 & 43. 7 & 58.5 & -0.64 & 15 & 23 & 9 & +0.24 \\
\hline & Groombridge 1431 & 831 & 43. 7 & 58.5 & -1.17 & 8 & 8 & 4 & -0.29 \\
\hline & Groombridge 1391 & 87 & .43 .8 & 58.4 & -1.16 & 8 & 8 & 4 & -0.28 \\
\hline & Bradley 3038 & 2248 & 43. 8 & 58.4 & -1.31 & 8 & 8 & 4 & -0.43 \\
\hline$\nu$ & Cephei & 2352 & 43.8 & 58.4 & -1.23 & 9 & 7 & 4 & -0.35 \\
\hline & Groombridge $2196 \ldots$ & 1456 & 44. 0 & 58. 2 & -1.36 & 8 & 8 & 4 & -0.49 \\
\hline 30 & H. Camelopardalis_- & 1020 & 44.1 & 58.1 & -0.90 & 46 & 56 & 25 & -0.03 \\
\hline & Bradley 256 & 23 & 44. 2 & 58. 0 & -0.90 & 8 & 8 & 4 & -0.03 \\
\hline & Bradley 2412 & 1835 & 44. 2 & 58.0 & -0.71 & 8 & 8 & 4 & +0.16 \\
\hline & Piazzi XIII, 263 $\ldots .$. & 1345 & 44.3 & 57.9 & -0.76 & 7 & 8 & 4 & +0.11 \\
\hline & Groombridge 2315 & 1553 & 44. 3 & 57.9 & -0.77 & 8 & 8 & 4 & +0.10 \\
\hline & Carrington $2965 \ldots$ & 1927 & 44.4 & 57.8 & -0.76 & 8 & 8 & 4 & +0.11 \\
\hline & Radcliffe $1845,4976 \ldots$ & 2038 & 44.4 & 57.8 & -0.96 & 8 & 8 & 4 & -0.09 \\
\hline & Groombridge 766 & 48 & 44. 7 & 57.5 & -0.81 & 9 & 8 & 4 & +0.06 \\
\hline 32 & H. Camelopardalis $p r_{\ldots}$ & 1248 & 45.0 & 57.2 & -0.88 & 8 & 9 & 4 & -0.01 \\
\hline 32 & H. Camelopardalis seq & 1248 & 45. 0 & 57.2 & -1.33 & 10 & 14 & 6 & -0.46 \\
\hline 36 & H. Cephei & 2255 & 45.0 & 57.2 & -0.89 & 8 & 10 & 5 & -0.02 \\
\hline & Groombridge 1359 & 756 & 45. 4 & 56. 8 & -1.03 & 8 & 8 & 4 & -0.16 \\
\hline & Carrington $1451 \ldots$ & 954 & 45.5 & 56. 7 & -1.28 & 10 & 8 & 4 & -0.41 \\
\hline & Groombridge $3212 \ldots$ & 2013 & 45.5 & 56. 7 & -1.11 & 9 & 8 & 4 & -0.24 \\
\hline & Radcliffe 1845,2218 & 857 & 45.6 & 56. 6 & -1.19 & 8 & 8 & 4 & -0.32 \\
\hline & Bradley 402 & 311 & 45. 7 & 56.5 & -1.05 & 9 & 8 & 4 & -0.18 \\
\hline 29 & H. Camelopardalis & 1017 & 45.8 & 56.4 & -0.91 & 8 & 8 & 4 & -0.04 \\
\hline & Groombridge $944 \ldots$ & 534 & 46. 3 & 55. 9 & -0.63 & 25 & 4 & 3 & +0.24 \\
\hline & Groombridge $750 \ldots$ & 48 & 46. 4 & 55.8 & -0.95 & 26 & 20 & 11 & -0.08 \\
\hline & Carrington 727 & 513 & 46. 7 & 55.5 & -0.79 & 8 & 8 & 4 & +0.08 \\
\hline 32 & H. Cephei & 2221 & 46. 8 & 55.4 & -1.17 & 9 & 8 & 4 & -0.30 \\
\hline 43 & H. Cephei & 056 & 46. 9 & 55. 3 & -0.82 & 39 & 44 & 22 & +0.05 \\
\hline & Radcliffe $1845,1311 \ldots$ & 50 & 46. 9 & 55. 3 & -0.86 & 8 & 8 & 4 & +0.01 \\
\hline & Radcliffe 1845,2612 & 114 & 47. 2 & 55.0 & -1.02 & 8 & 8 & 4 & -0.15 \\
\hline 128 & $\mathrm{H}^{1}$. Camelopardalis . . . & 120 & 47.2 & 55. 0 & -0.82 & 8 & 10 & 5 & +0.05 \\
\hline 149 & $\mathrm{H}^{1}$. Cephei & 338 & 47.5 & 54. 7 & -0.51 & 8 & 9 & 4 & +0.36 \\
\hline$\delta$ & Ursæ Minoris . . . & 181 & 47. 7 & 54.5 & -0.75 & 34 & 47 & 21 & +0.12 \\
\hline & Groombridge $3548 \ldots$ & 2117 & 47.8 & 54.4 & -0.82 & 8 & 8 & 4 & +0.05 \\
\hline & Groombridge 1004 & 612 & 47. 9 & 54. 3 & -0.90 & 8 & 8 & 4 & -0.03 \\
\hline & H. Cephei & 2327 & 47. 9 & 54. 3 & -0.76 & 52 & 42 & 24 & +0.11 \\
\hline 51 & H. Cephei & 7.0 & 48.3 & 53. 9 & -0.53 & 32 & 46 & 20 & +0.34 \\
\hline & Groombridge $2283 \ldots$ & 155 & 48. 7 & 53.5 & -0.92 & 34 & 31 & 17 & -0.05 \\
\hline & Bradley 1672 & 1214 & 49. 3 & 52.9 & -0.98 & 38 & 39 & 20 & -0.11 \\
\hline & Ursæ Minoris & 128 & 49. 9 & 52.3 & -0.91 & 237 & 234 & 123 & -0.04 \\
\hline & Groombridge 1119 & 810 & 50.0 & 52.2 & -0.64 & 21 & 28 & 13 & +0.23 \\
\hline & Ursæ Minoris & 199 & 50.1 & 52.1 & -0.55 & 15 & 26 & 10 & +0.32 \\
\hline
\end{tabular}


In the preceding table

$$
\begin{aligned}
& z= \text { the zenith distance of the star at upper culmination. } \\
& z^{\prime}= \text { the zenith distance of the star at lower culmination. } \\
& n= \text { the number of observations at upper culmination. } \\
& n^{\prime}= \text { the number of observations at lower culmination. } \\
& \delta^{\prime}-\delta= \text { the mean of the declinations from lower culminations minus the } \\
& \text { mean of the declinations from upper culminations as published } \\
& \text { in the Individual Results. See p. } 183 \text { et seq. } \\
& \text { Wt. }= \frac{1}{10}\left(\frac{n n^{\prime}}{n^{\prime} r^{\prime 2}+n r^{2}}\right) \text { where } r^{\prime} \text { and } r \text { are the probable errors of a single } \\
& \text { observation at lower and upper culminations. }
\end{aligned}
$$

Period 1909-1910.-During the years 1909-1910 the observations were too few in number and covered too small a range in zenith distance to determine a correction to the refraction constant. The refractions during this period were computed from DE BALL's refraction tables, while in the later work, 1911-1918, the Pulkowa refraction tables were used. The adopted correction to the Pulkowa refraction at zenith distance $45^{\circ}$, resulting from a discussion of the observations made in 19111918 , is $\Delta R=-0^{\prime \prime} .12$. The mean difference between the values of the refraction at $45^{\circ}$ zenith distance, computed from the Pulkowa and DE BALL tables, is $+0^{\prime \prime} .15$, in the sense Pulkowa minus DE BALL. The adopted correction to the refraction at $45^{\circ}$ zenith distance for the period 1909-1910 is therefore $\Delta R=+0^{\prime \prime} .03$.

The equations of condition for determining $\Delta \varphi$ and $\Delta R$ are of the form

$$
2 \Delta \varphi+\Delta R\left(\tan z+\tan z^{\prime}\right)=\delta^{\prime}-\delta
$$

Putting $\Delta R=+0^{\prime \prime} .03$, we obtain as a correction to the assumed latitude, 1909-1910,

$$
\begin{array}{cc}
\prime \prime \prime & \\
\Delta \varphi=+0.06 \pm 0.024 & \text { Circle A } \\
\Delta \varphi=+0.04 \pm 0.044 & \text { Circle B }
\end{array}
$$

Period 1911-1918. - The circumpolar observations made during the period 1911-1918 give 187 equations of condition for determining $\Delta \varphi$ and $\Delta R$. The resulting normal equations are

$$
\begin{aligned}
& \multicolumn{1}{l}{} \\
3678.60 \psi-176.94 \Delta R & =-1632.273 \\
-176.94+734.10 & =+38.572
\end{aligned}
$$

where $\psi=\Delta \varphi+1.5 \Delta R$.

Solving these equations we obtain

$$
\begin{aligned}
\psi & =-0.446 \pm 0.005 \\
\Delta R & =-0.055 \pm 0.013 \\
\Delta \varphi & =-0.364 \pm 0.021
\end{aligned}
$$

The quantities under the heading $v$ in the last column of the preceding table are residuals obtained by substituting the values of $\Delta \varphi$ and $\Delta R$, derived above, in the equations of condition.

. Before adopting values of $\Delta \varphi$ and $\Delta R$ for the period 1911-1918, a comparison was made with the positions given in the fundamental catalogue of 1293 stars, from observations made at the Royal Observatory, Cape of Good Hope, during the years 1905-1911. The latter observations were made with the new reversible transit circle, and were reduced in a fundamental manner, using the Pulkowa 
refractions. There are 583 stars common to the two catalogues, from declination $+36^{\circ} .0$ to declination $-43^{\circ} .8$, corresponding to zenith distances $2^{\circ} .9$ south to $82^{\circ} .7$ south at Washington, and $69^{\circ} .9$ north to $9^{\circ} .9$ south at the Cape. NewCoMB's proper motions were used in general to reduce the positions at Washington and the Cape to a common epoch. The proper motions of Boss were used when those of NEwcomB were not available. Weights were assigned in a manner similar to that employed in the discussion of the circumpolar stars, assuming the same probable error for an observation at the Cape as for one of the same zenith distance at Washington. The differences between the results at the two observatories were arranged in order of the declinations of the stars and divided into 55 groups of approximately equal weight. The mean differences by groups, $\delta_{\mathrm{c}}-\delta_{\mathrm{w}}$, appear in the following table:

Results of Comparison of Observations at Cape and Washington

\begin{tabular}{|c|c|c|c|c|c|c|c|c|c|}
\hline $\begin{array}{l}\text { Mean } \\
\text { Decl. }\end{array}$ & $z_{\mathrm{o}}$ & $z_{\mathrm{w}}$ & $\delta_{\mathrm{c}}-\delta_{\mathrm{w}}$ & $v$ & $\begin{array}{l}\text { Mean } \\
\text { Decl. }\end{array}$ & $z_{\mathrm{c}}$ & $z_{\mathrm{w}}$ & $\delta_{\mathrm{c}}-\delta_{\mathrm{w}}$ & $v$ \\
\hline 。 & $\circ$ & 。 & "' & " & 。 & 。 & $\circ$ & " & $"$ \\
\hline+34.2 & +68.2 & 4. 7 & +0.17 & +0.05 & +4.3 & +38.3 & 34.6 & -0.39 & -0.28 \\
\hline 31.9 & 65.9 & 7. 0 & +0.10 & +0.02 & 3.4 & 37.4 & 35.5 & -0.17 & -0.05 \\
\hline 29.3 & 63.3 & 9. 6 & -0.02 & -0.06 & 2.6 & 36. 6 & 36. 3 & -0.24 & -0.12 \\
\hline 28.1 & 62.1 & 10. 8 & +0.06 & +0.04 & 2.3 & 36.3 & 36.6 & -0.17 & -0.05 \\
\hline 27.0 & 61.0 & 11. 9 & -0.05 & -0.05 & +0.2 & 34.2 & 38.7 & -0.23 & -0.11 \\
\hline 25. 3 & 59. 3 & 13. 6 & +0.04 & +0.06 & -0.5 & 33. 5 & 39.4 & -0.13 & -0.01 \\
\hline 23. 9 & 57. 9 & 15. 0 & -0.03 & 0.00 & 1. 3 & 32.7 & 40.2 & -0.18 & -0.06 \\
\hline 22. 7 & 56. 7 & 16. 2 & +0.09 & +0.13 & 2.6 & 31.4 & 41.5 & -0.11 & 0.00 \\
\hline 21.6 & 55.6 & 17. 3 & -0.06 & -0.01 & 3.6 & 30.4 & 42.5 & +0.07 & +0.18 \\
\hline 20. 4 & 54. 4 & 18. 5 & -0.04 & +0.02 & 4. 9 & 29.1 & 43.8 & -0.10 & +0.01 \\
\hline 19. 1 & 53.1 & 19. 8 & -0.05 & +0.02 & 6.4 & 27.6 & 45. 3 & -0.07 & +0.04 \\
\hline 18. 5 & 52.5 & 20.4 & +0.05 & +0.12 & 8.2 & 25. 8 & 47. 1 & -0.11 & -0.01 \\
\hline 17. 0 & 51.0 & 21. 9 & -0.07 & +0.01 & 8. 4 & 25.6 & 47.3 & +0.03 & +0.13 \\
\hline 16. 1 & 50.1 & 22.8 & -0.17 & -0.09 & 9.2 & 24. 8 & 48.1 & -0.07 & +0.03 \\
\hline 15. 1 & 49.1 & 23. 8 & -0.10 & -0.01 & 10. 2 & 23.8 & 49. 1 & -0.03 & +0.06 \\
\hline 14. 6 & 48.6 & 24. 3 & -0.13 & -0.04 & 11. 4 & 22.6 & 50.3 & +0.02 & +0.11 \\
\hline 12. 9 & 46.9 & 26. 0 & -0.10 & 0.00 & 13.4 & 20.6 & 52.3 & -0.02 & +0.06 \\
\hline 12.2 & 46. 2 & 26. 7 & -0.13 & -0.03 & 14.8 & 19.2 & 53.7 & +0.13 & +0.20 \\
\hline 11. 4 & 45.4 & 27.5 & -0.11 & -0.01 . & 15.6 & 18.4 & 54.5 & 0.00 & +0.06 \\
\hline 10.3 & 44.3 & 28. 6 & -0.18 & -0.08 & 16. 7 & 17. 3 & 55.6 & -0.08 & -0.02 \\
\hline 9.6 & 43. 2 & 29. 7 & -0.08 & +0.03 & 18. 1 & 15. 9 & 57.0 & 0.00 & +0.05 \\
\hline 9.4 & 43.4 & 29. 5 & -0.19 & -0.08 & 20.1 & 13. 9 & 59.0 & -0.15 & -0.12 \\
\hline 8.7 & 42.7 & 30. 2 & -0.14 & -0.03 & 22.4 & 11.6 & 61.3 & +0.12 & +0.13 \\
\hline 7. 9 & 41.9 & 31. 0 & -0.12 & -0.01 & 24. 9 & 9.1 & 63.8 & +0.02 & -0.01 \\
\hline 6.7 & 40.7 & 32.2 & -0.17 & -0.06 & 27. 3 & 6. 7 & 66.2 & +0.06 & -0.01 \\
\hline 6.3 & 40.3 & 32.6 & -0.15 & -0.04 & 31. 2 & +2.8 & 70.1 & +0.08 & -0.08 \\
\hline 5. 8 & 39.8 & 33. 1 & -0.05 & +0.06 & -38.1 & -4.1 & 77. 0 & +0.42 & -0.04 \\
\hline+5.1 & +39.1 & 33.8 & -0.12 & -0.01 & & & & & \\
\hline
\end{tabular}

In the above table

$z_{\mathrm{o}}=$ the mean zenith distance north of the group at the Cape.

$z_{\mathrm{w}}=$ the mean zenith distance south of the group at Washington.

$\delta_{0}=$ the mean of the observed declinations at the Cape.

$\delta_{\mathrm{w}}=$ the mean of the observed declinations at Washington. 
From the quantities in the preceding table 55 equations of condition were obtained of the form

$$
\triangle \delta-\triangle R_{\mathrm{c}} \tan z_{\mathrm{c}}-\Delta R_{\mathrm{w}} \tan z_{\mathrm{w}}=\delta_{\mathrm{c}}-\delta_{\mathrm{w}}
$$

where $\triangle R_{\mathrm{c}}=$ the correction to the refraction at $45^{\circ}$ zenith distance at the Cape.

$\triangle R_{\mathrm{w}}=$ the correction to the refraction at $45^{\circ}$ zenith distance at Washington.

$\Delta \delta=$ the constant difference between the declinations at the Cape and those at Washington, after the refraction corrections given by the solution of these equations have been applied.

The normal equations derived from these equations of condition are

$$
\begin{array}{ll}
+55.00 \Delta \delta-48.42 \Delta R_{\mathrm{c}}-48.26 \Delta R_{\mathrm{w}} & =-3.05 \\
-48.42+59.69+25.12 & =+2.64 \\
-48.26+25.12+71.46 & =+0.35
\end{array}
$$

Solving these equations, we obtain

$$
\begin{gathered}
\Delta \delta=-0.425 \pm 0.032 \\
\Delta R_{\mathrm{c}}=-0.214 \pm 0.022 \\
\Delta R_{\mathrm{w}}=-0.207 \pm 0.016
\end{gathered}
$$

The quantities given under the heading $v$ in the fifth and tenth columns of the preceding table are the residuals resulting from the substitution of the above values of $\Delta \delta, \Delta R_{\mathrm{c}}$, and $\Delta R_{\mathrm{w}}$ in the equations of condition. From these corrections to the refraction and the circumpolar observations at the two observatories we obtain as corrections to the latitudes, $\Delta \varphi_{\mathrm{c}}=-0^{\prime \prime} .30$ and $\Delta \varphi_{\mathrm{w}}=-0^{\prime \prime} .13$. Using, therefore, the stars that are observed in common at the two observatories for determining the corrections to the Pulkowa Refraction Tables, and the circumpolar stars observed at each observatory to determine the corrections to the assumed latitudes, the fundamental positions determined at Washington are $0^{\prime \prime} .60\left(=+0^{\prime \prime} .43+0^{\prime \prime} .30\right.$ $\left.-0^{\prime \prime} .13\right)$ north of the Cape positions.

We have determined

and

$$
\begin{array}{ll}
\Delta R=-0.055 \pm 0.013 & \text { From circumpolar observations } \\
\Delta R=-0.207 \pm 0.016 & \text { From comparison with Cape }
\end{array}
$$

Assigning weights 3 and 2, respectively, in accordance with the probable errors, we have, as the adopted value of $\Delta R$, the correction to the Pulkowa refractions at $45^{\circ}$ zenith distance,

$$
\Delta R=-0^{\prime \prime} .116
$$

Using this value of $\Delta R$, the circumpolar observations give, as the correction to the assumed latitude,

$$
\Delta \varphi=-0^{\prime \prime} .27
$$

The adopted values of the corrections to the refraction at $45^{\circ}$ zenith distance and of the mean latitude of the transit circle for the two series of observations are

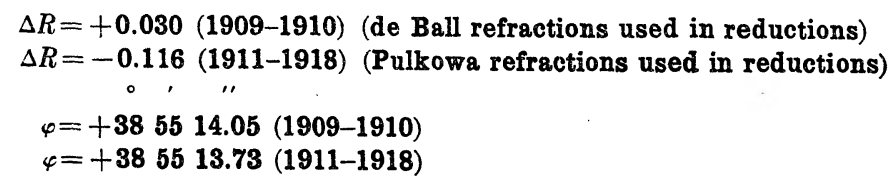


To obtain the mean latitude of the center of the clock room, a correction of $-0^{\prime \prime} .07$ must be applied to the adopted values of the latitude of the instrument.

Latitude from reflected observations of circumpolar stars.-From reflected observations of 15 stars observed at upper and lower culminations, with a value of $\Delta R=-0^{\prime \prime} .055$ determined from direct observations of circumpolar stars, there results the following correction to the assumed latitude:

$$
\Delta \varphi=-0^{\prime \prime} .44 \pm 0^{\prime \prime} .050
$$

Corrections to the observed declinations based on the adopted values of the latitude and refraction given above were computed and applied. These corrections are given in Table XI.

\section{PROBABLE ERROR OF AN OBSERVATION}

After the final positions had been obtained, the probable error of a single observation in declination for Circle A was determined by forming the differences, $v$, between the final mean and the individual observations of a star. No attempt was made to determine the probable error for individual observers.

The probable errors were computed in zones, $10^{\circ}$ wide from the zenith to a zenith distance of $70^{\circ}$, and $5^{\circ}$ wide from $70^{\circ}$ to $85^{\circ}$ zenith distance. The results are given in the following table:

Probable Error of a Single Observation of the Final Declination

\begin{tabular}{|c|c|c|c|c|c|}
\hline \multirow{2}{*}{$\begin{array}{l}\text { Zenith } \\
\text { Distance }\end{array}$} & \multicolumn{2}{|c|}{ Probable Error } & \multirow{2}{*}{$\begin{array}{c}\text { Zenith } \\
\text { Distance }\end{array}$} & \multicolumn{2}{|c|}{ Probable Error } \\
\hline & $\begin{array}{l}1909- \\
1910\end{array}$ & $\begin{array}{c}1911- \\
1918\end{array}$ & & $\begin{array}{c}1909 \\
1910\end{array}$ & $\begin{array}{c}1911- \\
1918\end{array}$ \\
\hline$\circ \quad 0$ & " & ", & & " & " \\
\hline 0 to 10 & 0.39 & 0.26 & 50 to 60 & 0.43 & 0.35 \\
\hline 10 to 20 & 0.41 & 0.29 & 60 to 70 & 0.53 & 0.40 \\
\hline 20 to 30 & 0.39 & 0.30 & 70 to 75 & 0.52 & 0.59 \\
\hline 30 to 40 & 0.36 & 0.25 & 75 to 80 & 0.80 & 0.81 \\
\hline 40 to 50 & 0.43 & 0.29 & 80 to 85 & $\ldots$ & 1. 42 \\
\hline
\end{tabular}

These probable errors are fairly well represented by the empirical formulæ

$$
\begin{array}{ll}
r=\sqrt{0^{\prime \prime} .146+0^{\prime \prime} .023 \tan ^{2} z} & 1909-1910 \\
r=\sqrt{0^{\prime \prime} .046+0^{\prime \prime} .032 \tan ^{2} z} & 1911-1918 .
\end{array}
$$

\section{DISCORDANT OBSERVATIONS}

The final results were examined for discordant observations. In general, the original records were examined, and the computations verified, of all observations which differed from the mean for the star concerned by more than three times the probable error. If no error was found, and the observation stood out from the mean by more than six times the probable error, the observation was rejected.

\section{UPPER CULMINATION MINUS LOWER CULMINATION}

The stars observed at both upper and lower culminations in the periods 1909-1910 and 1911-1918 were 16 and 187 in number, respectively. Differences were formed 
for each star between the final declination from observations above the pole and that from observations below the pole. Weights were assigned to these differences depending on the number of observations and on the probable error at each culmination. The differences were then combined in groups of approximately equal weight in general; the first group in the 1911-1918 work includes refraction stars only and has less weight than the others. The results are given in the following table:

\begin{tabular}{|c|c||c|c|}
\hline \multicolumn{2}{|c||}{$1909-1910$} & \multicolumn{2}{c|}{$1911-1918$} \\
\hline Decl. & $\delta-\delta^{\prime}$ & Decl. & $\delta-\delta^{\prime}$ \\
\hline 0. & $\prime \prime$ & $\circ$ & \\
\hline 72.7 & +0.08 & 61.3 & -0.29 \\
80.0 & -0.01 & 71.1 & -0.12 \\
86.0 & +0.07 & 76.9 & +0.01 \\
88.3 & -0.02 & 81.4 & +0.11 \\
& & 83.8 & +0.13 \\
& & 86.9 & -0.03 \\
& & 88.9 & +0.02 \\
\hline
\end{tabular}

\section{VARIATION OF THE OBSERVED DECLINATIONS DURING THE DAY AND NIGHT}

This variation was determined from a discussion of the observations of the clock and azimuth stars, 1911-1918, and certain other stars especially selected for this purpose which were observed-during the period 1916-1918.

The means of the observed declinations derived from night observations were formed for each star and subtracted from the individual observations, both day and night. The observations had been corrected for variation of latitude, flexure, and relative personal equation. The same relative personal equation corrections were applied to the day observations as were used for the night observations. The residuals were collected in twelve periods, according to the mean time of transit. These periods are the same as those used in connection with the right ascensions and defined on page 39. The results for the six night periods, 7 to 12 inclusive, are given in the following table:

Variation of the Observed Declinations during the Night, 1911-1918

\begin{tabular}{|c|c|c|c|c|c|c|c|c|c|c|c|c|}
\hline \multirow{2}{*}{$\delta$} & \multicolumn{2}{|c|}{ Period 7} & \multicolumn{2}{|c|}{ Period 8} & \multicolumn{2}{|c|}{ Period 9} & \multicolumn{2}{|c|}{ Period 10} & \multicolumn{2}{|c|}{ Period 11} & \multicolumn{2}{|c|}{ Period 12} \\
\hline & $\Delta \delta$ & $\begin{array}{l}\text { No. } \\
\text { Obs. }\end{array}$ & $\Delta \delta$ & $\begin{array}{l}\text { No. } \\
\text { Obs. }\end{array}$ & $\Delta \delta$ & $\begin{array}{l}\text { No. } \\
\text { Obs. }\end{array}$ & $\Delta \delta$ & $\begin{array}{l}\text { No. } \\
\text { Obs. }\end{array}$ & $\Delta \delta$ & $\begin{array}{l}\text { No. } \\
\text { Obs. }\end{array}$ & $\Delta \delta$ & $\begin{array}{l}\text { No. } \\
\text { Obs. }\end{array}$ \\
\hline 。 & " & & " & & " & & " & & " & & " & \\
\hline-35 to $\quad 0$ & +0.08 & 298 & -0.01 & 384 & 0.00 & 147 & +0.05 & 89 & -0.14 & 98 & -0.12 & 49 \\
\hline 0 to +39 & -0.03 & 772 & -0.01 & 1504 & +0.04 & 728 & +0.03 & 286 & -0.03 & 125 & -0.15 & 52 \\
\hline+39 to +60 & -0.05 & 93 & +0.05 & 84 & +0.04 & 23 & $\ldots$ & $\ldots$ & ... & $\ldots$ & $\therefore-$ & $\ldots$ \\
\hline+60 to +115 & -0.03 & 234 & +0.08 & 185 & +0.03 & 96 & +0.14 & 58 & -0.05 & 89 & -0.11 & 138 \\
\hline
\end{tabular}

These observations show no appreciable variation in the observed declinations during the night. 
Day minus night differences.-In discussing the residuals for the daylight periods it was found that the readings of the instrument thermometer and of the external thermometer differed during the day, although they were in substantial agreement at night. The refractions for all observations were based upon the readings of the instrument thermometer. The refractions for the day observations were also computed with the temperatures given by the external thermometer. The discussion of the differences between day and night observations was made in both cases.

The differences, day minus night, were collected in 10 zones of declination and the weighted means were formed for each period. The results for the case in which the instrument thermometer was used are given in the following table:

Day Minus Night Differences in Observed Declinations, 1911-1918

- [Refractions Based on the Instrument Thermometer]

\begin{tabular}{|c|c|c|c|c|c|c|c|c|c|c|c|c|c|}
\hline \multirow[b]{2}{*}{$\delta$} & \multirow[b]{2}{*}{$z$} & \multicolumn{2}{|c|}{ Period 1} & \multicolumn{2}{|c|}{ Period 2} & \multicolumn{2}{|c|}{ Period 3} & \multicolumn{2}{|c|}{ Period 4} & \multicolumn{2}{|c|}{ Period 5} & \multicolumn{2}{|c|}{ Period 6} \\
\hline & & $\Delta \delta$ & 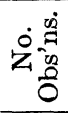 & $\Delta \delta$ & $\begin{array}{r}\dot{0} \\
\dot{2} \\
\dot{0} \\
0\end{array}$ & $\Delta \delta$ & $\dot{0}_{\dot{2}}^{\dot{2}}$ & $\Delta \delta$ & 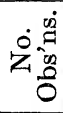 & $\Delta \delta$ & $\dot{0} \stackrel{\dot{2}}{\dot{2}}$ & $\Delta \delta$ & 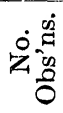 \\
\hline & 。 & " & & $"$ & & " & & $"$ & & " & & $"$ & \\
\hline-30 to -16 & -59 & +0.23 & 33 & +0.29 & 118 & +0.33 & 51 & +0.47 & 12 & +0.08 & 35 & +0.06 & 41 \\
\hline-16 to -6 & -49 & -0.02 & 76 & +0.12 & 259 & +0.21 & 122 & +0.04 & 79 & -0.06 & 132 & +0.06 & 103 \\
\hline-5 to +10 & -33 & -0.18 & 116 & -0.17 & 595 & -0.35 & 227 & -0.43 & 50 & -0.49 & 78 & -0.15 & 62 \\
\hline+10 to +20 & -23 & -0.07 & 96 & -0.21 & 568 & -0.43 & 302 & -0.53 & 57 & -0.43 & 103 & -0.24 & 87 \\
\hline+20 to +30 & -13 & +0.01 & 104 & -0.12 & 654 & -0.33 & 357 & -0.36 & 66 & -0.46 & 116 & -0.22 & 82 \\
\hline+30 to +39 & -5 & -0.01 & 54 & -0.14 & 300 & -0.30 & 167 & -0.36 & 41 & -0.27 & 54 & -0.15 & 48 \\
\hline+39 to +60 & +11 & +0.12 & 29 & -0.24 & 137 & -0.20 & 98 & -0.14 & 47 & -0.24 & 111 & +0.10 & 78 \\
\hline+60 to +84 & +29 & +0.10 & 53 & 0.00 & 58 & -0.14 & 29 & -0.10 & 22 & -0.02 & 28 & -0.01 & 54 \\
\hline+85 to +95 & +51 & +0.03 & 168 & -0.38 & 169 & -0.95 & 135 & -0.78 & 112 & -0.25 & 139 & -0.09 & 260 \\
\hline+97 to +105 & +65 & +0.12 & 27 & -0.55 & 23 & -1.48 & 4 & $\ldots$ & -. & -0.53 & 6 & -0.22 & 38 \\
\hline
\end{tabular}

The differences in the above table were plotted, as shown in Figure 4, and smooth curves were drawn through the points. The values of the differences were scaled off these curves for 9 a. m., 10 a. m., 11 a. m., noon, 1 p. m., 2 p. m., and 3 p. m. These values are given in the following table:

Adopted Values of the Day Minus Night Differences, 1911-1918

[Refractions Based on the Instrument Thermometer]

\begin{tabular}{|c|c|c|c|c|c|c|c|c|}
\hline$\delta$ & $z$ & 9 a. $\mathrm{m}$. & 10 a. $\mathrm{m}$. & 11 a. $\mathrm{m}$. & Noon & 1 p. m. & 2 p. m. & 3 p. $\mathrm{m}$ \\
\hline 0 & . 0 & $" \prime$ & " & " & " & " & " & " \\
\hline-20 & -59 & +0.31 & +0.35 & +0.38 & +0.38 & +0.35 & +0.27 & +0.14 \\
\hline-10 & -49 & +0.19 & +0.22 & +0.20 & +0.14 & +0.06 & 0.00 & -0.05 \\
\hline+6 & -33 & -0.20 & -0.29 & -0.37 & -0.42 & -0.46 & -0.50 & -0.50 \\
\hline+16 & -23 & -0.28 & -0.38 & -0.45 & -0.50 & -0.53 & -0.53 & -0.48 \\
\hline+26 & -13 & -0.18 & -0.27 & -0.35 & -0.40 & -0.44 & -0.45 & -0.45 \\
\hline+34 & -5 & -0.17 & -0.25 & -0.33 & -0.35 & -0.38 & -0.36 & -0.32 \\
\hline+50 & +11 & -0.24 & -0.23 & -0.17 & -0.10 & -0.08 & -0.10 & -0.17 \\
\hline+68 & +29 & -0.05 & -0.11 & -0.15 & -0.14 & -0.11 & -0.08 & -0.04 \\
\hline+90 & +51 & -0.55 & -0.80 & -0.97 & -0.95 & -0.83 & -0.62 & -0.36 \\
\hline+104 & +65 & -0.96 & -1.32 & -1.51 & -1.48 & -1.33 & -1.04 & -0.70 \\
\hline
\end{tabular}

$93432^{\circ}-27-7$ 
FigdRe 4.-Curves Showing the Differences, Day-Night, in Declination, for Observations Made during the Day at Various Zenith Distances

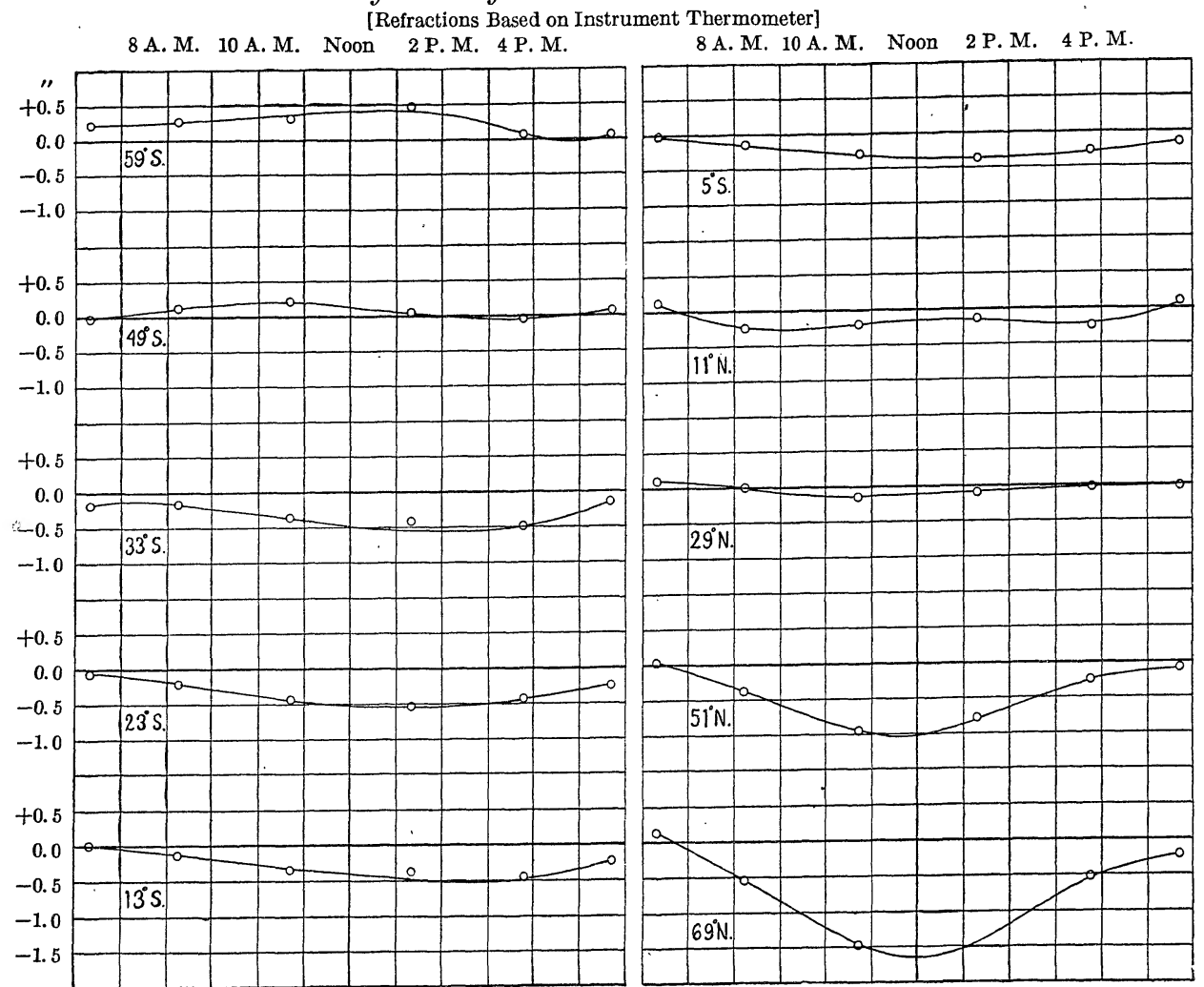

FIgURe 5.-Curves Showing the Differences, Day-Night, in Declination, for Observations Made at Various Times of Day and at All Zenith Distances

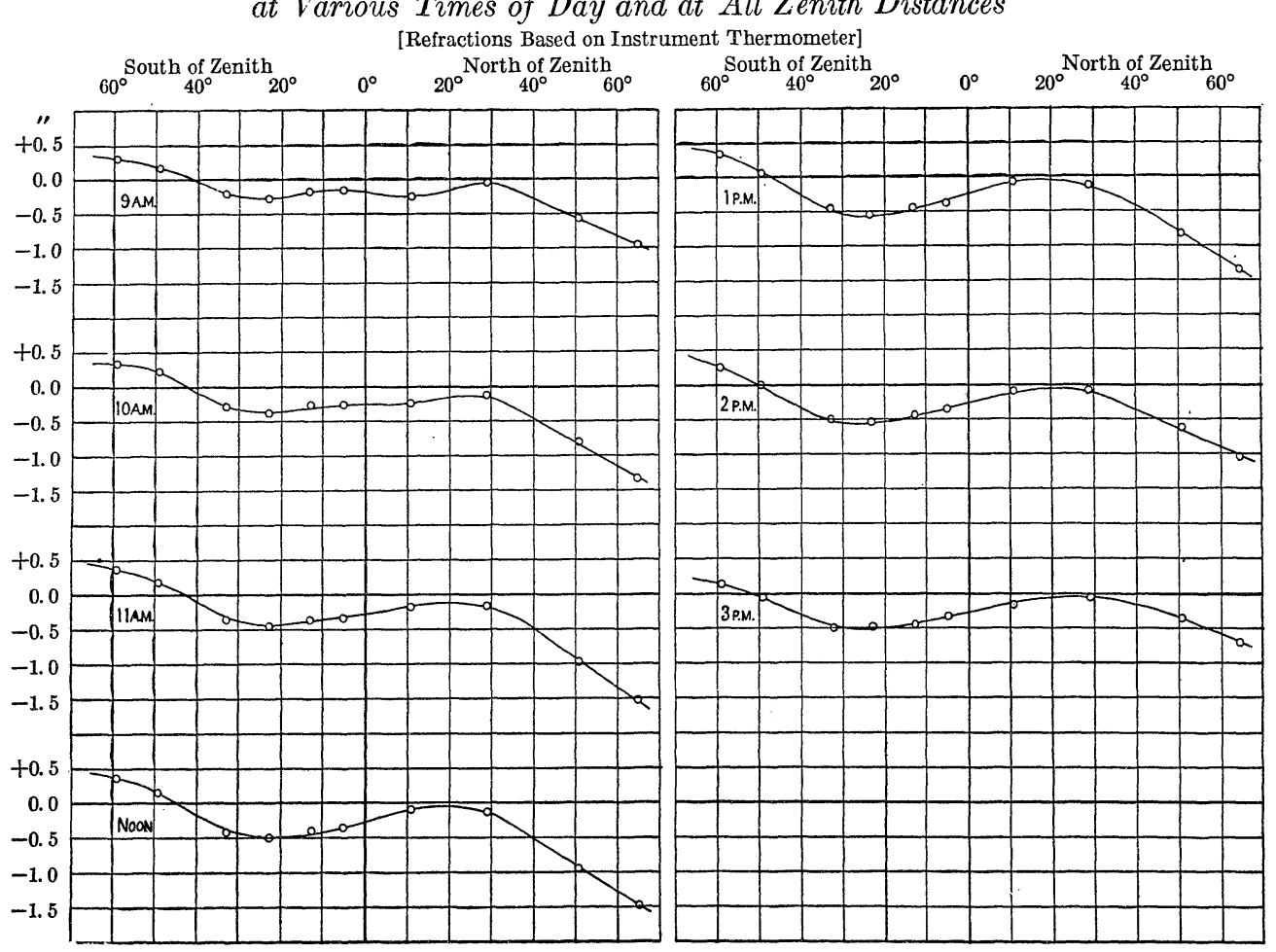


The adopted values of the Day and Night differences were plotted and interpolating curves were drawn through the points, as in Figure 5, from which were scaled off the corrections to the observed declinations derived from day observations. These are given in Table XII for such declinations as are needed in correcting the observations of the Sun, Mercury, and Venus.

The results obtained by using the refractions based on the external thermometer were treated in a similar manner.

Day Minus Night Differences in Observed Declinations, 1911-1918

[Refractions Based on the External Thermometer]

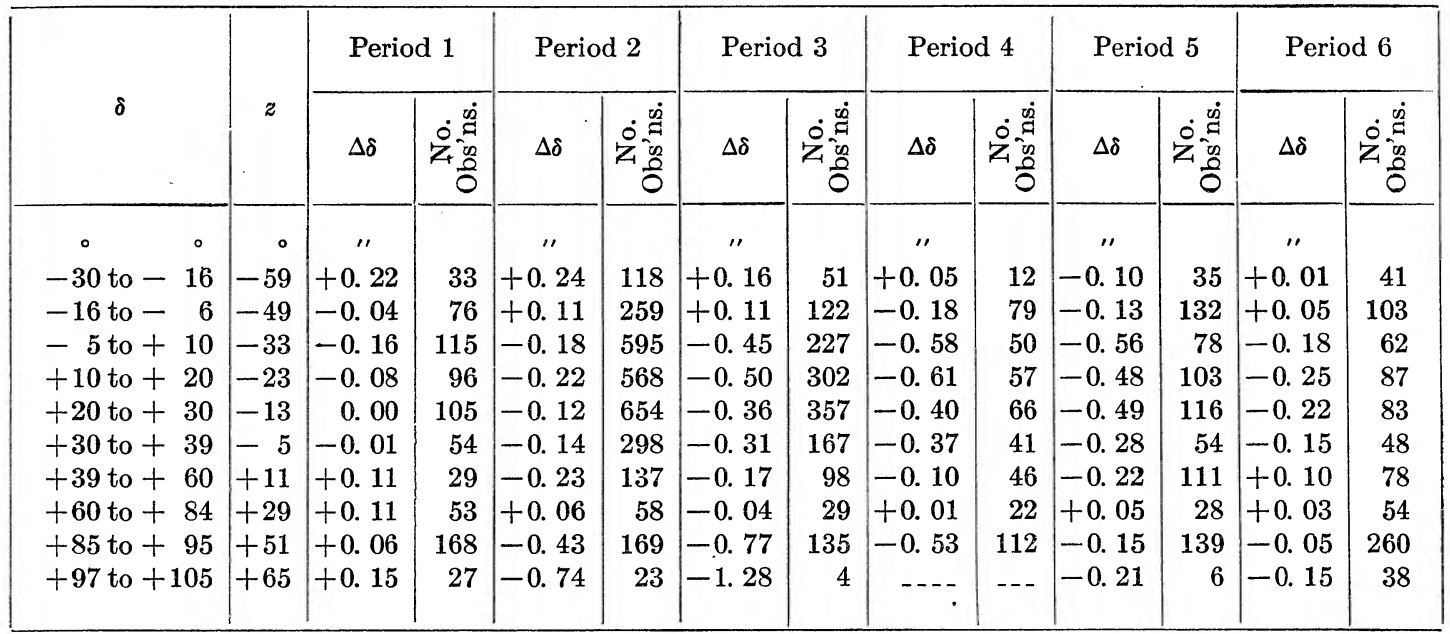

Adopted Values of the Day Minus Night Differences, 1911-1918

[Refractions Based on the External Thermometer]

\begin{tabular}{|c|c|c|c|c|c|c|c|c|}
\hline$\delta$ & $z$ & 9 a. $\mathrm{m}$. & 10 a. $\mathrm{m}$. & 11 a. $\mathrm{m}$. & Noon & 1 p. m. & 2 p. m. & 3 p. m. \\
\hline 。 & 。 & "' & " & $\prime \prime$ & "' & ", & "' & $" \prime$ \\
\hline-20 & -59 & +0.22 & +0.19 & +0.15 & +0.11 & +0.07 & -0.02 & -0.08 \\
\hline-10 & -49 & +0.13 & +0.13 & +0.08 & -0.01 & -0.08 & -0.14 & -0.15 \\
\hline+6 & -33 & -0.25 & -0.37 & -0.48 & -0.55 & -0.58 & -0.60 & -0.56 \\
\hline+16 & -23 & -0.29 & -0.41 & -0.52 & -0.59 & -0.61 & -0.60 & -0.54 \\
\hline+26 & -13 & -0.18 & -0.27 & -0.35 & -0.42 & -0.46 & -0.48 & -0.46 \\
\hline+34 & -5 & -0.17 & -0.25 & -0.33 & -0.35 & -0.38 & -0.36 & -0.32 \\
\hline+50 & +11 & -0.24 & -0.23 & -0.17 & -0.10 & -0.08 & -0.10 & -0.17 \\
\hline+68 & +29 & +0.04 & -0.03 & -0.04 & -0.02 & 0.00 & +0.03 & +0.05 \\
\hline+90 & +51 & -0.55 & -0.72 & -0.76 & -0.71 & -0.58 & -0.43 & -0.26 \\
\hline+104 & +65 & -0.92 & -1.18 & -1.31 & -1.25 & -1.07 & -0.78 & -0.45 \\
\hline
\end{tabular}

No satisfactory analytical expression depending on the hour angle of the Sun and representing the differences between day and night observations in the various zones could be found.

Seasonal variation of day minus night differences.-The material in Period 2 (refractions based on the instrument thermometer) was examined for a possible seasonal variation. All of the observations south of the zenith were divided into two zones of declination and each zone was subdivided into four parts, depending on the time of year at which the observations were made. The results are given in the following table, in which the subscripts indicate the number of observations. 
Seasonal Variation of Day Minus Night Differences

\begin{tabular}{|c|c|c|c|}
\hline$\overbrace{\text { Dates }}^{\delta}$ & $-30^{\circ}$ to $+10^{\circ}$ & $+10^{\circ}$ to $+39^{\circ}$ & $\begin{array}{l}\text { Weighted } \\
\text { Means }\end{array}$ \\
\hline $\begin{array}{l}\text { May } 6 \text { to Aug. } 6 \\
\text { Aug. } 6 \text { to Nov. } 6 \\
\text { Nov. } 6 \text { to Feb. } 6 \\
\text { Feb. } 6 \text { to May } 6\end{array}$ & $\begin{array}{c}\prime \prime \\
0.00_{86} \\
-0.12_{360} \\
0.00_{123} \\
-0.12_{99}\end{array}$ & $\begin{array}{c}\text { " } \\
-0.21_{363} \\
-0.24_{340} \\
-0.22_{219} \\
-0.19_{164}\end{array}$ & $\begin{array}{c}\prime \prime \\
-0.17_{449} \\
-0.18_{700} \\
-0.14_{342} \\
-0.16_{263}\end{array}$ \\
\hline
\end{tabular}

These observations show no appreciable seasonal change in the differences between day and night observed declinations.

Variation of the observed difference in declination between $\alpha$ Virginis and $\alpha$ Ursæ Minoris S. P.-The stars $\alpha$ Virginis and $\alpha$ Ursæ Minoris, which culminate within a few minutes of each other, were observed continuously during 1911-1918. By combining each observed correction to the ephemeris for $\alpha$ Virginis with that for $\alpha$ Ursæ Minoris s. P. obtained on the same day, there was derived a series of corrections to the difference in declination between the two stars. These corrections were assembled in 12 groups depending on the mean time, as defined on page 39. The weighted mean for the six night periods was subtracted from the means for all the periods, with the following results. (The refractions are based on the instrument thermometer.)

\begin{tabular}{|c|c||c|c|}
\hline $\begin{array}{c}\text { Day } \\
\text { Periods }\end{array}$ & $\Delta$. & $\begin{array}{c}\text { Night } \\
\text { Periods }\end{array}$ & $\Delta$ \\
\hline & $\prime \prime$ & & $\prime \prime$ \\
1 & $+0.16_{11}$ & 7 & $-0.15_{51}$ \\
2 & $-0.53_{28}$ & 8 & $-0.02_{42}$ \\
3 & $-1.79_{9}$ & 9 & $+0.06_{15}$ \\
4 & $-0.70_{55}$ & 10 & $+0.48_{5}$ \\
5 & $-0.06_{82}$ & 11 & $+0.09_{34}$ \\
6 & $-0.19_{45}$ & 12 & $+0.05_{18}$ \\
\hline
\end{tabular}

The results are in substantial agreement with those in the table showing the variation of the day minus night differences.

\section{COMPARISON WITH OTHER CATALOGUES}

Period 1909-1910.-The final declinations, given on pages 661-664, were compared with the positions of Newcomb and Boss and with those derived from the 1911-1918 work. (See pp. 667 et seq.) Half weight was given to those stars which were observed less than eight times. The subscripts indicate the number of stars in the various zones. 
$\Delta \delta$

\begin{tabular}{|c|c|c|c|}
\hline$\delta$ & $\mathrm{W}^{1}{ }_{10}-\mathrm{N}$ & $\mathrm{W}^{1}{ }_{10}-\mathrm{B}$ & $\mathrm{W}^{1}{ }_{10}-\mathrm{W}_{10}$ \\
\cline { 1 - 3 } & & & \\
\hline+115 to +102 & $+0.20_{13}$ & $+0.14_{13}$ & $+0.12_{12}$ \\
+102 to +90 & $-0.11_{11}$ & $+0.02_{11}$ & $+0.07_{11}$ \\
+90 to +78 & $-0.09_{12}$ & $0.00_{12}$ & $+0.03_{12}$ \\
+78 to +70 & $+0.26_{10}$ & $+0.18_{10}$ & $+0.18_{10}$ \\
+70 to +60 & $-0.07_{13}$ & $-0.03_{13}$ & $+0.01_{13}$ \\
+60 to +50 & $+0.09_{16}$ & $+0.32_{16}$ & $+0.06_{16}$ \\
+50 to +39 & $+0.06_{13}$ & $+0.39_{13}$ & $+0.21_{13}$ \\
+39 to +30 & $+0.08_{12}$ & $+0.41_{12}$ & $+0.35_{12}$ \\
+30 to +20 & $+0.12_{25}$ & $+0.38_{25}$ & $+0.32_{24}$ \\
+20 to +10 & $+0.11_{20}$ & $+0.42_{20}$ & $+0.30_{20}$ \\
+10 to 0 & $+0.05_{21}$ & $+0.32_{21}$ & $+0.32_{21}$ \\
-0 to -10 & $+0.07_{17}$ & $+0.38_{17}$ & $+0.45_{17}$ \\
-10. to -20 & $+0.09_{15}$ & $+0.31_{15}$ & $+0.37_{14}$ \\
-20 to -38 & $+0.52_{14}$ & $+0.33_{15}$ & $+0.46_{12}$ \\
\hline
\end{tabular}

Period 1911-1918. - The final declinations, given on pages 667-712, were compared with the positions of Newcomb, Boss, the Greenwich Catalogue of Fundamental Stars for 1910, the Second Cape Fundamental Catalogue for 1900, and the Washington Catalogue of 4526 Stars for 1900. In the last comparison, the material for the Ephemeris stars was furnished by the Nautical Almanac Office, United States Naval Observatory. All stars were given equal weight. The means at the bottom of each of the following tables are weighted according to the number of stars except in the case of $\mathrm{W}_{10}-\mathrm{W}_{00}$, where straight means are given.

$\Delta \delta\left(W_{10}-N\right)$

\begin{tabular}{|c|c|c|c|c|c|c|c|c|c|}
\hline${ }^{\alpha}$ & $0^{\mathrm{h}}$ to $3^{\mathrm{b}}$ & $3^{\mathrm{h}}$ to $6^{\mathrm{h}}$ & $6^{\mathrm{h}}$ to $9^{\mathrm{h}}$ & $9^{\mathrm{h}}$ to $12^{\mathrm{b}}$ & $\begin{array}{l}12^{\mathrm{h}} \text { to } \\
15^{\mathrm{h}}\end{array}$ & $\begin{array}{c}15^{\mathrm{h}} \text { to } \\
18^{\mathrm{h}}\end{array}$ & $\begin{array}{l}18^{\mathrm{b}} \text { to } \\
21^{\mathrm{b}}\end{array}$ & $\begin{array}{l}21^{\mathrm{h}} \text { to } \\
24^{\mathrm{h}}\end{array}$ & $0^{\mathrm{h}}$ to $24^{\mathrm{h}}$ \\
\hline $\begin{array}{l}{ }^{\circ} \\
+114 \text { to }+105 \\
+105 \text { to }+90 \\
+90 \text { to }+75 \\
+75 \text { to }+65 \\
+65 \text { to }+55 \\
+55 \text { to }+45 \\
+45 \text { to }+35 \\
+35 \text { to }+25 \\
+25 \text { to }+15 \\
+15 \text { to }+5 \\
+5 \text { to }-5 \\
-5 \text { to }-15 \\
-15 \text { to }-25 \\
-25 \text { to }-35\end{array}$ & $\begin{array}{c}\prime \prime \\
+0.08_{9} \\
-0.20_{5} \\
-0.23_{5} \\
-0.06_{9} \\
-0.06_{8} \\
-0.09_{10} \\
+0.07_{7} \\
-0.19_{11} \\
-0.10_{7} \\
-0.15_{14} \\
-0.28_{10} \\
-0.46_{9} \\
-0.60_{7} \\
+0.10_{6}\end{array}$ & $\begin{array}{l}\prime \prime \\
+0.35_{3} \\
+0.08_{5} \\
+0.04_{5} \\
+0.22_{3} \\
-0.08_{6} \\
+0.18_{9} \\
-0.08_{13} \\
0.00_{8} \\
-0.08_{19} \\
-0.01_{12} \\
-0.30_{8} \\
-0.42_{15} \\
-0.80_{8} \\
+0.18_{6}\end{array}$ & $\begin{array}{l}\prime \prime \\
+0.18_{7} \\
+0.02_{6} \\
-0.10_{6} \\
+0.10_{8} \\
-0.16_{6} \\
-0.24_{6} \\
-0.10_{7} \\
-0.37_{15} \\
-0.20_{14} \\
-0.27_{10} \\
-0.50_{7} \\
-0.90_{15} \\
-0.79_{8} \\
+0.11_{7}\end{array}$ & $\begin{array}{l}\prime \prime \\
+0.08_{5} \\
+0.14_{5} \\
+0.14_{5} \\
-0.02_{7} \\
+0.06_{7} \\
+0.14_{4} \\
-0.24_{11} \\
-0.28_{6} \\
-0.29_{10} \\
-0.25_{14} \\
-0.56_{13} \\
-0.53_{5} \\
-0.23_{6} \\
+0.51_{4}\end{array}$ & $\begin{array}{l}\prime \prime \\
+0.33_{4} \\
-0.27_{5} \\
-0.06_{5} \\
+0.12_{6} \\
+0.07_{8} \\
+0.14_{4} \\
-0.05_{11} \\
-0.17_{8} \\
-0.15_{7} \\
+0.04_{7} \\
-0.34_{9} \\
-0.03_{11} \\
-0.40_{10} \\
+0.28_{3}\end{array}$ & $\begin{array}{l}\prime \prime \\
+0.21_{6} \\
-0.04_{6} \\
-0.02_{6} \\
+0.13_{7} \\
-0.06_{10} \\
-0.02_{6} \\
+0.02_{8} \\
-0.14_{16} \\
0.00_{9} \\
-0.09_{7} \\
-0.42_{10} \\
-0.59_{5} \\
-0.28_{12} \\
+0.09_{7}\end{array}$ & $\begin{array}{c}\prime \prime \\
+0.26_{8} \\
+0.14_{6} \\
+0.03_{6} \\
+0.19_{8} \\
-0.29_{6} \\
-0.06_{5} \\
-0.30_{12} \\
-0.30_{9} \\
-0.26_{10} \\
-0.18_{14} \\
-0.04_{10} \\
-0.24_{8} \\
-0.26_{11} \\
-0.06_{13}\end{array}$ & $\begin{array}{l}\prime \prime \\
+0.33_{9} \\
-0.33_{5} \\
-0.27_{5} \\
+0.18_{10} \\
-0.16_{9} \\
-0.02_{6} \\
-0.15_{10} \\
-0.16_{7} \\
-0.04_{7} \\
-0.12_{12} \\
-0.28_{8} \\
-0.28_{13} \\
-0.07_{14} \\
+0.02_{7}\end{array}$ & $\begin{array}{l}\prime \prime \\
+0.21_{51} \\
-0.02_{43} \\
-0.06_{43} \\
+0.10_{58} \\
-0.10_{60} \\
0.00_{50} \\
-0.11_{79} \\
-0.21_{80} \\
-0.14_{83} \\
+0.14_{90} \\
-0.35_{75} \\
-0.41_{71} \\
-0.39_{76} \\
+0.10_{53}\end{array}$ \\
\hline $\begin{array}{l}+90 \text { to }+45 \\
+35 \text { to }-25\end{array}$ & $\begin{array}{l}-0.09_{32} \\
-0.28_{58}\end{array}$ & $\begin{array}{l}+0.09_{23} \\
-0.24_{70}\end{array}$ & $\begin{array}{l}-0.09_{26} \\
-0.50_{69}\end{array}$ & $\begin{array}{l}+0.07_{23} \\
-0.36_{54}\end{array}$ & $\begin{array}{l}+0.07_{23} \\
-0.20_{52}\end{array}$ & $\begin{array}{r}0.00_{29} \\
-0.23_{59}\end{array}$ & $\begin{array}{l}-0.01_{25} \\
-0.21_{62}\end{array}$ & $\begin{array}{l}-0.04_{30} \\
-0.16_{61}\end{array}$ & $\begin{array}{l}-0.01_{211} \\
-0.28_{485}\end{array}$ \\
\hline
\end{tabular}


$\Delta \delta\left(W_{10}-B\right)$

\begin{tabular}{|c|c|c|c|c|c|c|c|c|c|}
\hline${ }^{\alpha}$ & $0^{\mathrm{h}}$ to $3^{\mathrm{h}}$ & $3^{\mathrm{h}}$ to $6^{\mathrm{h}}$ & $6^{\mathrm{h}}$ to $9^{\mathrm{b}}$ & $9^{\mathrm{h}}$ to $12^{\mathrm{h}}$ & $\begin{array}{c}12^{\mathrm{h}} \text { to } \\
15^{\mathrm{h}}\end{array}$ & $\begin{array}{c}15^{\mathrm{h}} \text { to } \\
18^{\mathrm{h}}\end{array}$ & $\begin{array}{c}18^{\mathrm{b}} \text { to } \\
21^{\mathrm{h}}\end{array}$ & $\begin{array}{c}21^{\mathrm{h}} \text { to } \\
24^{\mathrm{h}}\end{array}$ & $0^{\mathrm{h}}$ to $24^{\mathrm{h}}$ \\
\hline $\begin{array}{l}\text { ० } \\
+114 \text { to }+105 \\
+105 \text { to }+90 \\
+90 \text { to }+75 \\
+75 \text { to }+65 \\
+65 \text { to }+55 \\
+55 \text { to }+45 \\
+45 \text { to }+35 \\
+35 \text { to }+25 \\
+25 \text { to }+15 \\
+15 \text { to }+5 \\
+5 \text { to }-5 \\
-5 \text { to }-15 \\
-15 \text { to }-25 \\
-25 \text { to }-35\end{array}$ & $\begin{array}{c}\prime \prime \\
+0.04_{9} \\
-0.20_{7} \\
-0.13_{7} \\
-0.12_{10} \\
+0.23_{11} \\
+0.18_{16} \\
+0.23_{17} \\
+0.06_{17} \\
+0.05_{17} \\
+0.13_{20} \\
-0.03_{19} \\
-0.16_{17} \\
-0.21_{11} \\
+0.01_{12}\end{array}$ & $\begin{array}{c}\prime \prime \\
+0.06_{4} \\
-0.07_{10} \\
-0.05_{10} \\
-0.14_{5} \\
0.00_{12} \\
+0.23_{13} \\
+0.17_{21} \\
+0.26_{10} \\
+0.09_{31} \\
+0.11_{21} \\
-0.11_{16} \\
-0.14_{29} \\
-0.38_{15} \\
-0.12_{15}\end{array}$ & $\begin{array}{c}\prime \prime \\
+0.12_{8} \\
+0.01_{10} \\
+0.03_{10} \\
+0.02_{11} \\
+0.21_{13} \\
+0.19_{12} \\
+0.15_{13} \\
+0.03_{19} \\
+0.11_{27} \\
-0.02_{22} \\
-0.27_{17} \\
-0.22_{13} \\
-0.22_{23} \\
-0.06_{14}\end{array}$ & $\begin{array}{l}\prime \prime \\
+0.08_{5} \\
-0.16_{8} \\
-0.10_{8} \\
+0.04_{7} \\
+0.18_{10} \\
+0.22_{10} \\
+0.13_{17} \\
+0.20_{16} \\
+0.10_{19} \\
+0.11_{22} \\
+0.10_{21} \\
-0.07_{16} \\
-0.03_{12} \\
+0.08_{18}\end{array}$ & $\begin{array}{l}. \\
+0.19_{4} \\
-0.01_{10} \\
+0.11_{10} \\
+0.06_{8} \\
+0.18_{11} \\
+0.25_{13} \\
+0.31_{13} \\
+0.11_{14} \\
+0.08_{13} \\
+0.14_{15} \\
+0.12_{17} \\
-0.06_{20} \\
+0.01_{15} \\
+0.24_{14}\end{array}$ & $\begin{array}{l}\prime \prime \\
+0.20_{7} \\
+0.14_{9} \\
+0.11_{9} \\
+0.04_{9} \\
+0.03_{13} \\
+0.31_{11} \\
+0.25_{10} \\
+0.24_{22} \\
+0.17_{16} \\
+0.10_{12} \\
+0.07_{22} \\
+0.01_{14} \\
+0.12_{22} \\
0.00_{17}\end{array}$ & $\begin{array}{c}\prime \prime \\
+0.28_{8} \\
+0.07_{10} \\
+0.08_{10} \\
+0.20_{9} \\
+0.23_{12} \\
+0.22_{10} \\
+0.17_{15} \\
+0.20_{17} \\
+0.09_{19} \\
+0.10_{21} \\
+0.26_{14} \\
+0.05_{21} \\
+0.02_{24} \\
+0.05_{23}\end{array}$ & $\begin{array}{c}\prime \prime \\
+0.32_{9} \\
-0.14_{10} \\
+0.01_{10} \\
+0.15_{10} \\
+0.01_{13} \\
+0.19_{9} \\
+0.20_{17} \\
+0.19_{13} \\
+0.41_{10} \\
+0.22_{20} \\
+0.09_{20} \\
0.00_{23} \\
+0.01_{27} \\
+0.25_{10}\end{array}$ & $\begin{array}{l}\prime \prime \\
+0.17_{54} \\
-0.04_{74} \\
+0.02_{74} \\
+0.04_{69} \\
+0.13_{95} \\
+0.22_{94} \\
+0.19_{123} \\
+0.16_{128} \\
+0.12_{152} \\
+0.11_{153} \\
+0.03_{146} \\
-0.07_{153} \\
-0.06_{149} \\
+0.05_{123}\end{array}$ \\
\hline $\begin{array}{l}+90 \text { to }+45 \\
+35 \text { to }-25\end{array}$ & $\begin{array}{l}+0.08_{44} \\
-0.01_{101}\end{array}$ & $\begin{array}{l}+0.04_{40} \\
-0.03_{122}\end{array}$ & $\begin{array}{l}+0.12_{46} \\
-0.08_{121}\end{array}$ & $\begin{array}{l}+0.10_{35} \\
+0.08_{106}\end{array}$ & $\begin{array}{l}+0.16_{42} \\
+0.06_{94}\end{array}$ & $\begin{array}{l}+0.12_{42} \\
+0.13_{108}\end{array}$ & $\begin{array}{l}+0.18_{41} \\
+0.11_{78}\end{array}$ & $\begin{array}{l}+0.08_{42} \\
+0.12_{113}\end{array}$ & $\begin{array}{l}+0.11_{332} \\
+0.04_{843}\end{array}$ \\
\hline
\end{tabular}

$\Delta \delta\left(W_{10}-W_{00}\right)$

\begin{tabular}{|c|c|c|c|c|c|c|c|c|c|}
\hline$\delta$ & $0^{\mathrm{h}}$ to $3^{\mathrm{h}}$ & $3^{\mathrm{h}}$ to $6^{\mathrm{h}}$ & $6^{\mathrm{h}}$ to $9^{\mathrm{b}}$ & $9^{\mathrm{h}}$ to $12^{\mathrm{h}}$ & $\begin{array}{c}12^{\mathrm{h}} \text { to } \\
15^{\mathrm{h}}\end{array}$ & $\begin{array}{c}15^{\mathrm{h}} \text { to } \\
18^{\mathrm{h}}\end{array}$ & $\begin{array}{c}18^{\mathrm{h}} \text { to } \\
21^{\mathrm{h}}\end{array}$ & $\begin{array}{c}21^{\mathrm{h}} \text { to } \\
24^{\mathrm{h}}\end{array}$ & $0^{\mathrm{h}}$ to $24^{\mathrm{h}}$ \\
\hline $\begin{array}{l}\circ \\
+115 \text { to }+110 \\
+110 \text { to }+100 \\
+100 \text { to }+90 \\
+90 \text { to }+80 \\
+80 \text { to }+70 \\
+70 \text { to }+60 \\
+60 \text { to }+50 \\
+50 \text { to }+39 \\
+39 \text { to }+30 \\
+30 \text { to }+20 \\
+20 \text { to }+10 \\
+10 \text { to } \\
-0 \text { to }-10 \\
-10 \text { to }-20 \\
-20 \text { to }-30 \\
-30 \text { to }-35\end{array}$ & $\begin{array}{l}\prime \prime \\
+0.17_{5} \\
+0.06_{7} \\
-0.09_{4} \\
-0.11_{4} \\
-0.21_{7} \\
-0.20_{8} \\
-0.22_{13} \\
-0.41_{7} \\
-0.49_{12} \\
-0.63_{14} \\
-0.81_{15} \\
-0.68_{23} \\
-0.89_{13} \\
-1.05_{7} \\
-0.80_{10} \\
-1.07_{3}\end{array}$ & $\begin{array}{c}\prime \prime \\
+0.04_{1} \\
0.00_{5} \\
-0.04_{4} \\
-0.09_{4} \\
-0.04_{4} \\
-0.20_{7} \\
-0.19_{3} \\
-0.43_{18} \\
-0.46_{9} \\
-0.69_{21} \\
-0.71_{20} \\
-0.79_{15} \\
-0.94_{14} \\
-1.00_{9} \\
-0.81_{8} \\
-0.59_{5}\end{array}$ & $\begin{array}{l}\prime \prime \\
-0.11_{5} \\
+0.12_{5} \\
+0.06_{4} \\
-0.11_{4} \\
+0.06_{5} \\
+0.01_{8} \\
-0.24_{7} \\
-0.48_{10} \\
-0.54_{8} \\
-0.67_{29} \\
-0.78_{20} \\
-0.82_{10} \\
-0.91_{5} \\
-0.82_{9} \\
-0.76_{8} \\
-0.50_{4}\end{array}$ & $\begin{array}{c}\prime \prime \\
-0.04_{3} \\
+0.16_{4} \\
-0.04_{4} \\
-0.09_{5} \\
-0.04_{4} \\
-0.17_{7} \\
+0.07_{7} \\
-0.45_{8} \\
-0.34_{8} \\
-0.55_{10} \\
-0.75_{22} \\
-0.74_{23} \\
-1.06_{12} \\
-0.78_{9} \\
-0.77_{5} \\
-0.83_{3}\end{array}$ & $\begin{array}{c}\prime \prime \\
+0.02_{1} \\
-0.20_{6} \\
-0.04_{2} \\
+0.04_{2} \\
-0.08_{6} \\
-0.15_{6} \\
-0.17_{8} \\
-0.38_{10} \\
-0.52_{5} \\
-0.55_{7} \\
-0.65_{10} \\
-0.71_{11} \\
-1.01_{24} \\
-1.00_{20} \\
-0.98_{10} \\
-0.61_{4}\end{array}$ & $\begin{array}{l}\prime \prime \\
-0.25_{5} \\
+0.02_{7} \\
-0.12_{2} \\
+0.04_{2} \\
-0.01_{1} \\
-0.11_{7} \\
-0.28_{10} \\
-0.32_{8} \\
-0.37_{12} \\
-0.70_{12} \\
-0.75_{11} \\
-0.80_{10} \\
-1.02_{6} \\
-0.96_{23} \\
-0.90_{25} \\
-0.90_{4}\end{array}$ & $\begin{array}{c}\prime \prime \\
+0.25_{1} \\
+0.02_{10} \\
-0.04_{4} \\
-0.11_{4} \\
-0.09_{10} \\
-0.16_{4} \\
-0.26_{6} \\
-0.39_{8} \\
-0.53_{12} \\
-0.74_{8} \\
-0.82_{14} \\
-0.76_{11} \\
-0.85_{11} \\
-0.87_{18} \\
-0.77_{33} \\
-0.90_{2}\end{array}$ & $\begin{array}{c}\prime \prime \\
+0.17_{2} \\
-0.10_{10} \\
-0.15_{4} \\
-0.13_{4} \\
-0.13_{10} \\
-0.26_{7} \\
-0.31_{6} \\
-0.43_{11} \\
-0.47_{6} \\
-0.61_{10} \\
-0.79_{7} \\
-0.70_{15} \\
-0.80_{23} \\
-0.75_{27} \\
-0.77_{10} \\
-0.64_{6}\end{array}$ & $\begin{array}{c}\prime \prime \\
-0.02_{23} \\
0.00_{54} \\
-0.05_{28} \\
-0.09_{29} \\
-0.09_{47} \\
-0.15_{54} \\
-0.20_{60} \\
-0.42_{80} \\
-0.46_{72} \\
-0.65_{111} \\
-0.76_{119} \\
-0.74_{118} \\
-0.92_{108} \\
-0.89_{122} \\
-0.82_{109} \\
-0.72_{31}\end{array}$ \\
\hline $\begin{array}{l}+70 \text { to }+39 \\
+39 \text { to }-30\end{array}$ & $\begin{array}{l}-0.28 \\
-0.76\end{array}$ & $\begin{array}{l}-0.27 \\
-0.77\end{array}$ & $\begin{array}{l}-0.24 \\
-0.76\end{array}$ & $\begin{array}{l}-0.18 \\
-0.71\end{array}$ & $\begin{array}{l}-0.23 \\
-0.77\end{array}$ & $\begin{array}{l}-0.24 \\
-0.79\end{array}$ & $\begin{array}{l}-0.27 \\
-0.76\end{array}$ & $\begin{array}{l}-0.33 \\
-0.70\end{array}$ & \\
\hline
\end{tabular}

